\title{
Efficient finite element modeling of WT sections subjected to uniaxial tension
}

\author{
Ramanand V. Nukala \\ West Virginia University
}

Follow this and additional works at: https://researchrepository.wvu.edu/etd

\section{Recommended Citation}

Nukala, Ramanand V., "Efficient finite element modeling of WT sections subjected to uniaxial tension" (2001). Graduate Theses, Dissertations, and Problem Reports. 1162.

https://researchrepository.wvu.edu/etd/1162

This Thesis is protected by copyright and/or related rights. It has been brought to you by the The Research Repository @ WVU with permission from the rights-holder(s). You are free to use this Thesis in any way that is permitted by the copyright and related rights legislation that applies to your use. For other uses you must obtain permission from the rights-holder(s) directly, unless additional rights are indicated by a Creative Commons license in the record and/ or on the work itself. This Thesis has been accepted for inclusion in WVU Graduate Theses, Dissertations, and Problem Reports collection by an authorized administrator of The Research Repository @ WVU. For more information, please contact researchrepository@mail.wvu.edu. 


\title{
Efficient Finite Element Modeling of WT Sections Subjected to Uniaxial Tension
}

\author{
Ramanand Nukala \\ Thesis submitted to the College of Engineering and Mineral Resources at \\ West Virginia University in partial fulfillment of the \\ requirements for the Degree of \\ Masters of Science \\ in \\ Engineering \\ Dr. Karl E. Barth, Chair \\ Dr. Indrajit Ray \\ Dr. Julio Davalos \\ Department of Civil and Environmental Engineering
}

Morgantown, West Virginia

2001

Keywords: Finite element modeling, Connection eccentricity, Uniaxial tension 


\section{ABSTRACT \\ Efficient Finite Element Modeling of WT Sections Subjected to Uniaxial Tension}

\section{Ramanand Nukala}

Tension members with bolted end connections are frequently used in trusses and lateral bracing systems, and three limit states are normally considered in the design of the members: full yield of the gross area (producing excessive elongation but not rupture), a block shear failure at the connection, and rupture of the net section. The presence of bending moments in tension members can also substantially reduce member load capacity. Such moments may develop directly from transverse loading, or from connection eccentricity. The latter is a common occurrence in lateral bracing members, which are often designed using single and double angles, WTs, and similar sections, with bolted connections. Connection eccentricity arises when the bolt line (or centroid of multiple bolt lines) does not coincide with the neutral axis of the bracing member. In design, this eccentricity is often neglected. Present design specifications for statically loaded tension members do not consider the effects of connection eccentricity as it induces bending in statically loaded members. Previous experimental tests conducted at West Virginia University [WVU] have shown that connection eccentricity induced bending effects have the potential to significantly reduce the net section rupture capacity of a section. However, these studies only examined a limited range of parameters. It is the goal of this project to develop accurate and robust finite element tools that may be used in more comprehensive studies.

The present study is focussed on developing finite element tools capable of capturing the peak loads and behavioral response exhibited is the previous WVU experimental tests. The main objective of the finite element analysis is not only to estimate the failure loads of the WT section specimens but also to trace the entire load versus deflection path. In the experimental specimens, failure of the WT sections is typically caused by severe necking of the outside edge adjacent to the lead bolthole, followed by the fracture of the outside edge. Thus, for an accurate representation of the failure load it is essential to capture the underlying necking behavior in the vicinity of the lead bolthole. The finite element analysis is performed using 3D solid elements that are capable of representing large deformation geometric and material nonlinearities. The commercial finite element program ABAQUS is used to perform the analysis.

In this study, the finite element analysis of the WT section is carried out using eight node incompatible elements. In the finite element model, the connecting bolts are assumed to be rigid and surface-to-surface contact is used. A tri-linear type stress-strain curve is used to represent the material nonlinear effects. The load corresponding to the load limit point is taken as the failure load of the WT specimen. Preliminary results based on the above analysis indicate an excellent agreement between the experimentally observed and numerically estimated failure capacities of the WT sections subjected to tensile loading. 


\section{ACKNOWLEDGEMENTS}

I would like to express my deepest gratitude to my advisor Dr. Karl E. Barth for his support, guidance, and encouragement throughout the course of my graduate study at West Virginia University and who offered me the opportunity to work under his direction in the pursuit of my graduate degree. His exemplary work ethic and commitment to quality and excellence have been sources of inspiration making it a privilege to work with him. He provided the guidance and support to make this present study and accompanying thesis possible. The instruction and training I received under him have challenged me to grow as an individual and as an engineer.

I would like to express my sincere gratitude to Dr. Julio Davalos for serving on my graduate advisory committee and for encouraging me to pursue my Master's degree and challenging me in my studies.

I would like to thank Dr. Indrajit Ray for the instruction I received from him while at West Virginia University and his willingness to serve on my committee.

I would also like to thank all my friends for their warm friendship. Finally, my heartfelt gratitude to my parents for their love and affection. I would also like to thank my sisters and brother for their love and encouragement. This research work would not have been possible without their support throughout my endeavors. 


\section{TABLE OF CONTENTS}

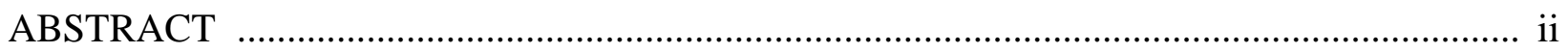

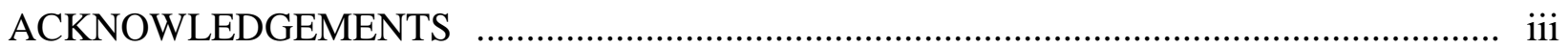

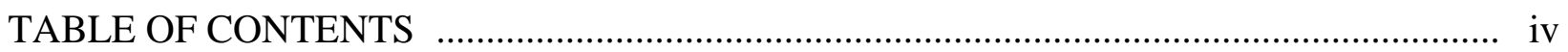

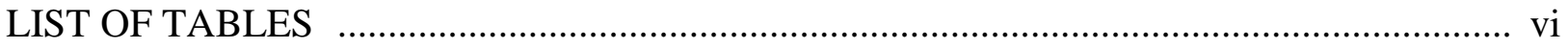

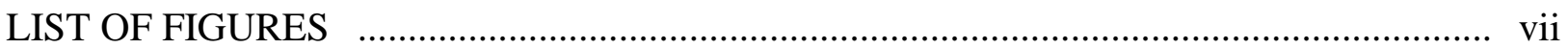

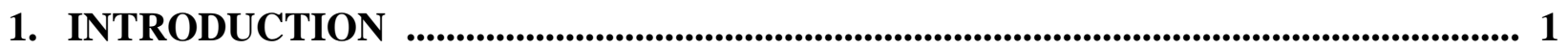

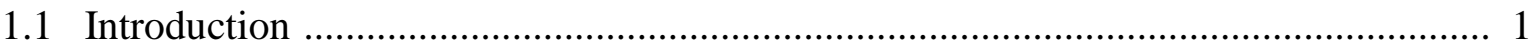

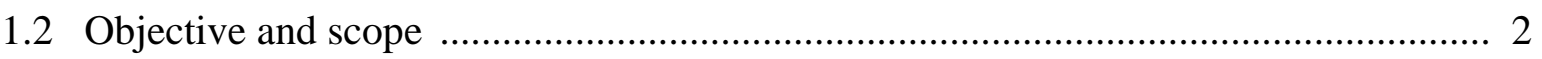

1.3 Organization

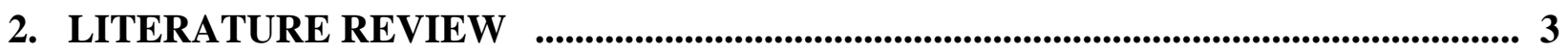

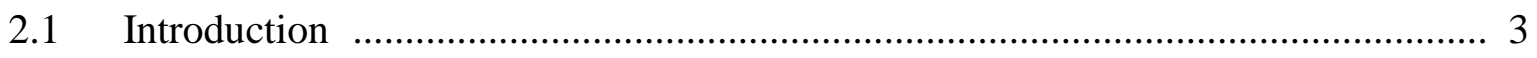

2.2 Rickles and Yura (1983) finite element study $\quad$............................................... 3

2.3 Epstein and Chamarajanagar (1996b) finite element study ............................... 5

$2.4 \quad$ Kulak and $\mathrm{Wu}(1997)$ finite element study ............................................... 7

2.5 Epstein and McGinnis (2000) finite element study ....................................... 9

\section{DEVELOPMENT OF AN ACCURATE AND EFFICIENT FINITE ELEMENT}

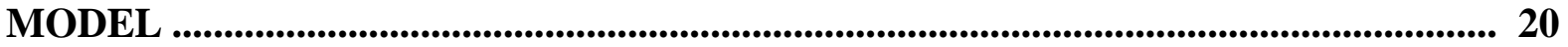

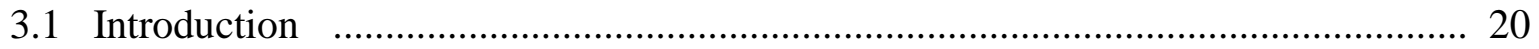

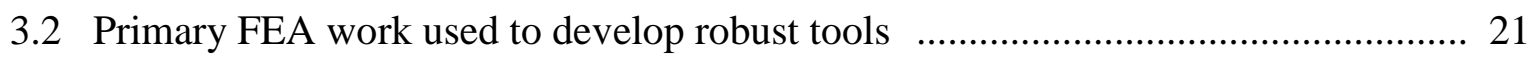

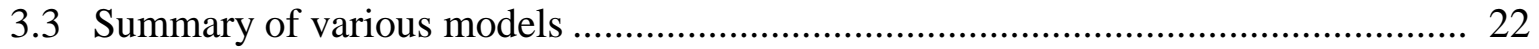

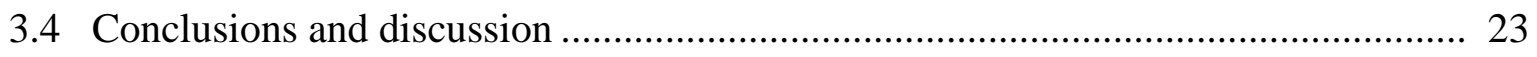

3.5 Other Miscellaneous Analysis of Kulak's specimens....................................... 25 
4. FINITE ELEMENT MODELING OF WVU SPECIMENS ........................................ 36

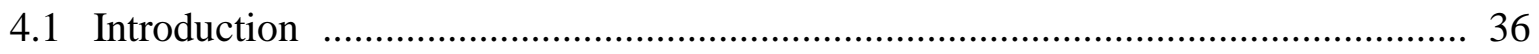

4.2 Description of WVU specimens ..................................................................... 37

4.3 Experimental setup of WVU specimens ............................................................. 38

4.4 Summary of finite element modeling procedures used with WVU specimens ........ 39

5. RESULTS AND DISCUSSION .................................................................................................. 45

5.1 Comparison of analytical results with experimental results ................................... 45

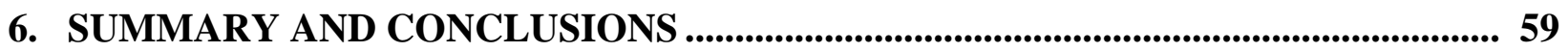

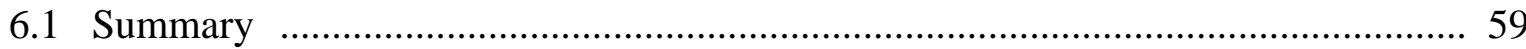

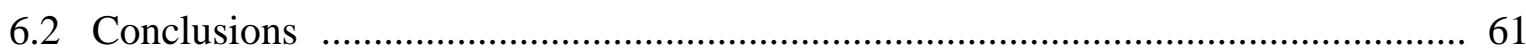

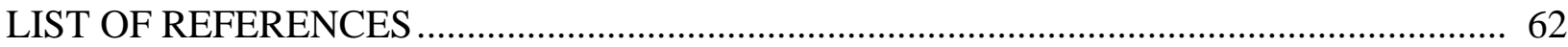

\section{APPENDICES}

Appendix A: NOMENCLATURE …………………….......................................... 64

Appendix B: WT 4 BOLT SPECIMEN CONTOUR PLOTS ........................................ 66

Appendix C: WT 5 BOLT SPECIMEN CONTOUR PLOTS ………………………... 75

Appendix D: WT 3 BOLT SPECIMEN CONTOUR PLOTS ........................................ 84 


\section{LIST OF TABLES}

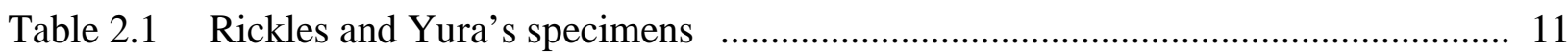

Table 2.2 Epstein and Chamarajanagar's specimens .................................................. 12

Table 2.3 Kulak and Wu's specimens .................................................................... 14

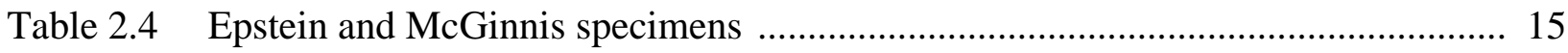

Table 3.1 Model titles and their results comparing with the experimental results ............... 26

Table 3.2 Comparison of Model D and experimental failure loads for specimens

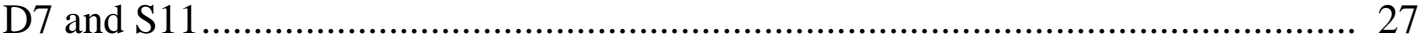

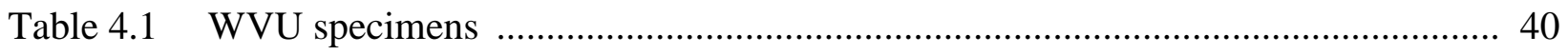

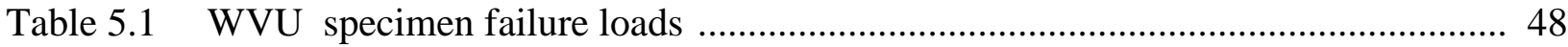




\section{LIST OF FIGURES}

Figure 2.1 Rickles and Yura's test setup ..................................................................... 16

Figure 2.2 Epstein and Chamarajanagar's specimen ........................................................ 17

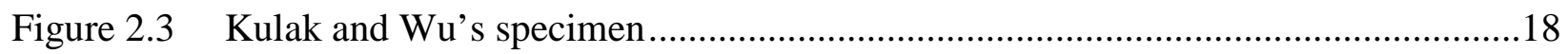

Figure 2.4 Epstein and McGinnis's specimen …….................................................... 19

Figure $3.1 \quad$ Typical constitutive models ........................................................................ 28

Figure 3.2 Boundary conditions using Model C for Kulak and Wu's D9 specimen .............. 29

Figure 3.3 Comparison of Model A and experimental failure loads for Kulak and Wu's D9 specimen .................................................................................... 30

Figure 3.4 Comparison of Model B and experimental failure loads for Kulak and Wu's D9 specimen ........................................................................................... 31

Figure 3.5 Comparison of Model C and experimental failure loads for Kulak and Wu's D9 specimen ....................................................................................... 32

Figure 3.6 Comparison of FE results using model D1 condition with Kulak and Wu's D9 specimen ........................................................................................... 33

Figure 3.7 Deformed shape, stress contours, and plastic strain contours of Model D1 at the maximum load for Kulak and Wu's D9 specimen ........................................ 34

Figure 3.8 Comparison of FE results using model D1 condition with Kulak and Wu's

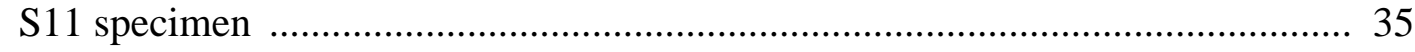

Figure 4.1 Typical WT specimen configuration and grip assembly $\quad$.................................... 41

Figure 4.2 Typical WT specimen in UTM ................................................................. 42

Figure 4.3 Typical failure modes (a) partial net section rupture medium eccentricity, (b) partial net section rupture large eccentricity, (c) block shear failure, and

(d) full net section rupture failure 43

Figure 4.4 Typical finite element mesh for WVU specimens showing boundary conditions

Figure 5.1 Load deflection curve for WVU 4 bolt specimens 49 
Figure 5.2 Deformed shape, stress contours and plastic strain contours of WVU

specimen \# 1a

Figure 5.3 Deformed shape, stress contours and plastic strain contours of WVU specimen \# 2a

Figure 5.4 Deformed shape, stress contours and plastic strain contours of WVU specimen \# 7a 52

Figure 5.5 FEA and Experimental Deformed Shapes for Specimen 1a 53

Figure 5.6 Load deflection curve for WVU 5 bolt specimens 54

Figure 5.7 Deformed shape, stress contours and plastic strain contours of WVU specimen \# 1b

Figure 5.8 Deformed shape, stress contours and plastic strain contours of WVU specimen \# 7b 56

Figure 5.9 Load deflection curve for WVU 3 bolt specimens 57

Figure 5.10 Deformed shape, stress contours and plastic strain contours of WVU specimen \# 5c 58 


\section{Chapter 1}

\subsection{Introduction:}

Tension members with bolted end connections are frequently used in trusses and lateral bracing systems, and three limit states are normally considered in the design of the members: full yield of the gross area (producing excessive elongation but not rupture), a block shear failure at the connection, and rupture of the net section. The load capacity with respect to net section rupture has been shown previously (Munse and Chesson, 1963) to be influenced potentially by several factors, including the ductility of the steel,

the ratio of gage to bolt diameter, method of hole fabrication (punched or drilled), and shear lag. Shear lag is a term used to describe the reduction in the capacity of a tension member connected to parts of the cross-section but not all of the cross-section. For example, single angle tension members connected by only one leg are frequently seen as bracing elements. Because only one leg is connected, stress in the unconnected leg must be "transferred" through the connected leg. This stress is said to "lag" and produces some inefficiency in the load carrying capacity of the member. With current hot rolled steels and connection geometries, the effect of the first two factors has been found to be negligible (Wu and Kulak, 1993). The influence of punched hole fabrication relative to drilled holes can be significant, and shear lag may also reduce the net section rupture load capacity; both are currently addressed by the American Institute for Steel Construction Specifications (LRFD, 1995; ASD 1989).

The presence of bending moments in tension members can also substantially reduce member load capacity (Bartels et al., 2000; Orbison et al., 2000). Such moments may develop directly from transverse loading, or from connection eccentricity. The latter is a 
common occurrence in lateral bracing members, which are often designed using single and double angles, WTs, and similar sections, with bolted connections. Connection eccentricity arises when the bolt line (or centroid of multiple bolt lines) does not coincide with the neutral axis of the bracing member. In design of statically loaded tension members, this eccentricity is often neglected.

\subsection{Objective and scope:}

The specific objective of this study is to develop finite element tools capable of predicting failure loads and accurately modeling the observed behavior of a series of WT uniaxial tension tests conducted previously at West Virginia University [WVU]. The tools will first be developed and calibrated using the results of a series of tension tests similar in nature to the WVU tests that were conducted by Kulak and Wu (1997). The Kulak and Wu's data was selected as a benchmark as they have extensive data reported for both experimental and analytical efforts that they conducted.

\subsection{Organization:}

The thesis is organized in six chapters. The first chapter presents the introduction, objective and scope of the project. Chapter two is a literature review of previous analytical and experimental work that relates to the ultimate capacity of tension members. Chapter three presents the development of a finite element model that is used in further studies. Chapter four makes use of the finite element model developed in chapter three to analyze a set of WT specimens that were previously studied experimentally at WVU. Chapter five presents a comparative summary between the experimental behavior and the finite element results. Lastly, chapter six presents a summary and conclusions of the current study and describes potential directions for future work. 


\section{Chapter 2}

\section{LITERATURE REVIEW}

\subsection{Introduction:}

Finite element studies are extremely useful when used in conjunction with an experimental testing program. Examining the failure modes of tension members with bolted connections using a finite element analysis method allows for a more extensive parametric investigation of the underlying behavior than is possible in a laboratory setting. Following is a brief summary of previous finite element modeling studies that have been used to estimate the failure loads of connections subjected to block shear and net section rupture.

\subsection{Rickles and Yura (1983) finite element study:}

Rickles and Yura (1983) conducted full-scale testing of double-row bolted-web connections supplemented by an elastic finite element analysis of coped and uncoped specimens. Table 2.1 presents a summary of tests conducted by Rickles and Yura and Fig. 2.1 shows the test setup. The beam was connected by two rows of 13/16 inch shear connectors with $\mathrm{L} 7 \times 4 \times 3 / 8$ framing clip angles on both sides of the web. 


\section{Finite element modeling information:}

A finite element analysis was conducted on specimen 18-10 only. The main objective of this finite element study was to obtain the elastic stress distributions in the vicinity of shear connector bolt holes and to develop a modified block shear failure model which is in close agreement with the experimental results. The stress distribution results obtained from such an elastic analysis would facilitate in the development of simple analytical models to predict block shear connection capacity.

The finite element model consisted of two-dimensional 4-node quadrilateral and 3-node triangular elements. The material response was modeled by a purely elastic stressstrain curve to capture the stress distribution in the vicinity of the connection region. The clip angle was idealized as a simple connection plate with attached springs to simulate the stiffness of the outstanding leg to the rotation of the clip angle. The bottom corner of the connection plate was constrained in the horizontal direction and a spring whose stiffness is equal to the flexural stiffness of the outstanding leg of the clip angle was placed at the top corner. The bolted connections between the clip angle and the beam were modeled by constraining the plate and web nodes located at the bolted connection to have equal displacements. In addition, the connection plate was constrained at the bolt lines in the vertical direction to simulate the connection between the outstanding leg and the column flange. 


\section{Results and discussion:}

A linear finite element program was used to capture the stress distributions in the vicinity of the connection. The results obtained from the analysis indicate that the buckling of the web at the cope may control the connection's capacity whenever the cope is long. If the flange is uncoped, then the web may yield and buckle directly above the top line of the bolts. However, if the flange is coped, block shear failure may be controlled. Results of both the experimental as well as the finite element analysis are shown in the Table 2.1.

\subsection{Epstein and Chamarajanagar (1996b) finite element study:}

The main objective of the Epstein's work was to develop analytical tools capable of capturing the experimentally observed failure loads of a series of single angle tests with staggered bolted connections. The group of experimental tests focused on studying the influence of number of bolts and stagger geometry on the capacity of the single angle tension members. The tests conducted by Epstein and Chamarajanagar are shown in Table 2.2. The length of the experimental specimens was 30 inches. In all the specimens, standard gage distances as given by AISC, 3/4 inch diameter bolts, $3 / 2$ inch edge distance and a pitch of 3 inch were used. Typical specimen geometry is shown in the Fig. 2.2.

\section{Finite element modeling information:}

A 20-node quadratic brick element was used in the FEA model. The material nonlinear effects were modeled using the von- Mises yield criterion and the material stress-strain curve was assumed to be elastic perfectly plastic with a yield stress of 36 
Ksi. A nonlinear incremental solution strategy was adopted to capture the nonlinear loaddeflection response of the angle sections. In general, it is necessary to include both geometric and material nonlinear effects into the model for obtaining an accurate estimation of failure loads in the angle sections. However, based on the amount of deformation observed at the failure, the nonlinear geometric effects were considered to be negligible compared to the material nonlinear effects, and hence were ignored in this finite element study. During this study, the experimental specimens showed little deformation of the upper half of each hole. Based on these experimental and preliminary finite element analyses results, the top half of each hole was assumed to be fixed. A strain based failure criteria in which failure was assumed to have occurred once the maximum strain reached five times the initial yield strain was used to estimate the failure load. The model was subjected to a uniform pressure on the connected leg of the specimen. The amount of load applied in the first load step corresponds to the initial yield of the specimen. Subsequently, the load was increased in $10 \%$ increments of this initial yield load.

\section{Results and discussion:}

From the experimental and finite element results, it was concluded that the shear lag effect present in these angles significantly reduced the load carrying capacity of the tension member. Further, it was also observed that the stagger of bolts and sign of the stagger have a significant effect on the tensile failure loads. In all of the finite element simulations, failure was initiated at the outside edge of the connected leg adjacent to the lead bolt on the outer gage. 
In conclusion, although this finite element study includes only the material nonlinearity as represented by a simple elastic-perfectly plastic von Mises yield criterion, the finite element results indicate a reasonably good correlation with the experimental results for block shear failure modes. These results suggest that a comprehensive finite element modeling of the angle sections that include both geometric and material large deformation effects may be performed for an accurate representation of block shear as well as net section rupture failure modes.

\subsection{Kulak and Wu (1997) finite element study:}

Kulak and $\mathrm{Wu}$ (1997) conducted an exhaustive experimental investigation of single and double angle tension members to examine the effect of shear lag on the net section rupture capacity of the cross-sections. Additionally, they also conducted a limited finite element investigation. The main goal of this finite element analysis was to evaluate the stress distribution of the critical cross section at ultimate load. The tests conducted by Kulak and Wu are shown in Table 2.3. A $3.0 \times 2.0 \times 0.189$ inches double angle member with long leg connected with 10.4 x 22.0 x 0.75 inches gusset plate was used for finite element study. Figure 2.3 shows the typical test set-up for Kulak and Wu's experimental program.

\section{Finite element modeling information:}

A large strain four-node quadrilateral shell element (ANSYS STIF43) with six degrees of freedom per node was used in the finite element modeling of the double angle member. The gusset plate was modeled using an elastic four-node quadrilateral shell 
element (ANSYS STIF63), as the yielding of the gusset plate was not observed in the experimental tests. The von-Mises yield criterion was adopted to represent the material nonlinear effects. The stress-strain curve was described by five different straight lines. Note that slope values and line transition locations were not reported by Kulak and $\mathrm{Wu}$. The finite element model included both geometric as well as material nonlinear effects.

Based on the symmetry considerations of the specimen, only half the length of the specimen was modeled. Similarly, due to the symmetry of the double angle members about the gusset plate, only one of the pair angles was modeled. The leading edge of the gusset plate was constrained in all the directions except for the longitudinal direction.

In this finite element study, the bolts were assumed to be rigid and the load was transferred from the gusset plate to the angle fully by the bearing of the bolts. Therefore, the longitudinal and the in-plane transverse displacements of the nodes present on the bearing surfaces, i.e., the surfaces on which the bolt surface bears against the hole surfaces, were coupled to one another. Similarly, as the bolts were pre-tensioned, the outof-plane displacements corresponding to the nodes present on the leading semi-circle of the angle and the trailing semi-circle of the gusset plate were constrained to each other.

\section{Results and discussion:}

In the analysis, the solution usually converged very slowly after yielding, and a small load increment was used for each load step. As the load-deflection curve reached the maximum load, the analysis was terminated because the solution diverged even for extremely small load step increments. However, the analysis never crossed the load limit 
point. The failure load of the angle specimen was taken as the load corresponding to the last converged load step.

Even though the above analysis included both material and geometric nonlinear effects to capture the nonlinear load versus deflection behavior of angles, the analysis was unable to trace the entire pre- and post-peak load versus deflection behavior beyond the load limit point. The above analysis did not include the interaction between the bolt and the web holes and its effect on the failure load. Furthermore, necking of the net area between the leg edge and the lead bolt hole was not accurately captured by this analysis.

\subsection{Epstein and McGinnis (2000) finite element study:}

Epstein and McGinnis conducted a second study aimed at refining the tools developed in Epstein's 1996 work. Additionally, the 2000 effort focused on studying the failure capacity and failure path of WT sections. These efforts were geared towards modeling the block shear behavior of WT sections bolted through their flanges and subjected to uniaxial tension. Two sets of WT's were modeled. One set consisted of various WT $4 \times 14,5 \times 13$, and 6 × 9.5 section that were focussed on capturing associated block shear phenomenon. A second set of WT 4 x 9's were also analyzed and experimentally tested that focussed on the influence of section depth (Note that all specimens were cut from a W 8 × 19 and were produced with variable depths) on the failure path and failure capacity. In the WT $4 \times 9$ tests, the length of a typical experimental specimen was 54 in. and was connected by two rows of 0.75 in. diameter two boltholes on one side and no bolt holes were modeled at the other end of the member. 
The WT had a flange width of $5.25 \mathrm{in}$. and a flange thickness of $0.33 \mathrm{in}$. The specimen is shown in the Fig. 2.4.

\section{Finite element modeling information:}

The boundary conditions and the solution procedure are identical to the 1996 Epstein study and are explained in section 2.3. The entire length of the tee was modeled due to the unknown distribution of load at half the length of the tee along the axis of symmetry location, which would need to be applied. The bolt holes were modeled only on one side of the WT. The other end where bolt holes were not modeled, the load was applied along the gage lines that would connect to the tee at that end.

\section{Results and discussion:}

Although this finite element study included only the material nonlinearity as represented by a simple elastic-perfectly-plastic yield criterion, the finite element results indicate a reasonably good correlation with the experimental results. The results are shown in Table 2.4. 
Table 2.1 Rickels and Yura's specimens (Rickles and Yura et al., 1983)

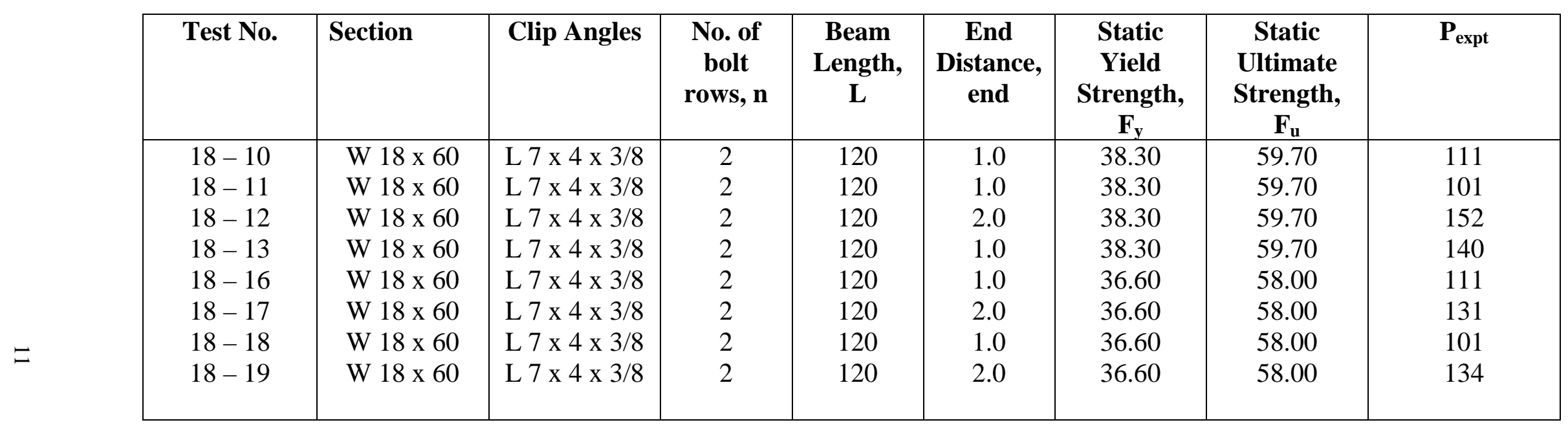

a. Dimensions are in inches, Strengths are in Ksi, and Loads are in Kips. 
Table 2.2 Epstein and Chamarajanagar's specimens (Epstein and Chamarajanagar et al., 1996)

\begin{tabular}{|c|c|c|c|c|c|}
\hline $\begin{array}{c}\text { Connection } \\
\text { No. }\end{array}$ & Angle Size & $\begin{array}{c}\text { Connection } \\
\text { Geometry }\end{array}$ & $\begin{array}{c}\text { Static Yield } \\
\text { Strength, } \mathbf{F}_{\mathbf{y}}\end{array}$ & $\begin{array}{c}\text { Static } \\
\text { Ultimate } \\
\text { Strength, } \mathbf{F}_{\mathbf{u}}\end{array}$ & $\mathbf{P}_{\text {expt }}$ \\
\hline 1 & $6 \times 6 \times 5 / 16$ & $2 / 2^{+}$ & 36 & 73.9 & 183 \\
2 & $6 \times 6 \times 5 / 16$ & $2 / 2^{-}$ & 36 & 77.0 & 204 \\
3 & $6 \times 6 \times 5 / 16$ & $2 / 2^{0}$ & 36 & 75.5 & 189 \\
4 & $6 \times 6 \times 5 / 16$ & $2 / 3^{-}$ & 36 & 77.2 & 243 \\
5 & $6 \times 6 \times 5 / 16$ & $3 / 2^{+}$ & 36 & 73.6 & 205 \\
6 & $6 \times 6 \times 5 / 16$ & $2 / 3^{0}$ & 36 & 75.0 & 260 \\
7 & $6 \times 6 \times 5 / 16$ & $3 / 3^{0}$ & 36 & 74.8 & 237 \\
8 & $6 \times 6 \times 5 / 16$ & $4 / 4^{0}$ & 36 & 72.4 & 72 \\
\hline 9 & $6 \times 4 \times 5 / 16$ & $2 / 2^{+}$ & 36 & 68.2 & 68 \\
10 & $6 \times 4 \times 5 / 16$ & $2 / 2^{-}$ & 36 & 80.0 & 71 \\
11 & $6 \times 4 \times 5 / 16$ & $2 / 2^{0}$ & 36 & 70.2 & 70 \\
12 & $6 \times 4 \times 5 / 16$ & $2 / 3^{-}$ & 36 & 68.9 & 69 \\
13 & $6 \times 4 \times 5 / 16$ & $3 / 2^{+}$ & 36 & 64.9 & 65 \\
14 & $6 \times 4 \times 5 / 16$ & $2 / 3^{0}$ & 36 & 65.7 & 66 \\
15 & $6 \times 4 \times 5 / 16$ & $3 / 3^{0}$ & 36 & 74.5 & 75 \\
16 & $6 \times 4 \times 5 / 16$ & $4 / 4^{0}$ & 36 & 76.6 & 77 \\
\hline 17 & $6 \times 3.5 \times 5 / 16$ & $2 / 2^{+}$ & 36 & 78.2 & 78 \\
18 & $6 \times 3.5 \times 5 / 16$ & $2 / 2^{-}$ & 36 & 68.5 & 69 \\
19 & $6 \times 3.5 \times 5 / 16$ & $2 / 2^{0}$ & 36 & 69.4 & 69 \\
20 & $6 \times 3.5 \times 5 / 16$ & $2 / 3^{-}$ & 36 & 69.1 & 69 \\
21 & $6 \times 3.5 \times 5 / 16$ & $3 / 2^{+}$ & 36 & 69.7 & 70 \\
22 & $6 \times 3.5 \times 5 / 16$ & $2 / 3^{0}$ & 36 & 36 & \\
23 & $6 \times 3.5 \times 5 / 16$ & $3 / 3^{0}$ & 36 & & \\
24 & $6 \times 3.5 \times 5 / 16$ & $4 / 4^{0}$ & & & \\
\hline
\end{tabular}


Table 2.2 Epstein and Chamarajanagar's specimens (Epstein and Chamarajanagar et al., 1996) (contd.)

\begin{tabular}{|c|c|c|c|c|c|}
\hline $\begin{array}{c}\text { Connection } \\
\text { No. }\end{array}$ & Angle Size & $\begin{array}{c}\text { Connection } \\
\text { Geometry }\end{array}$ & $\begin{array}{c}\text { Static Yield } \\
\text { Strength, } \mathbf{F}_{\mathbf{y}}\end{array}$ & $\begin{array}{c}\text { Static } \\
\text { Ultimate } \\
\text { Strength, } \mathbf{F}_{\mathbf{u}}\end{array}$ & $\mathbf{P}_{\text {expt }}$ \\
\hline 25 & $5 \times 5 \times 5 / 16$ & $2 / 2^{+}$ & 36 & 62.0 & 62 \\
26 & $5 \times 5 \times 5 / 16$ & $2 / 2^{-}$ & 36 & 61.5 & 62 \\
27 & $5 \times 5 \times 5 / 16$ & $2 / 3^{-}$ & 36 & 63.2 & 63 \\
28 & $5 \times 5 \times 5 / 16$ & $3 / 2^{+}$ & 36 & 70.1 & 70 \\
\hline 29 & $5 \times 3.5 \times 5 / 16$ & $2 / 2^{+}$ & 36 & 71.6 & 72 \\
30 & $5 \times 3.5 \times 5 / 16$ & $2 / 2^{-}$ & 36 & 67.8 & 68 \\
31 & $5 \times 3.5 \times 5 / 16$ & $2 / 3^{-}$ & 36 & 68.2 & 68 \\
32 & $5 \times 3.5 \times 5 / 16$ & $3 / 2^{+}$ & 36 & 72.6 & 73 \\
\hline 33 & $5 \times 3 \times 5 / 16$ & $2 / 2^{+}$ & 36 & 59.4 & 59 \\
34 & $5 \times 3 \times 5 / 16$ & $2 / 2^{-}$ & 36 & 61.0 & 61 \\
35 & $5 \times 3 \times 5 / 16$ & $2 / 3^{-}$ & 36 & 62.6 & 63 \\
36 & $5 \times 3 \times 5 / 16$ & $3 / 2^{+}$ & 36 & 61.1 & 61 \\
37 & $5 \times 3 \times 5 / 16$ & $1 / 2^{-}$ & 36 & 65.4 & 65 \\
38 & $5 \times 3 \times 5 / 16$ & $2 / 1^{+}$ & 36 & 61.8 & 62 \\
\hline
\end{tabular}

a. Dimensions are in inches, strengths are in Ksi, and Loads are in Kips

b. $\quad$ Positive, negative, and zero are all signs of stagger as shown in the Fig. 2.2. 
Table 2.3 Kulak and Wu's specimens (Kulak and Wu et al., 1997)

\begin{tabular}{|c|c|c|c|c|c|c|c|c|}
\hline $\begin{array}{l}\text { Specimen } \\
\text { No. }\end{array}$ & Size & $\begin{array}{l}\text { Connected } \\
\text { Leg }\end{array}$ & $\begin{array}{l}\text { No.of } \\
\text { Bolts per } \\
\text { line, } n\end{array}$ & $\begin{array}{l}\text { Member } \\
\text { Length, } \mathrm{L}\end{array}$ & $\begin{array}{l}\text { Bolt } \\
\text { Gauge, g }\end{array}$ & $\begin{array}{l}\text { Static } \\
\text { Yield } \\
\text { Strength, } \text { F }_{\mathrm{y}}\end{array}$ & $\begin{array}{l}\text { Static } \\
\text { Ultimate } \\
\text { Strength, } \text { F }_{\mathrm{u}}\end{array}$ & $\mathbf{P}_{\text {expt }}$ \\
\hline S1 & $4.0 \times 4.0 \times 0.25$ & 4.0 & 6 & 80.16 & 2.5 & 49.31 & 76.03 & 115 \\
\hline S2 & $4.0 \times 4.0 \times 0.25$ & 4.0 & 6 & 80.16 & 2.5 & 48.85 & 76.55 & 117 \\
\hline S3 & $4.0 \times 4.0 \times 0.25$ & 4.0 & 6 & 80.16 & 2.5 & 48.37 & 76.02 & 109 \\
\hline S4 & $3.0 \times 3.0 \times 0.189$ & 3.0 & 6 & 80.16 & 1.75 & 46.72 & 68.62 & 62 \\
\hline S5 & $4.0 \times 3.0 \times 0.25$ & 4.0 & 6 & 82.52 & 2.5 & 47.43 & 69.87 & 100 \\
\hline S6 & $4.0 \times 3.0 \times 0.25$ & 3.0 & 6 & 82.52 & 1.75 & 47.01 & 69.25 & 91 \\
\hline S7 & $4.0 \times 3.0 \times 0.25$ & 4.0 & 6 & 109.30 & 2.5 & 47.14 & 69.33 & 97 \\
\hline S8 & $3.0 \times 2.0 \times 0.374$ & 3.0 & 6 & 77.80 & 1.75 & 48.38 & 70.83 & 93 \\
\hline S9 & $3.0 \times 2.0 \times 0.189$ & 3.0 & 6 & 77.80 & 1.75 & 49.40 & 70.80 & 53 \\
\hline S10 & $3.0 \times 2.0 \times 0.189$ & 3.0 & 4 & 78.43 & 1.75 & 49.33 & 70.45 & 54 \\
\hline S11 & $3.0 \times 2.0 \times 0.189$ & 3.0 & 2 & 78.43 & 1.75 & 49.17 & 70.71 & 45 \\
\hline D1-1 & $4.0 \times 4.0 \times 0.25$ & 4.0 & 6 & 70.31 & 1.75 & 49.31 & 76.03 & 219 \\
\hline D1-2 & $4.0 \times 4.0 \times 0.25$ & 4.0 & 6 & 70.31 & 2.5 & 48.85 & 76.55 & 224 \\
\hline D1-3 & $4.0 \times 4.0 \times 0.25$ & 4.0 & 6 & 70.31 & 2.5 & 48.37 & 76.02 & 223 \\
\hline D2 & $3.0 \times 3.0 \times 0.189$ & 3.0 & 6 & 70.31 & 1.75 & 46.72 & 68.62 & 111 \\
\hline D3-1 & $4.0 \times 3.0 \times 0.25$ & 4.0 & 6 & 70.31 & 2.5 & 47.43 & 69.87 & 188 \\
\hline D3-2 & $4.0 \times 3.0 \times 0.25$ & 4.0 & 6 & 70.31 & 2.5 & 47.01 & 69.25 & 191 \\
\hline D4-1 & $4.0 \times 3.0 \times 0.25$ & 3.0 & 6 & 70.31 & 1.75 & 47.52 & 69.87 & 179 \\
\hline D4-2 & $4.0 \times 3.0 \times 0.25$ & 3.0 & 6 & 70.31 & 1.75 & 47.00 & 69.20 & 176 \\
\hline D5 & $4.0 \times 3.0 \times 0.25$ & 4.0 & 6 & 109.30 & 2.5 & 47.23 & 69.06 & 193 \\
\hline D6 & $3.0 \times 2.0 \times 0.374$ & 3.0 & 6 & 70.31 & 1.75 & 48.38 & 70.83 & 183 \\
\hline D7 & $3.0 \times 2.0 \times 0.189$ & 3.0 & 6 & 70.31 & 1.75 & 49.40 & 70.80 & 93 \\
\hline D8 & $3.0 \times 2.0 \times 0.189$ & 3.0 & 4 & 70.55 & 1.75 & 49.33 & 70.45 & 97 \\
\hline D9 & $3.0 \times 2.0 \times 0.189$ & 3.0 & 2 & 70.55 & 1.75 & 49.17 & 70.71 & 72 \\
\hline
\end{tabular}

a. Dimensions are in inches, strengths are in Ksi, and Loads are in Kips.

b. S designates a single angle specimens and D a double angle specimens. The difference between the D1-1, D1-2, D1-3, D3-1, and D4-1 and other specimens is simply that slightly different end fixture conditions were used while testing. 
Table 2.4 Epstein and McGinnis's specimens (Epstein and McGinnis et al., 2000)

\begin{tabular}{|c|c|c|c|c|c|c|c|c|c|}
\hline Section No. & $\begin{array}{l}\text { Area } \\
\text { A }\end{array}$ & $\begin{array}{c}\text { Depth } \\
\text { d }\end{array}$ & $\begin{array}{l}\text { No. of } \\
\text { rows of } \\
\text { Bolts, } n \\
\end{array}$ & $\begin{array}{l}\text { Bolt } \\
\text { Gauge, g }\end{array}$ & $\begin{array}{l}\text { Static Yield } \\
\text { Strength, } F_{y}\end{array}$ & $\begin{array}{l}\text { Static } \\
\text { Ultimate } \\
\text { Strength, } F_{u}\end{array}$ & $\mathbf{P}_{\text {expt }}$ & $\mathbf{P}_{\text {relative expt }}$ & $\mathbf{P}_{\text {relative FEA }}$ \\
\hline $\begin{array}{l}\text { WT } 4 \times 9-1^{\mathrm{c}} \\
\text { WT } 4 \times 9^{\mathrm{b}} \\
\text { WT } 4 \times 9+1 \\
\text { WT } 4 \times 9+2 \\
\text { WT } 4 \times 9+3 \\
\text { WT } 4 \times 9+4 \\
\text { WT } 4 \times 9+5 \\
\text { WT } 4 \times 9+6 \\
\text { WT } 4 \times 9+7 \\
\text { WT } 4 \times 9+8\end{array}$ & $\begin{array}{l}2.4 \\
2.63 \\
2.86 \\
3.09 \\
3.32 \\
3.55 \\
3.78 \\
4.01 \\
4.24 \\
4.47 \\
5.16\end{array}$ & $\begin{array}{l}3.07 \\
4.07 \\
5.07 \\
6.07 \\
7.07 \\
8.07 \\
9.07 \\
10.07 \\
11.07 \\
12.07 \\
1507\end{array}$ & $\begin{array}{l}2 \\
2 \\
2 \\
2 \\
2 \\
2 \\
2 \\
2 \\
2 \\
2 \\
2\end{array}$ & $\begin{array}{l}2.5 \\
2.5 \\
2.5 \\
2.5 \\
2.5 \\
2.5 \\
2.5 \\
2.5 \\
2.5 \\
2.5 \\
2.5\end{array}$ & $\begin{array}{l}48.20 \\
48.20 \\
48.20 \\
48.20 \\
48.20 \\
48.20 \\
48.20 \\
48.20 \\
48.20 \\
48.20 \\
4820\end{array}$ & $\begin{array}{l}71.60 \\
71.60 \\
71.60 \\
71.60 \\
71.60 \\
71.60 \\
71.60 \\
71.60 \\
71.60 \\
71.60\end{array}$ & $\begin{array}{l}133.1 \\
136.8 \\
138.7 \\
137.6 \\
- \\
- \\
- \\
- \\
- \\
-\end{array}$ & $\begin{array}{l}0.988 \\
1.000 \\
1.030 \\
1.025 \\
- \\
- \\
- \\
- \\
- \\
-\end{array}$ & $\begin{array}{l}0.982 \\
1.000 \\
1.023 \\
1.046 \\
1.063 \\
1.070 \\
1.076 \\
1.079 \\
1.079 \\
1.080 \\
1.083\end{array}$ \\
\hline
\end{tabular}

a. Dimensions are in inches, strengths are in Ksi, and Loads are in Kips

b. The standard WT $4 \times 9$

c. The nonstandard WT sections were identified by a + or - sign and a number indicating inches of deviation from the nominal depth. 


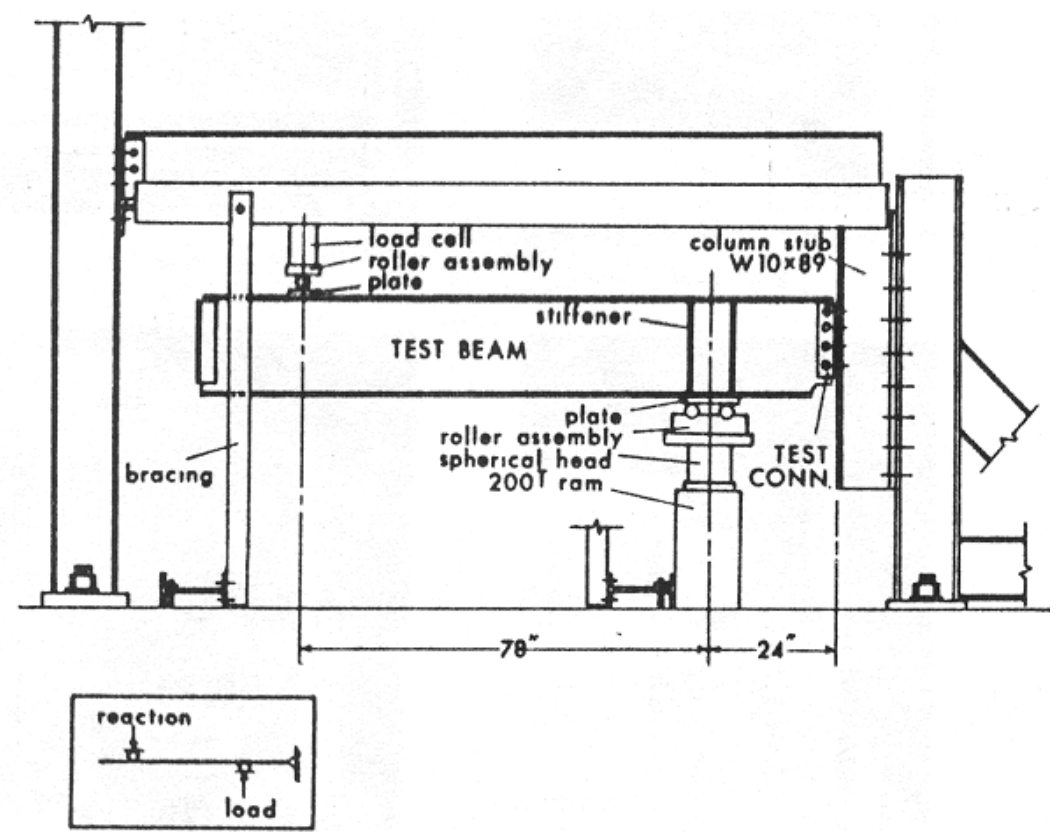

Figure 2.1 Rickles and Yura's test setup 

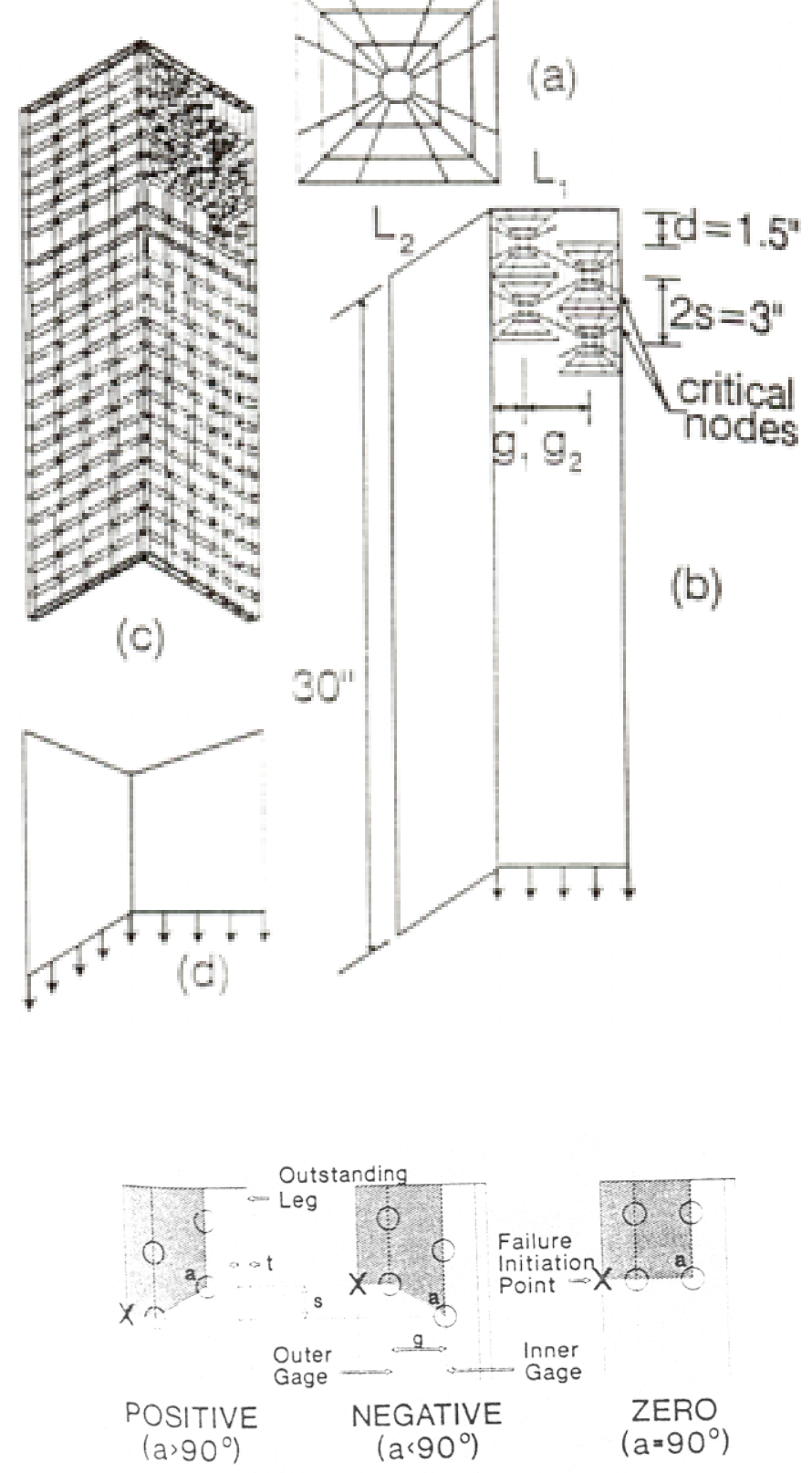

Figure 2.2 Epstein and Chamarajanagar's specimen 


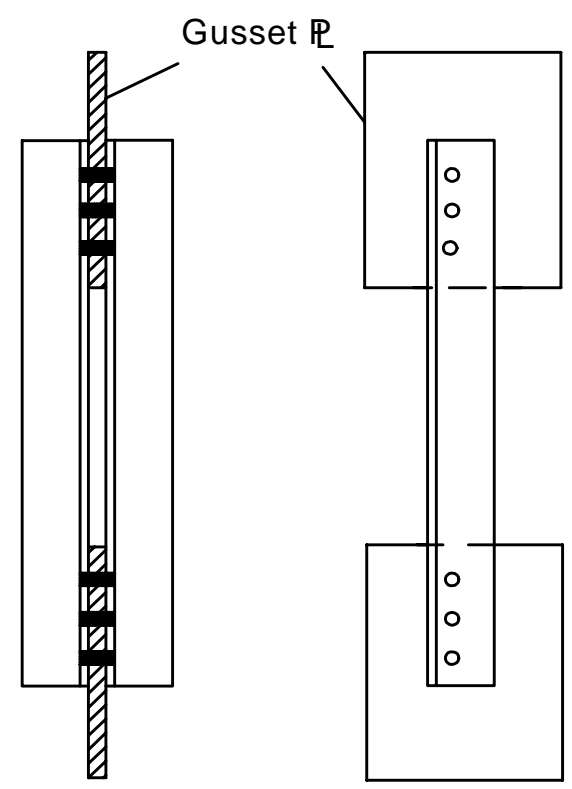

Double Angle

Setup

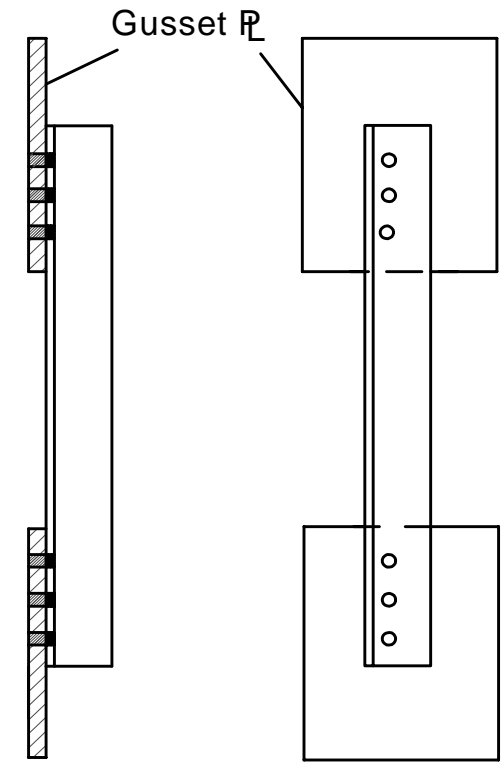

Single Angle

Setup

Figure 2.3 Kulak and Wu's specimen 


\begin{tabular}{ll}
\hline f fiange width \\
$d$ depth \\
e edge distance \\
9 goge \\
$p$ plitch \\
$t_{f}$ fiange thickness \\
$f_{w}$ web thickness \\
$x^{\prime}$ length \\
$c e$ centroidal axis \\
$k$ fillet distance
\end{tabular}

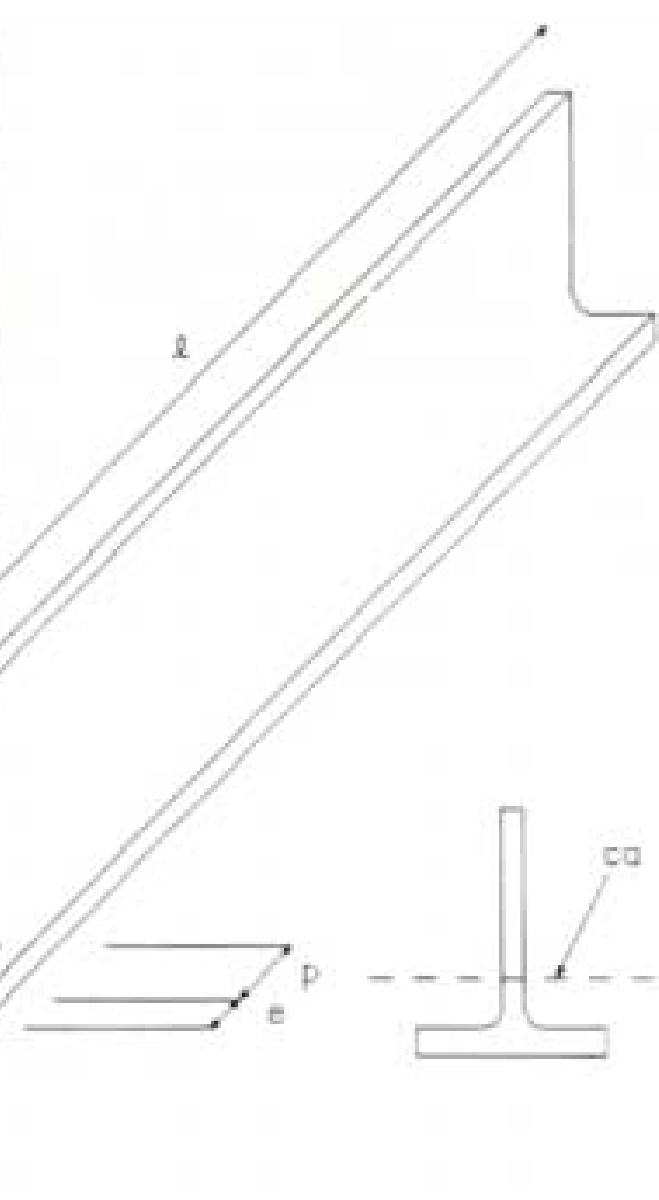

Figure 2.4 Epstein and McGinnis's specimen 


\section{Chapter 3}

\section{DEVELOPMENT OF AN ACCURATE AND EFFICIENT FINITE ELEMENT}

\section{MODEL}

\subsection{Introduction:}

Several investigations (Rickles and Yura et al.,1983, Epstein and Chamarajanagar et al., 1996, Kulak and Wu et al., 1997, Epstein and McGinnis et al., 2000) have previously conducted finite element analysis of bolted uniaxial tension specimens. However, the bulk of this work was conducted using small deformation linear elastic models. Typical failure modes of the types of specimens described in this work involve large strains and necking of the material in the vicinity of the lead bolt hole. In order to more accurately understand the flow of stresses in these regions it is therefore necessary to develop models capable of representing this behavior.

This chapter presents a preliminary study conducted to develop an accurate and robust finite element model that may be used as a tool in further analyses. The calibration of these tools will be based on previous work on tension specimens conducted by Kulak and $\mathrm{Wu}$ (1997). The failure behavior exhibited by these specimens is similar to the behavior of the West Virginia University test specimens. 
Four models, labeled A, B, C, and D discussed in the subsequent sections of this chapter were used in the calibration procedure using specimen D9 from Kulak and Wu's work. The model that performed "best" was be selected for use in further finite element analyses. This model was also verified by analyzing two other specimens from Kulak and Wu's work, D7 and S11.

\subsection{Primary FEA work used to develop robust tools:}

The primary purpose of this section is to develop an accurate and efficient finite element model using Kulak and Wu's (1997) work as a reference. In this section, Kulak and Wu's specimen D9 is modeled using different elements, different boundary conditions and different constitutive laws for the material response. These results are then compared to Kulak and Wu's (1997) finite element and experimental results.

The four models used to analyze Kulak and Wu's (1997) specimen D9 are labeled Model A, Model B, Model C, and Model D. Table 3.1 presents basic model parameters used for each of these. In essence, Model A represents the most basic model performed where as Model D represents the most complex model performed. These various stages of modeling are conducted to determine an appropriate level required for capturing accurate and robust results. 


\subsection{Summary of various models:}

In the various models, two different elements are examined; a solid element capable of representing large deformation geometric and material nonlinearities and a plastic quadrilateral shell. Both full and reduced integration schemes are studies for the shell element.

Also, two constitutive material models are studied; a multi linear stress-strain curve and a power law type stress-strain curve. These curves are shown in Fig. 3.1.

The von-Mises yield criterion is used to represent the material nonlinearity and the modified Riks solution scheme is used to capture the nonlinear load versus deflection response. A mapped meshing, shown in Fig. 3.2, is used to accurately capture the stress behavior in the vicinity of the hole.

Two conditions are used to explore the bolt interaction; nodal constraints and surface contact. In models $\mathrm{A}$ and $\mathrm{B}$, nodal constraint is imposed for $\mathrm{X}$ and $\mathrm{Y}$ translational degrees of freedom on opposite sides of the bolt hole, whereas in models C and D surface contact is used between rigid bolt surfaces and the web and gusset plate hole surfaces. The nodal constraints imposed in models A and B do not account for rotation of the bolt due to load eccentricities and also do not explicitly consider the bolt-web interaction. Hence, in this study, surface contact option is used between the rigid bolt surfaces and the web and gusset plate hole surfaces.

The failure capacities obtained using the finite element analysis of models A, B, C, and D are compared with the experimental failure load of the specimen in Table 3.1. Figures 3.3 through 3.6 present the load versus displacement plots obtained using each of 
the models. At the time of failure in the experimental specimen, large inelastic deformations were observed in the vicinity of lead bolt holes. Based on this observation and the results presented in Table 3.1, it is clear that large strain analysis may be needed for accurately capturing the failure capacities of the experimental specimen. The type of material stress-strain curve (either tri-linear or power law), although is important in terms of stiffness in the elastic-plastic transition and ductility, does not significantly influence the failure load capacities. The nodal constraints imposed in models A and B do not account for the rotation of the bearing reaction direction between the bolt and the web hole surfaces. In the experimental study, the load from the bolt to the web is transferred at an angle to the longitudinal axis. This rotation of the bearing reaction direction is caused due to load eccentricities. Based on these observations, in this work, model D1 is adopted for subsequent analyses. The deformed shape presented in Fig. 3.7 indicates substantial amount of necking of the material between the outside edge of the web and the lead bolt hole. The equivalent plastic strain contours around the lead bolt hole indicate that the failure of the specimen may have occurred due to the partial net section rupture of the material adjacent to the lead bolt hole.

\subsection{Conclusions and discussion:}

In the previous sections, various models in terms of material and geometric nonlinearities, different material stress-strain curves (tri-linear or power law), different element types (brick or shell elements), and different bolt to web surface interactions have been presented within the context of Kulak's D9 specimen. From the results shown 
in Table 3.1, it is clear that the results obtained using the above modeling techniques agree closely with the experimental failure loads. In particular, models using large strain material nonlinear effects are in excellent agreement with the experimental results. This is expected as appreciable necking of the cross-section is observed at failure loads. The effect of tri-linear or power law type material stress-strain curve manifests itself only in terms of the stiffness in the elasto-plastic transion region. The failure load capacities of the specimen are relatively independent of the material stress-strain curve as long as the same ultimate stresses are used in the material stress-strain curves. The nodal constraints imposed in models A and B do not account for rotation of the bolt due to load eccentricities and also does not explicitly consider the bolt-web interaction. Hence, in this study, surface contact option is used between the rigid bolt surfaces and the web and gusset plate hole surfaces. Thus, from modeling point of view, Model D1 that satisfies all the above conditions is adopted in this study.

Furthermore, Kulak and Wu (1997) included both geometric as well as material nonlinear effects to capture the pre-peak nonlinear load versus deflection behavior of angles. However, the analysis was unable to trace the entire pre and post-peak load versus deflection behavior beyond the load limit point. In addition, none of Kulak's analyses include the interaction between the bolt and the web holes and its effect on the failure load. Furthermore, necking of the net area between the leg edge and the lead bolt hole was not accurately captured in the Kulak and $\mathrm{Wu}$ analyses. Hence, a comprehensive finite element modeling of the angle sections that include large deformation geometric and material nonlinear effects is performed to trace the entire load versus deflection 
behavior beyond the load limit point. These observations form the basis for the current numerical study of connections subjected to block shear and net section rupture of crosssections.

\subsection{Other miscellaneous analysis of Kulak's specimens:}

Table 3.2 presents the finite element analysis results of Kulak and Wu's (1997) S11 and D7 specimens. The finite element model used is based on Model D1 as explained in section 3.3.

The load versus deflection response for S11 specimen is shown in the Fig. 3.8. Based on this load displacement curve and the results presented in Table 3.2, it is clear that the analytical results correlate well with the experimental results. At failure, necking is observed between the outside edge of the web and the leading edge of the bolt hole.

In the next chapter, finite element modeling of WT-section specimens with boundary conditions as specified in Model D1 is performed to capture their failure capacities. 
Table 3.1 Model titles and their results comparing with the experimental results.

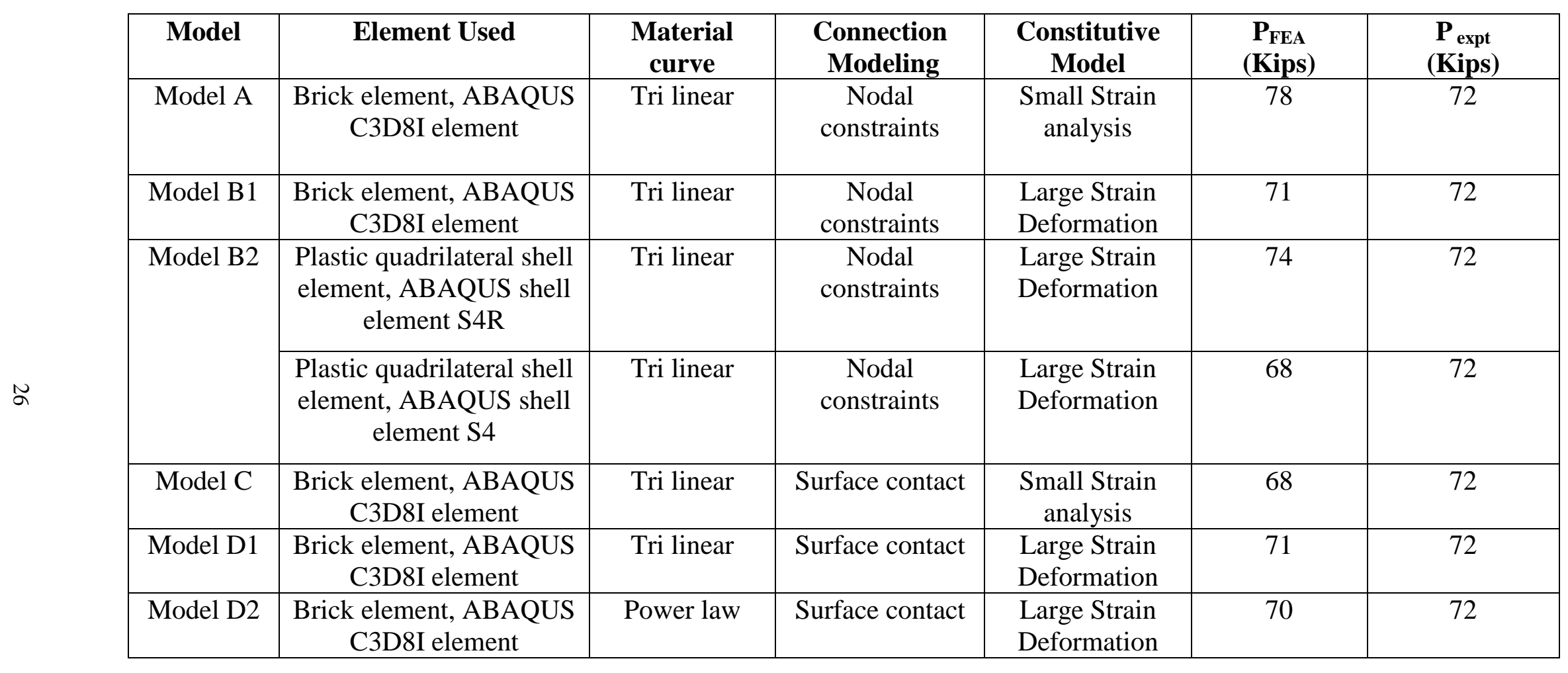


Table 3.2 Comparison of Model D, and experimental failure loads for specimens D7 and S11

\begin{tabular}{|c|c|c|c|c|c|}
\hline Specimen & Element used & $\begin{array}{c}\text { Connection } \\
\text { Modeling }\end{array}$ & $\begin{array}{c}\text { Material } \\
\text { Curve } \\
\text { Used }\end{array}$ & $\begin{array}{c}\text { P }_{\text {FEA }} \\
\text { (Kips) }\end{array}$ & $\begin{array}{c}\text { P }_{\text {expt }} \\
\text { (Kips) }\end{array}$ \\
\hline D7 & $\begin{array}{c}\text { Brick Element, ABAQUS } \\
\text { C3D8I element }\end{array}$ & Contact Surface & Tri-Linear & 92 & 93 \\
\hline S11 & $\begin{array}{c}\text { Brick Element, ABAQUS } \\
\text { C3D8I element }\end{array}$ & Contact Surface & Tri-Linear & 45 & 45 \\
\hline
\end{tabular}




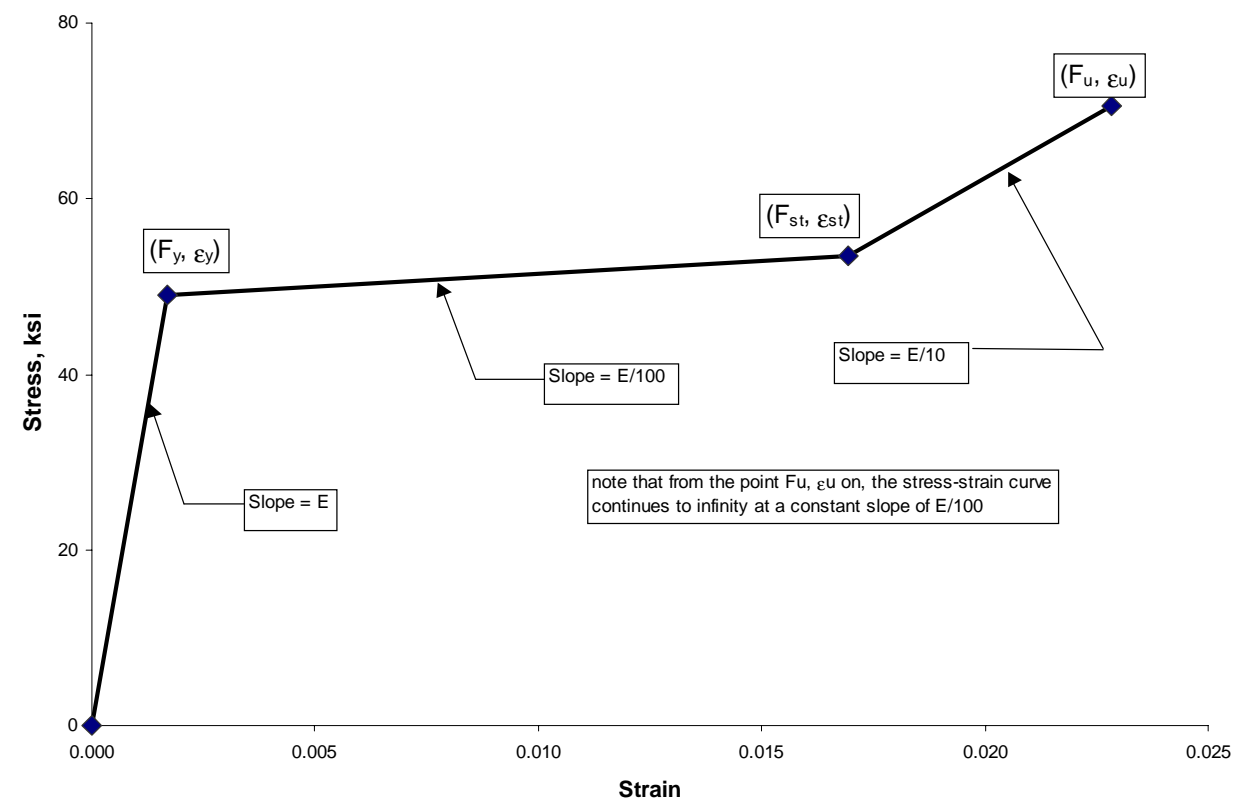

Figure 3(a) Typical Tri Linear Material Curve

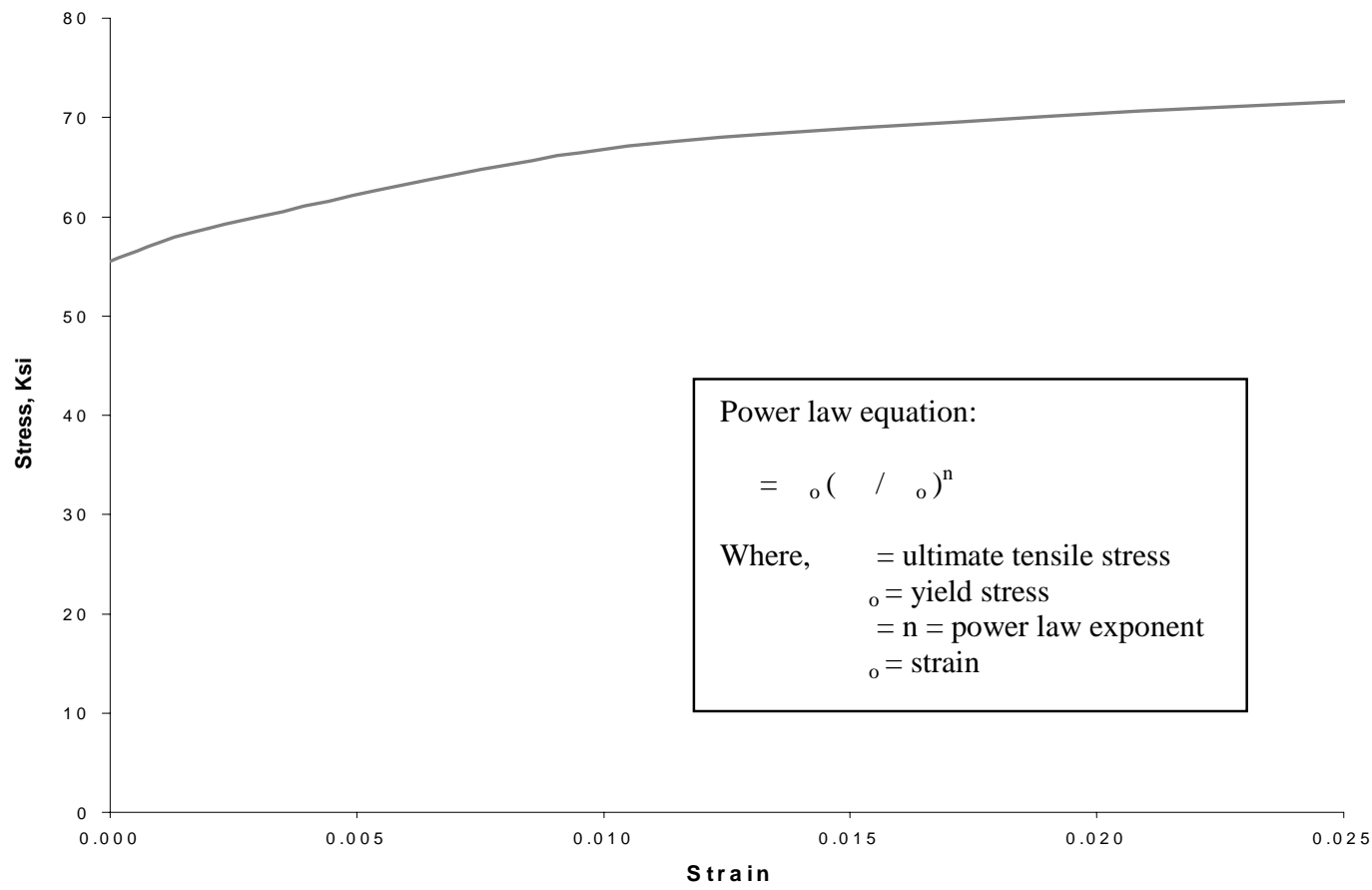

Figure 3(b) Typical power law type constitutive model

Figure 3.1 Typical constitutive models 


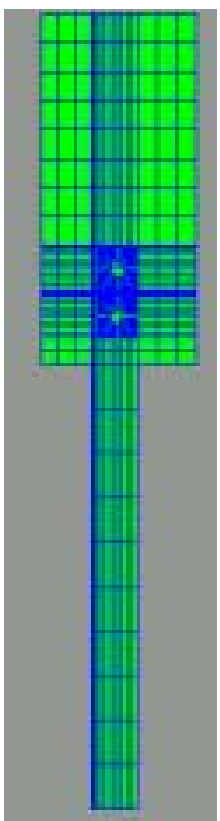

Overall mesh
Mid length symmetry

\section{Web meshing}

Load induced by displacement control $\mathrm{U}_{\mathrm{x}}=\mathrm{U}_{\mathrm{z}}=\theta_{\mathrm{x}}=\theta_{\mathrm{y}}=\theta_{\mathrm{z}}=0$

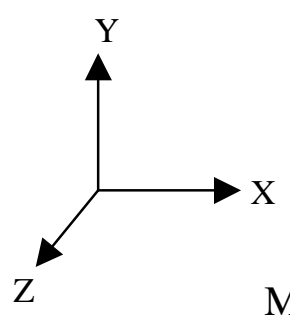

Mesh in vicinity of holes
Contact Surface is used between the Bolts outer Surface and web hole inner surface as well as between the Bolts outer surface and gusset plate inner surface.

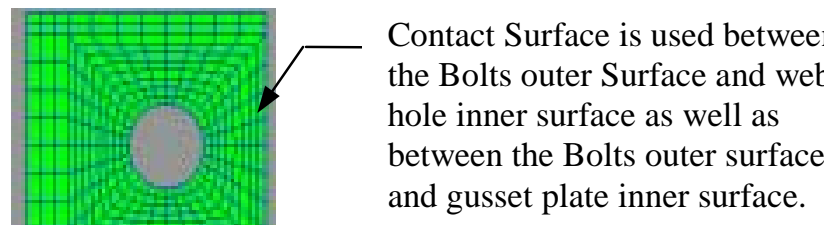

Figure 3.2 Boundary conditions using model C for Kulak and Wu's D9 specimen 


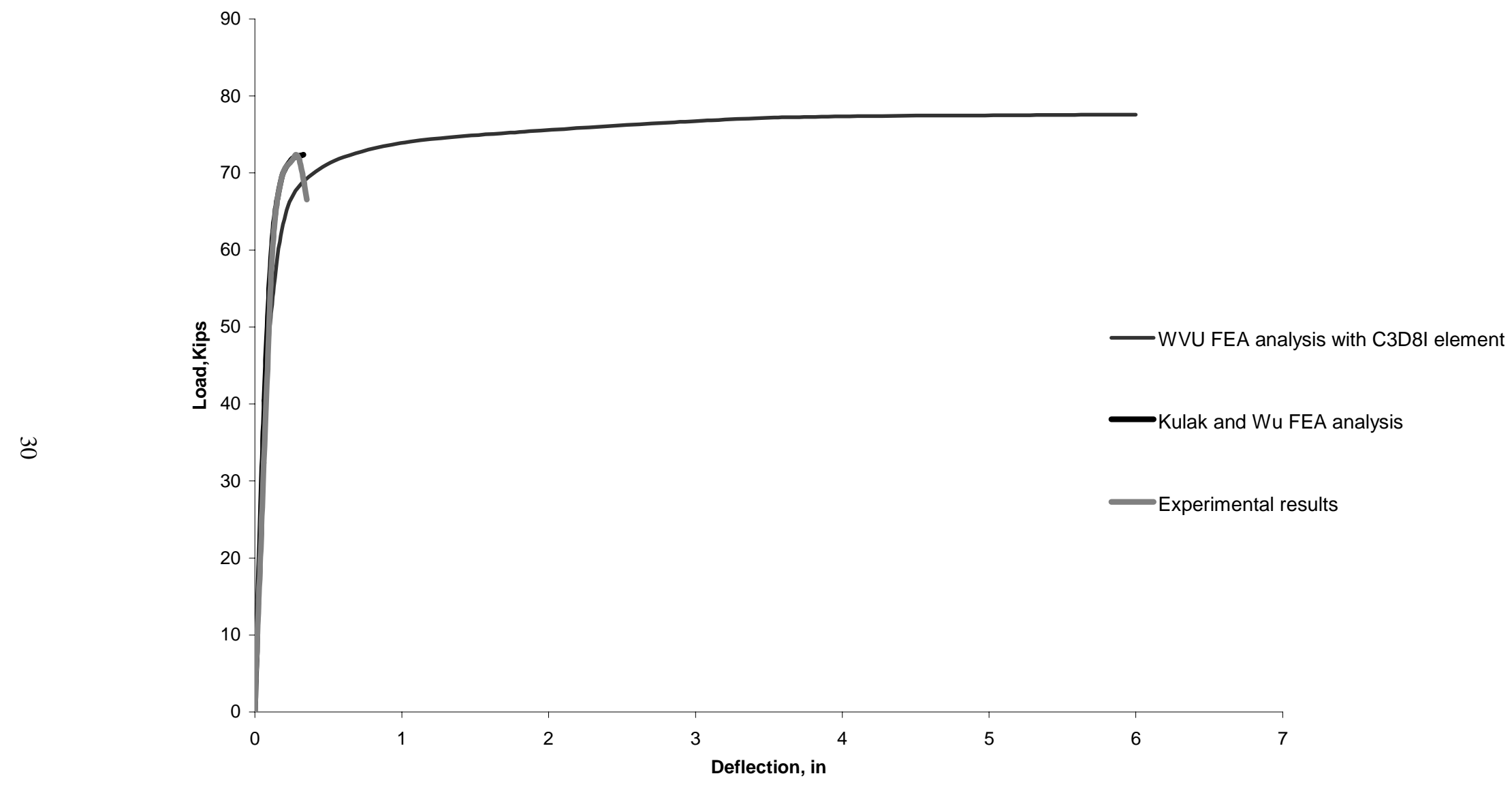

Figure 3.3 Comparison of model A and experimental failure loads for Kulak and Wu's D9 specimen 


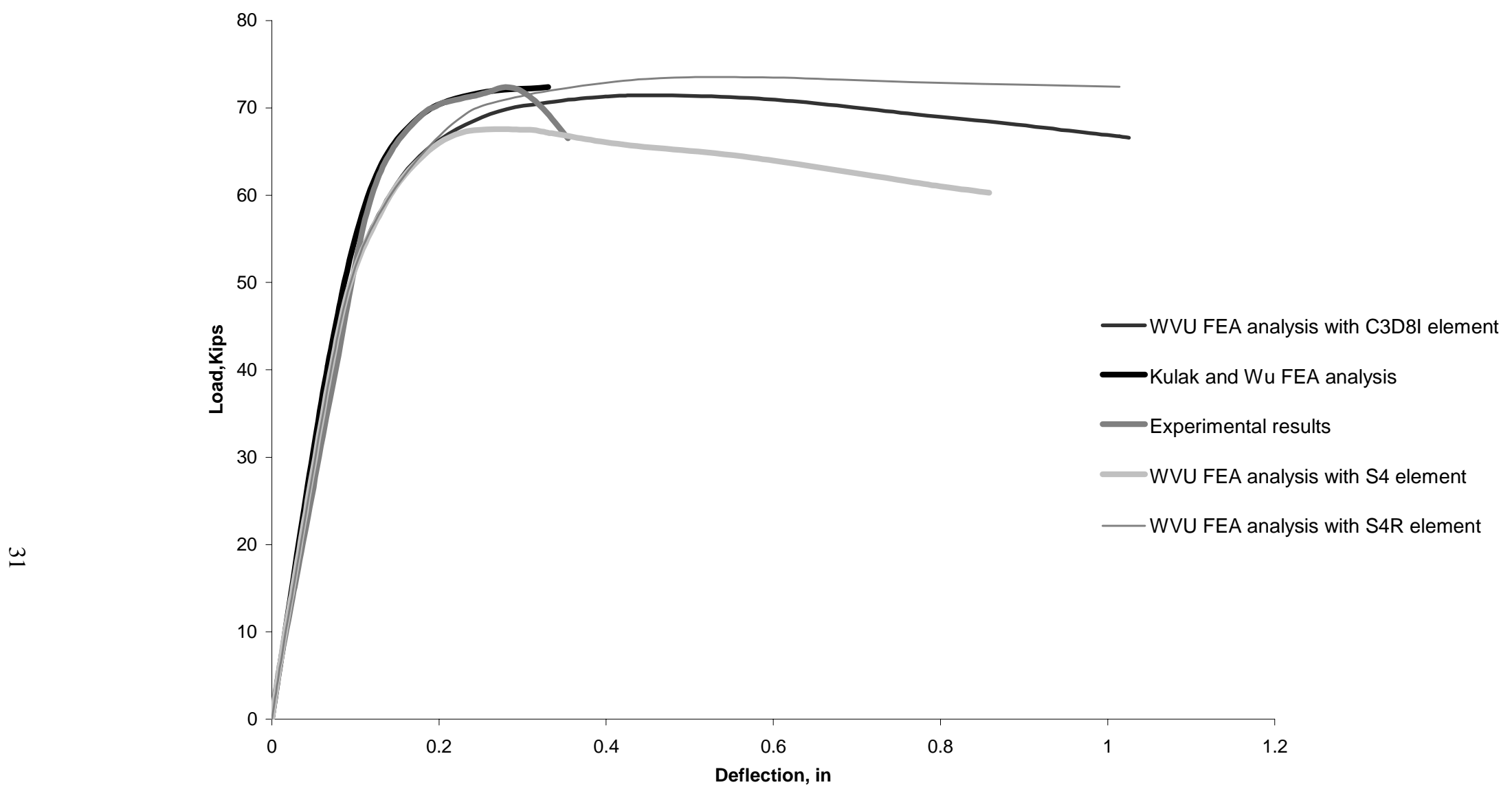

Figure 3.4 Comparison of model B and experimental failure loads for Kulak and Wu's D9 specimen 


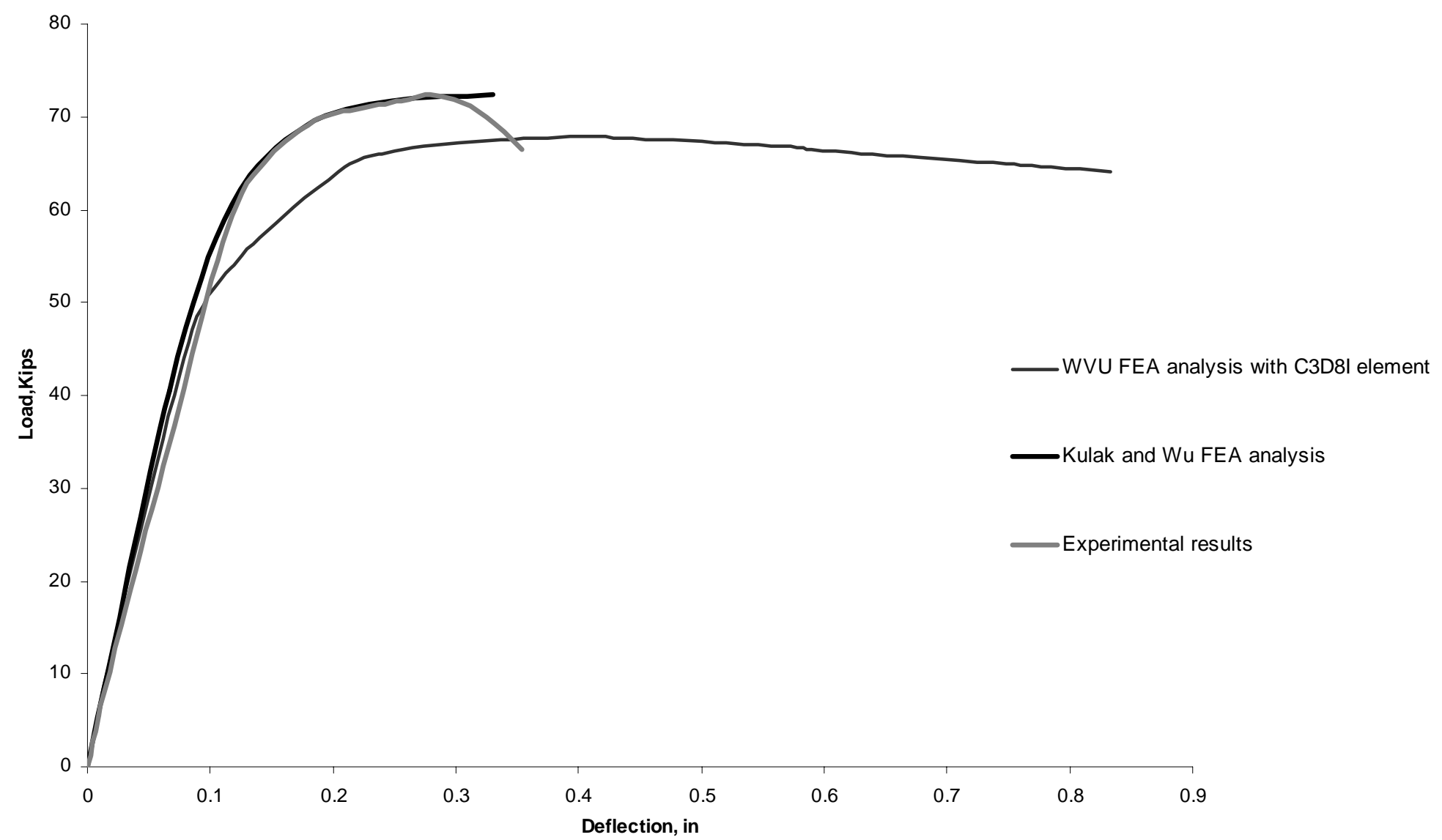

Figure 3.5 Comparison of model C and experimental failure loads for Kulak and Wu's D9 specimen 


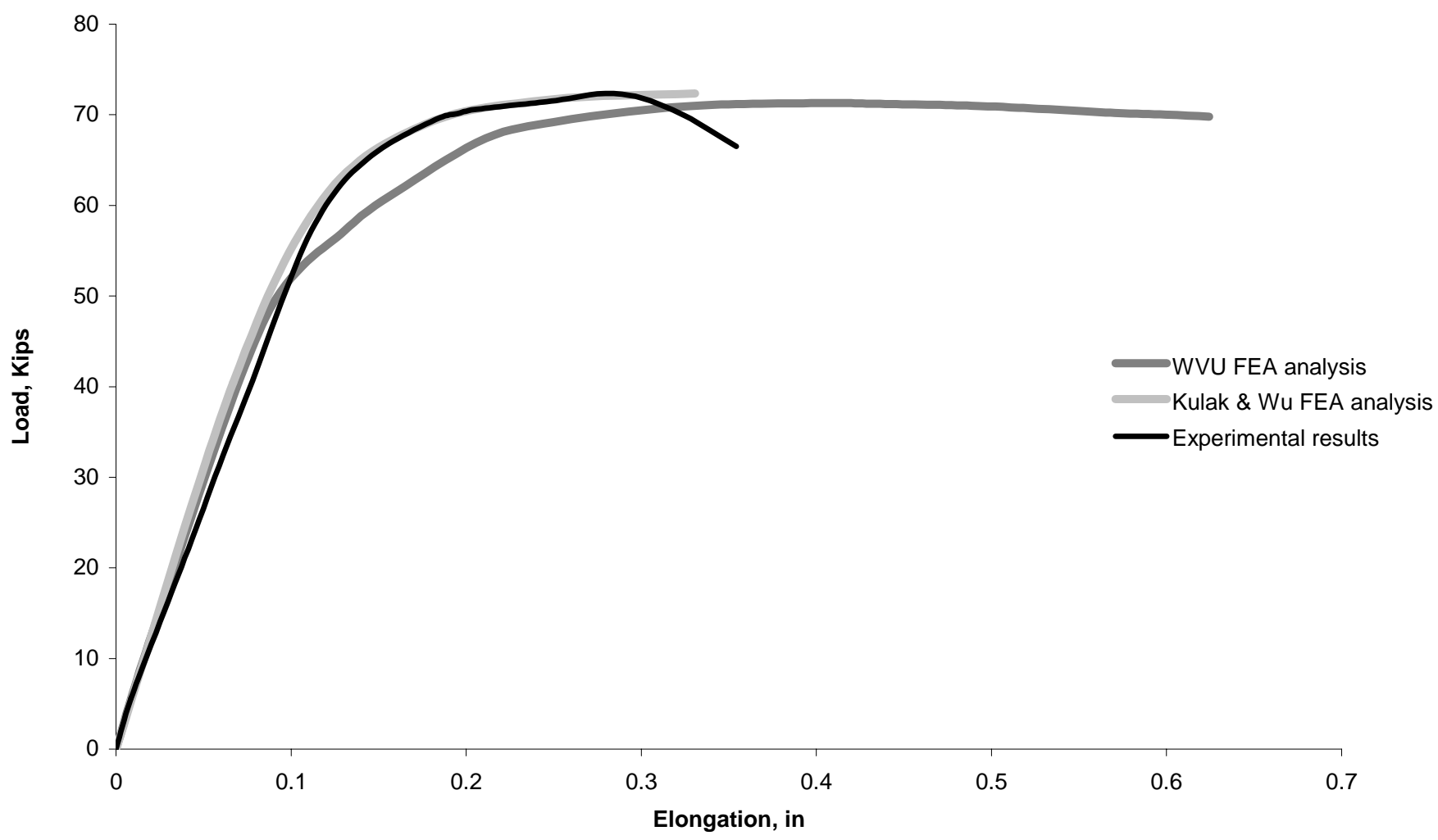

Figure 3.6 Comparison of FE results using model D1 condition with Kulak and Wu's D9 specimen 


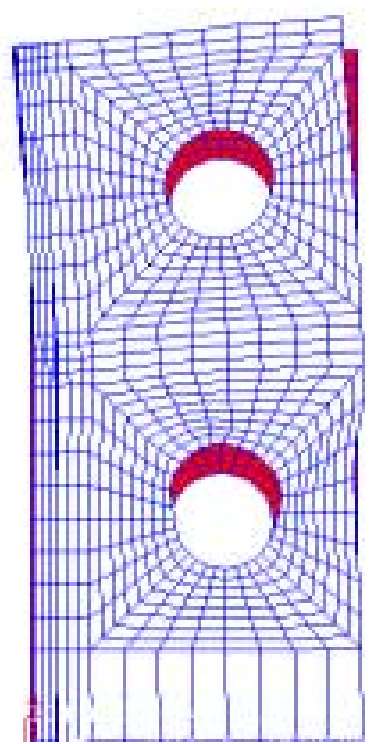

Deformed shape
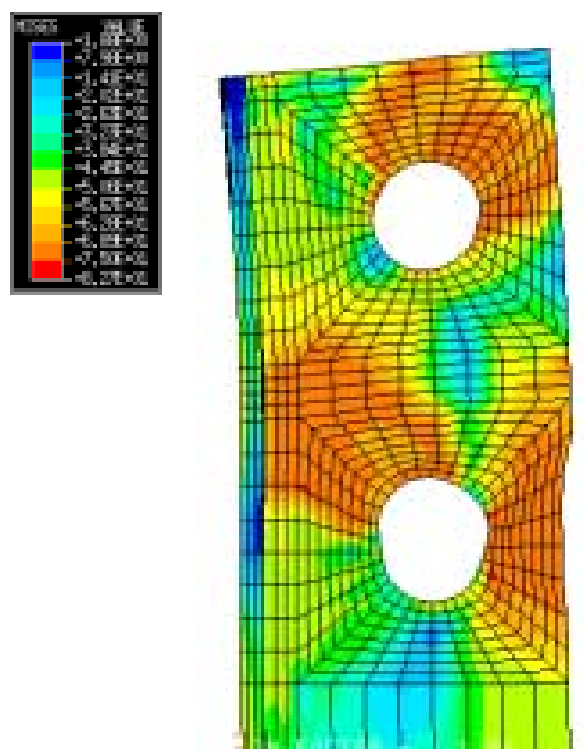

Stress contours

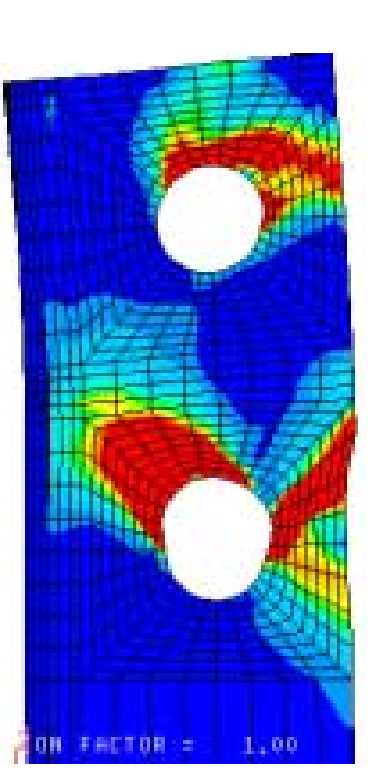

Plastic strain contours

Figure 3.7 Deformed shape, stress contours, and plastic strain contours at the maximum load for Kulak and Wu's D9 specimen using model D1. 


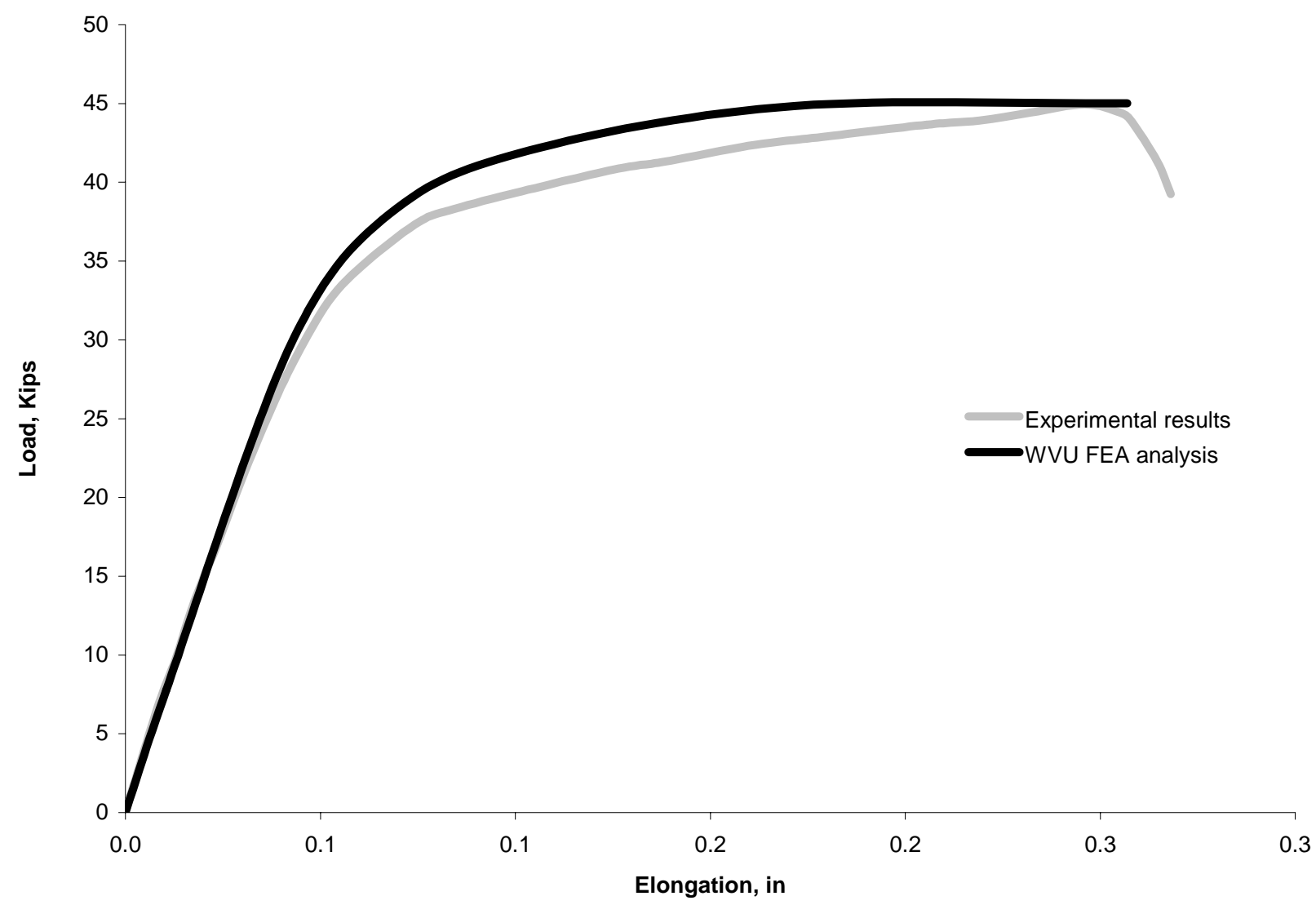

Figure 3.8 Comparison of FE results using model D1 with Kulak and Wu's S11 specimen 


\section{Chapter 4}

\section{FINITE ELEMENT MODELING OF WVU SPECIMENS}

\subsection{Introduction:}

The purpose of this study has been to develop accurate and robust finite element analysis tools that may be used in future efforts to conduct more detailed parametric studies of bolted single angle, double angle, and WT bolted sections subjected to uniaxial tension. Recently a limited set of experimental studies focused at understanding the influence of connection eccentricity, connection length, and hole drilling techiniques on the capacity of uniaxial tension members was conducted at West Virginia University (Bartels et al., 2000; Barth et al., 2000; Orbison et al., 2000). In this chapter, the finite element analysis tools developed in Chapter 3 will be used to model the recent WVU experimental specimens.

In the following, finite element modeling of the experimental WT section specimens is described. The main objective of the finite element analysis is not only to estimate the failure loads of the WT section specimens but also to trace the entire load versus deflection path and to develop an accurate behavioral representation of the specimens. In the experimental specimens with medium to large connection eccentricities, failure of the WT sections is typically caused by severe necking of the outside edge adjacent to the lead bolthole, followed by the fracture of the outside edge. 
Thus, for an accurate representation of the failure load, it is essential to capture the underlying necking behavior in the vicinity of the lead bolthole. In the experimental specimens with small eccentricities, failure is typically caused by either full net section rupture or block shear. The model must be able to capture the combined fracture and yielding associated with block shear and also must be able to represent the large plastic strains associated with full net section rupture. The finite element analysis is performed using 3D solid elements that are capable of representing large deformation geometric and material nonlinearities. The commercial finite element program ABAQUS was used to perform the analysis. These analyses are conducted using model D1, described in chapter 3.

This chapter is divided into three sections: description of WVU specimens, experimental setup of WVU specimens, summary of finite element modeling procedures used with WVU specimens.

\subsection{Description of WVU specimens:}

The WVU specimens consist of three sets of short WT tension members. All specimens are 36 inches in length and connected with a single row bolt holes of 0.75 inch in diameter through their webs at both ends shown in the Fig. 4.1. There are two sets of WT $6 \times 7$ specimens and one set of WT $4 \times 12$ specimens are shown in the Table 4.1 . Variable parameters in the experimental studies include; number of bolts, bolt-line eccentricity, and hole fabrication procedure. 


\subsection{Experimental setup of WVU specimens:}

This section describes the experimental setup of the WT tension members tested at WVU. To simulate the effects of gusset plates bar stock grips were used in the experimental setup to transfer the load from the Baldwin 200 kip Universal Testing Machine (UTM) to the WT tension member. They are fabricated using 3 x 0.75 inch cold rolled steel bar stock having 0.8125 -inch diameter boltholes drilled at appropriate locations. Spacer plates of the same thickness of the specimens web were placed in between the ends of the grips in order to prevent the bending of the grip ends and thus enabling the UTM wedge grips to have a contact surface with the grips as shown in the Fig. 4.1.

The grips were fastened to a WT specimen by bolts, which were tightened to the snug tight condition. The top and bottom gusset plates were first installed in either of the hydraulic grips as shown in the Fig. 4.2. The bar stock grips were reused from the previous tests since no bending was observed during the experimental setup. The bolts were reused if they were visually undamaged from the previous tests. Each specimen was tested to failure (at which point the load applied by the UTM would drop off considerably) by steadily increasing the applied load.

In the experimental test program, three modes of failure were observed. The first failure mode, typically exhibited by the specimens having medium and large connection eccentricities, is caused by severe necking of the outside edge adjacent to the lead bolt hole, followed by the fracture of the outside edge. This failure mode is termed as partial rupture of the net section. The second failure mode is due to block shear failure as evidenced by the rupture of net tension area and either partial or full rupture of the gross 
shear area. The third mode of failure is due to full net section rupture of the web on either side of the lead bolt hole, which propagated through the rest of both the flange and web areas simultaneously. The partial net section rupture with medium eccentricity, partial net section rupture with large eccentricity, block shear failure, and full net section rupture are shown in the Fig. 4.3.

\subsection{Summary of finite element modeling procedures used with WVU specimens:}

In the following section, finite element modeling of the experimental WT section specimens is described. In the current study, each of the WVU specimens, shown in Table 4.1, have been analyzed.

The finite element analysis tools developed in Chapter 3 are used in modeling the recent WVU experimental specimens. Model D1 finite element methodology, as presented in Section 3.3, is used in the simulation of the WT section specimens tested at WVU. The geometric dimensions and the connection details are given in Table 4.1. Figure 4.1 shows the WT specimen configuration and the test set-up used in the experiments. The boundary conditions and typical mesh used in the finite element simulation are shown in Fig. 4.4. The material properties of the specimen are based on a tri-linear stress versus strain relationship as shown in Fig. 3.1. 
Table 4.1 WVU specimens

\begin{tabular}{|c|c|c|c|c|c|c|c|c|}
\hline $\begin{array}{c}\text { Specimen } \\
\text { No. }\end{array}$ & Type & $\begin{array}{c}\text { No of bolt holes } \\
n\end{array}$ & edge & d & tw & $d_{h}$. & $F_{y}$ & $\mathrm{Fu}_{\mathrm{u}}$ \\
\hline $1 a(p)^{b}$ & WT 6x7 & 4 & 0.915 & 5.915 & 0.195 & 0.780 & 58.75 & 75.13 \\
\hline $2 a(d)$ & WT 6x7 & 4 & 0.935 & 5.935 & 0.195 & 0.821 & 58.75 & 75.13 \\
\hline $3 a(p)$ & WT 6x7 & 4 & 2.430 & 5.930 & 0.195 & 0.780 & 58.75 & 75.13 \\
\hline $4 a(d)$ & WT 6x7 & 4 & 2.405 & 5.905 & 0.196 & 0.818 & 58.75 & 75.13 \\
\hline $5 a(d)$ & WT 6x7 & 4 & 3.430 & 5.930 & 0.192 & 0.802 & 58.75 & 75.13 \\
\hline $6 a(p)$ & WT 6x7 & 4 & 3.468 & 5.968 & 0.199 & 0.780 & 58.75 & 75.13 \\
\hline $7 a(p)$ & WT 6x7 & 4 & 4.145 & 5.975 & 0.195 & 0.814 & 58.75 & 75.13 \\
\hline $8 a(d)$ & WT 6x7 & 4 & 4.095 & 5.925 & 0.194 & 0.814 & 58.75 & 75.13 \\
\hline $1 \mathrm{~b}(\mathrm{~d})$ & WT 6x7 & 5 & 0.922 & 5.922 & 0.205 & 0.815 & 61.97 & 76.34 \\
\hline $2 b(p)$ & WT 6x7 & 5 & 0.906 & 5.906 & 0.205 & 0.812 & 61.97 & 76.34 \\
\hline $3 b(d)$ & WT 6x7 & 5 & 2.402 & 5.902 & 0.205 & 0.815 & 61.97 & 76.34 \\
\hline $4 b(d)^{c}$ & WT 6x7 & 5 & 2.434 & 5.934 & 0.205 & 0.812 & 61.97 & 76.34 \\
\hline $5 b(d)$ & \begin{tabular}{|l|} 
WT $6 \times 7$ \\
\end{tabular} & 5 & 3.477 & 5.977 & 0.205 & 0.819 & 61.97 & 76.34 \\
\hline $6 b(p)$ & WT 6x7 & 5 & 3.469 & 5.969 & 0.201 & 0.812 & 61.97 & 76.34 \\
\hline $7 b(d)$ & WT 6x7 & 5 & 4.075 & 5.906 & 0.205 & 0.815 & 61.97 & 76.34 \\
\hline $8 b(p)$ & WT 6x7 & 5 & 4.107 & 5.938 & 0.205 & 0.812 & 61.97 & 76.34 \\
\hline $1 c(d)$ & WT $4 \times 12$ & 3 & 0.985 & 3.985 & 0.288 & 0.812 & 58.35 & 68.79 \\
\hline $2 c(p)$ & WT $4 \times 12$ & 3 & 1.004 & 4.004 & 0.288 & 0.808 & 58.35 & 68.79 \\
\hline $3 c(d)$ & WT $4 \times 12$ & 3 & 1.489 & 3.989 & 0.288 & 0.815 & 58.35 & 68.79 \\
\hline $4 c(p)$ & WT $4 \times 12$ & 3 & 1.477 & 3.977 & 0.288 & 0.808 & 58.35 & 68.79 \\
\hline $5 c(d)$ & WT $4 \times 12$ & 3 & 2.083 & 4.083 & 0.292 & 0.819 & 58.35 & 68.79 \\
\hline $6 c(p)$ & WT $4 \times 12$ & 3 & 2.012 & 4.012 & 0.288 & 0.812 & 58.35 & 68.79 \\
\hline
\end{tabular}

a. Dimensions are in inches and strengths are in Ksi.

b. (p) designates a specimen with punched holes and (d) a specimen with drilled holes

c. Due to fabrication error specimen 4b's bolt holes were drilled rather than punched 

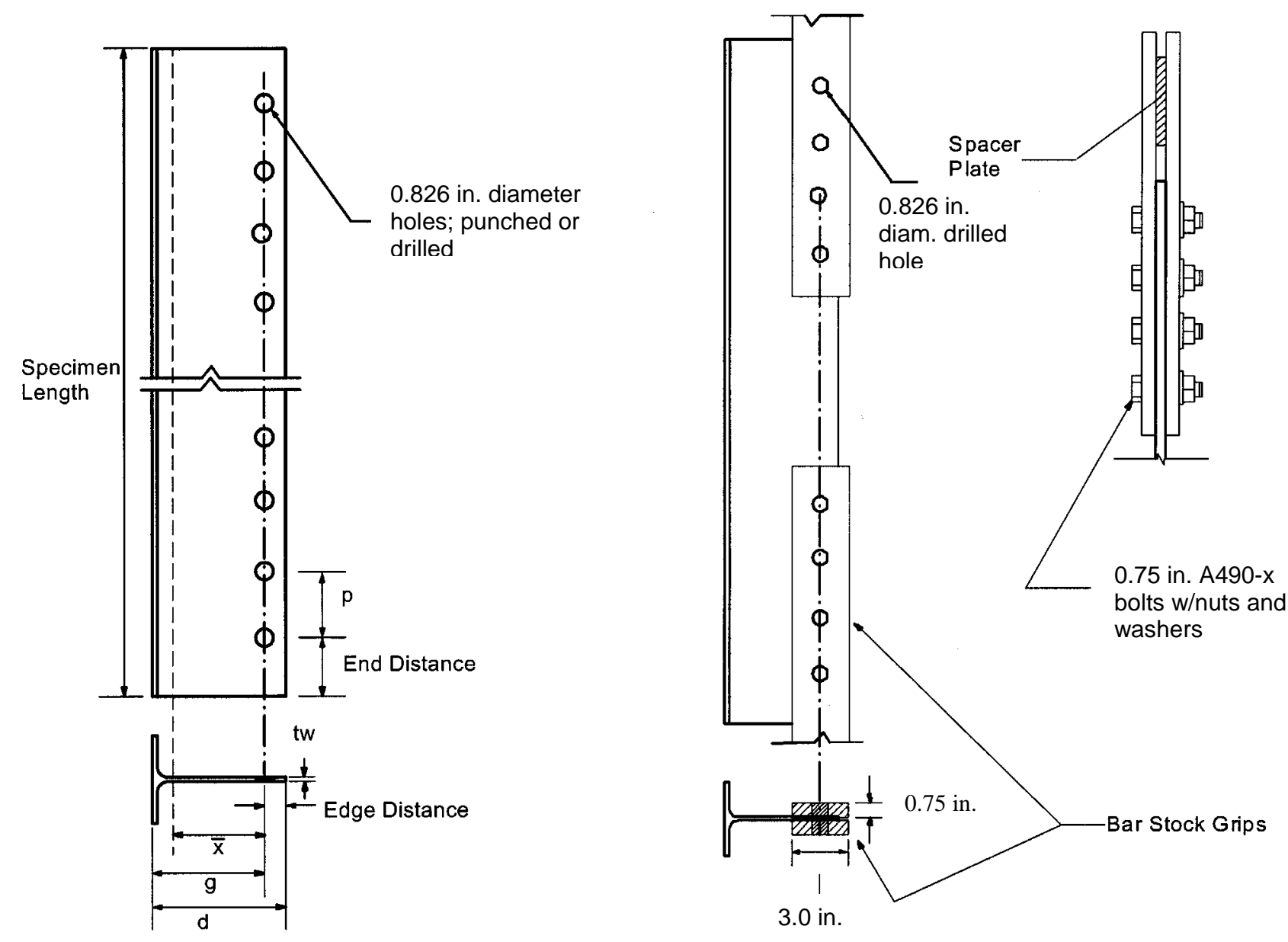

Figure 4.1 Typical WT specimen configuration and grip assembly 


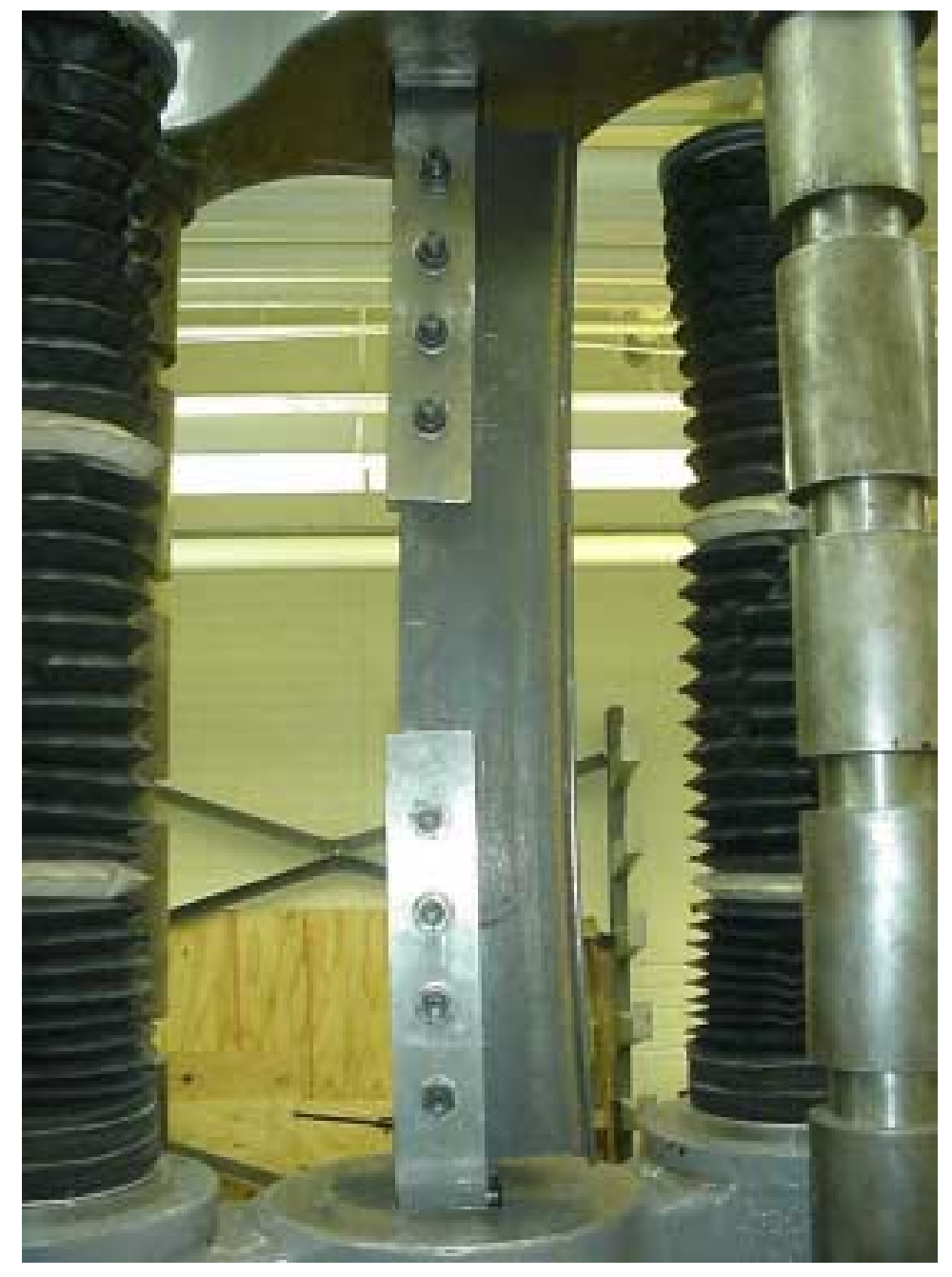

Figure 4.2 Typical WT specimen in UTM 

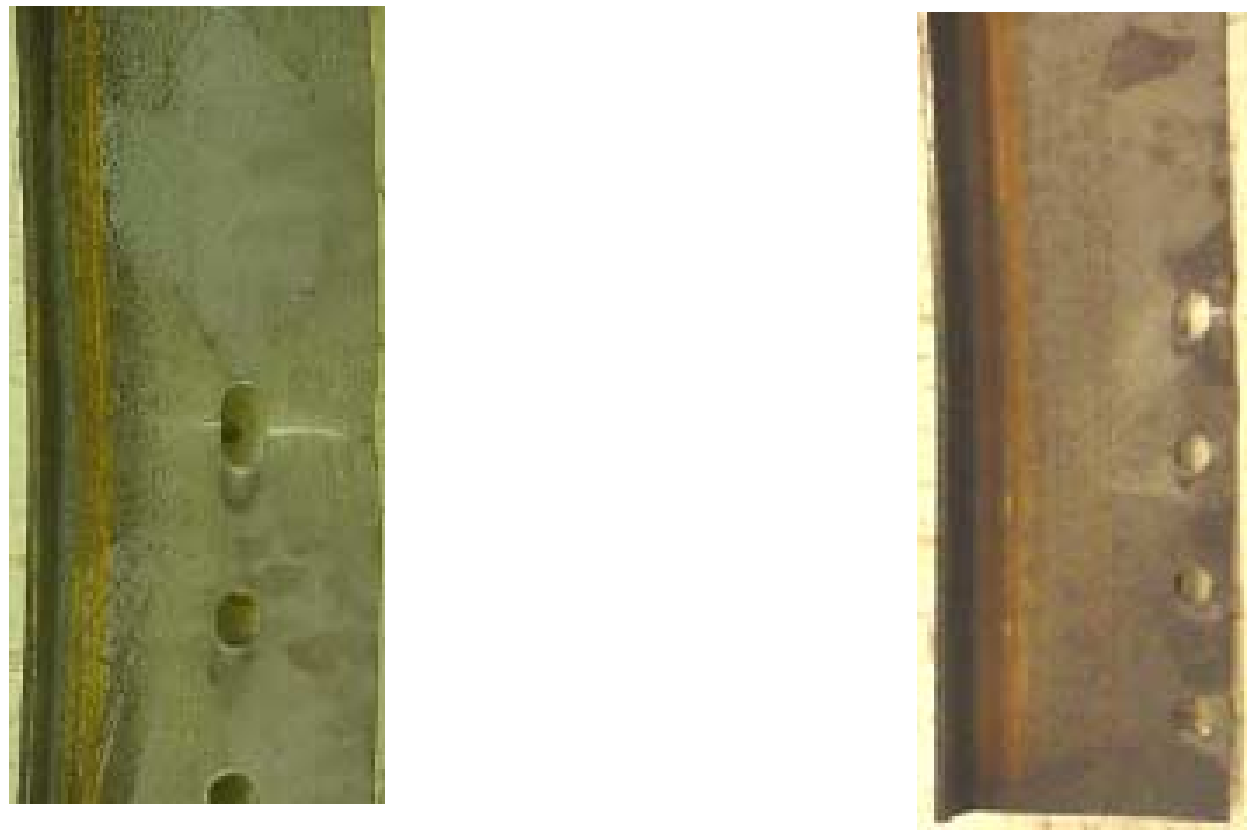

a: Partial net section rupture medium eccentricity b: Partial net section rupture large eccentricity

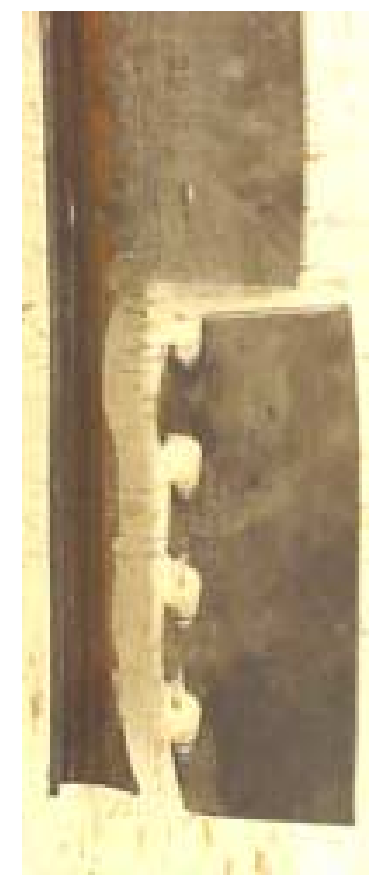

c: Block Shear Failure

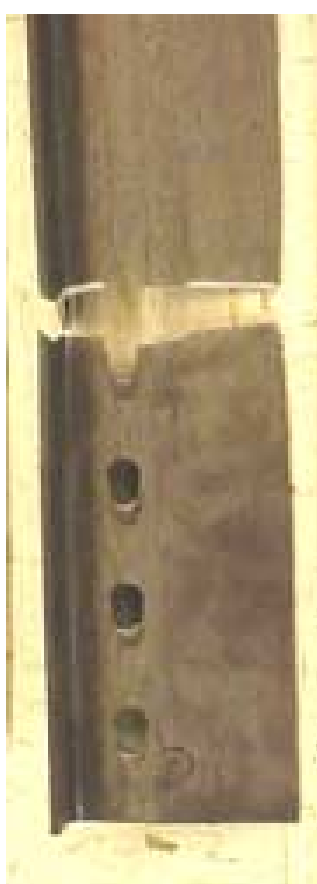

d: Full net section rupture failure

Figure 4.3 Typical failure modes (a) Partial net section rupture medium eccentricity, (b) Partial net section rupture large eccentricity (c) Block shear failure, and (d) Full net section rupture failure 


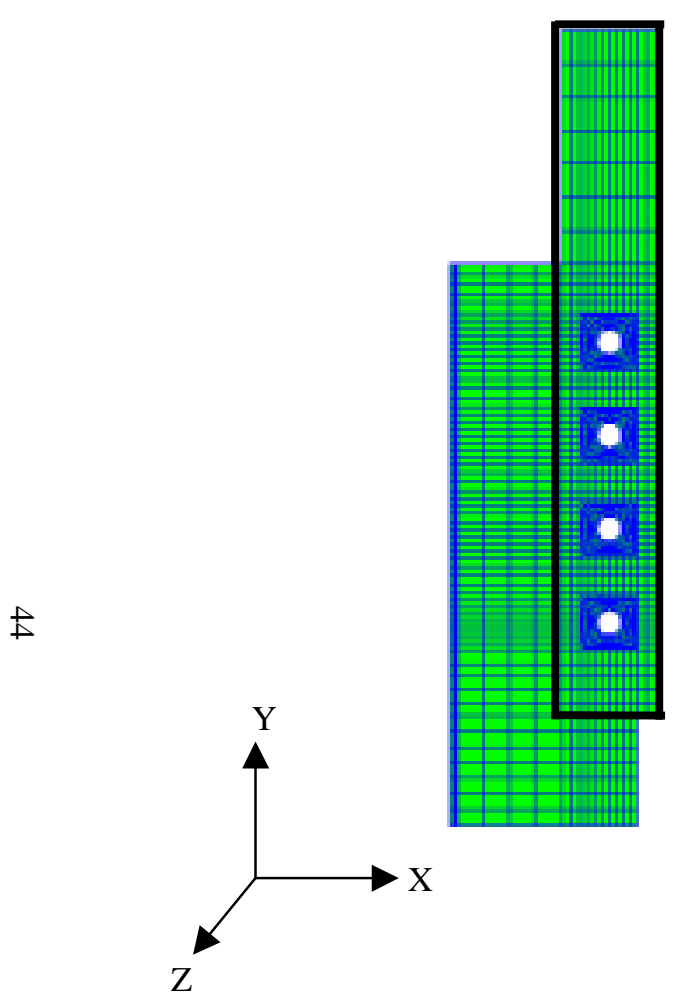

(a) Typical FEA mesh

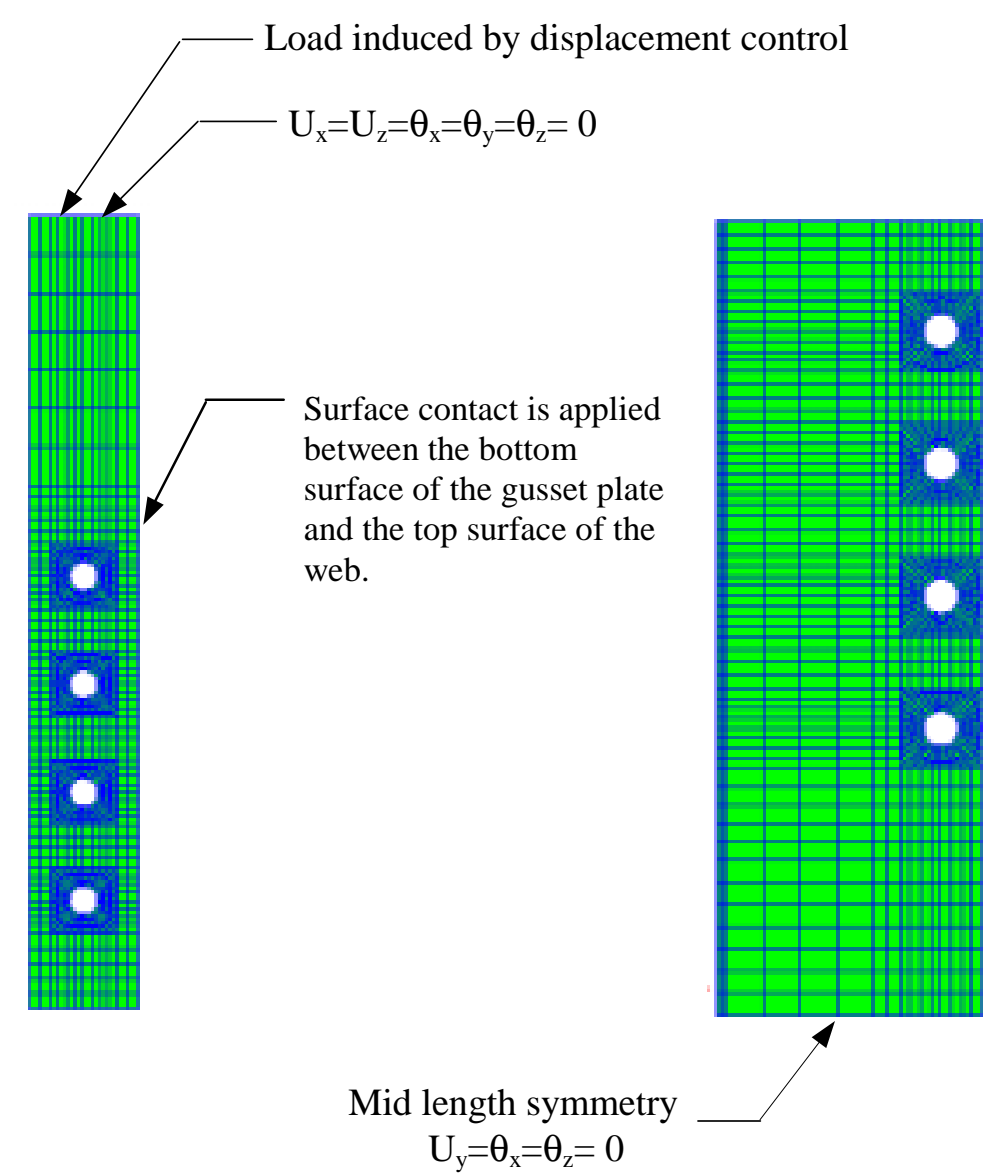

(b) Gusset Plate

(c) WT specimen

Figure 4.4 Typical finite element mesh for WVU specimens showing boundary conditions 


\section{Chapter 5}

\section{RESULTS AND DISCUSSION}

This chapter discusses the trends observed in the finite element study in chapter four and comparison of these analytical results with the experimental test results conducted at West Virginia University.

\subsection{Comparison of analytical results with the experimental results:}

In this section, finite element modeling of West Virginia University experimental specimens is conducted using the Model D1 boundary conditions described in section 3.3. Experimental studies of WT section specimens with medium to large eccentricities suggest that failures are typically caused by severe necking of the outside edge adjacent to the lead bolt hole, followed by the fracture of the outside edge. In the analytical study of these specimens, failure is characterized by the necking behavior in the vicinity of the lead bolt holes. Thus, for these specimens, the failure load is taken as the load corresponding to the load limit point. In the experimental specimens with small to medium eccentricities, failure is typically caused either by block shear or net section rupture of the cross section. In the analytical study of these specimens, although the material nonlinearity is significant the nonlinear geometric effects are not significant, and hence a load limit point is not observed. Under these circumstances, the load corresponding to the last converged configuration is taken as the failure load. 
Table 5.1 presents a summary of finite element results of all WT specimens. Based on these results, it is clear that the finite element modeling of these specimens using Model D1 conditions captures the experimental failure capacities with a reasonable accuracy. The load versus deflection behavior for four bolt specimens are shown in Fig. 5.1. A good correlation is obtained between the experiment and finite element results. Figures 5.2 through 5.4 present the deformed shape and equivalent stress and plastic strain contours for specimens $1 \mathrm{a}, 2 \mathrm{a}$, and $7 \mathrm{a}$ respectively. The deformed shapes obtained using the finite element model are in excellent agreement with the deformed shape of experimental specimen as shown in Fig. 5.5. The Mises stress around the lead bolt hole is 75.13 Ksi representing the ultimate stress of the stress-strain curve. The equivalent plastic strain contours around the lead bolt hole indicate the fracture of the outside edge adjacent to the lead bolt hole. In particular, these contours indicate the failure of the specimens 1a and $2 \mathrm{a}$ due to partial net section rupture and failure of the specimen $7 \mathrm{a}$ due to full net section rupture as observed in the experimental study.

Similarly, Table 5.1 compares the summary of failure loads predicted by the analytical studies with the failure capacities of the 5 bolt WT specimens observed in the experimental study. The load versus deflection behavior of these specimens deflection plots are shown in Fig. 5.6. Once again, these results indicate the capabilities of the present finite element methodology in capturing the failure behavior of WT specimens subjected tensile loading. Similar to the results presented in the previous paragraph, Fig. 5.7 and 5.8 present the deformed shape and equivalent stress and plastic strain contours for specimens $1 \mathrm{~b}$ and $7 \mathrm{~b}$ respectively. The deformed shape and the equivalent plastic strain contours in Fig. 5.7 for specimen $1 \mathrm{~b}$ indicate that the failure of the specimen 
occurred due to partial net section rupture. However, the deformed shape and the equivalent plastic strain contours in Fig. 5.8 indicate a full net section rupture failure mode for specimen $7 b$.

For specimens with 3 bolt holes, Table 5.1 compares the failure capacities predicted by the finite element analysis with the failure loads observed in the experimental study. Also, Fig. 5.9 presents the load versus deflection plots for these specimens. These results are in excellent agreement with the experimental values. The deformed shape and the equivalent plastic strain contours in Fig. 5.10 indicate that the failure of specimen $5 \mathrm{c}$ occurred in block shear mode.

Note that the deformed shape, stress contours, and the equivalent plastic strain contours are presented for the 4, 5, and 3 bolt specimens in Appendices B, C, and D respectively.

In conclusion, Table 5.1 presents the comparison of experimental, numerical and AISC predicted failure capacities of WT specimens. The failure capacities predicted by the AISC specifications based on net section rupture and block shear failure modes are overly unconservative when compared to the experimental failure loads. Numerical simulation results based on the procedure described in Section 3.3 are in close agreement with the experimental failure loads. In addition, these models are able to accurately capture the partial net section rupture failure mode, full net section rupture failure mode, and the block shear failure mode as observed in the experimental specimens. 
Table 5.1 WVU specimens failure loads

\begin{tabular}{|c|c|c|c|c|c|}
\hline $\begin{array}{c}\text { Specimen } \\
\text { No. }\end{array}$ & WT Section & $\begin{array}{c}\text { Spec. Failure } \\
\text { Type }\end{array}$ & $\mathbf{P}_{\mathrm{AISC}}$ & $\mathbf{P}_{\text {WVU FeA }}$ & $\mathbf{P}_{\text {expt }}$ \\
\hline $1 \mathrm{a}$ & $6 \times 7(p)$ & PNS & 86 & 52 & 53 \\
\hline $2 a$ & $6 \times 7(d)$ & PNS & 86 & 58 & 59 \\
\hline $3 a$ & $6 \times 7(p)$ & PNS & 103 & 93 & 94 \\
\hline $4 a$ & $6 \times 7(d)$ & PNS & 103 & 103 & 103 \\
\hline $5 a$ & $6 \times 7(d)$ & PNS & 114 & 124 & 126 \\
\hline $6 a$ & $6 \times 7(p)$ & PNS & 117 & 118 & 118 \\
\hline $7 a$ & $6 \times 7(p)$ & FNS & 122 & 131 & 130 \\
\hline $8 a$ & $6 \times 7(d)$ & BS & 122 & 137 & 137 \\
\hline $1 \mathrm{~b}$ & $6 \times 7(d)$ & PNS & 107 & 66 & 67 \\
\hline $2 b$ & $6 \times 7(p)$ & PNS & 107 & 57 & 59 \\
\hline $3 b$ & $6 \times 7(d)$ & PNS & 123 & 121 & 121 \\
\hline $4 b$ & $6 \times 7(d)^{c}$ & PNS & 123 & 119 & 120 \\
\hline $5 b$ & $6 \times 7$ (d) & PNS & 123 & 136 & 137 \\
\hline $6 b$ & $6 \times 7(p)$ & PNS & 123 & 132 & 131 \\
\hline $7 b$ & $6 \times 7(d)$ & FNS & 123 & 140 & 144 \\
\hline $8 b$ & $6 \times 7(p)$ & FNS & 123 & 134 & 134 \\
\hline $1 \mathrm{c}$ & $4 \times 12(d)$ & PNS & 94 & 74 & 75 \\
\hline $2 c$ & $4 \times 12(p)$ & PNS & 94 & 70 & 69 \\
\hline $3 c$ & $4 \times 12(d)$ & PNS & 101 & 96 & 100 \\
\hline $4 c$ & $4 \times 12(p)$ & PNS & 101 & 93 & 92 \\
\hline $5 c$ & $4 \times 12(d)$ & $\mathrm{BS}$ & 112 & 112 & 122 \\
\hline $6 c$ & $4 \times 12(p)$ & $\mathrm{BS}$ & 109 & 109 & 116 \\
\hline
\end{tabular}

a. Dimensions are in inches, and loads are in Kips.

b. (p) designates a specimen with punched holes and (d) a specimen with drilled holes.

c. Due to fabrication error specimen 4a's bolt holes were drilled rather than punched.

d. $\mathrm{PNS}=$ Partial net section rupture, FNS $=$ Full net section rupture, BS $=$ Block Shear. 


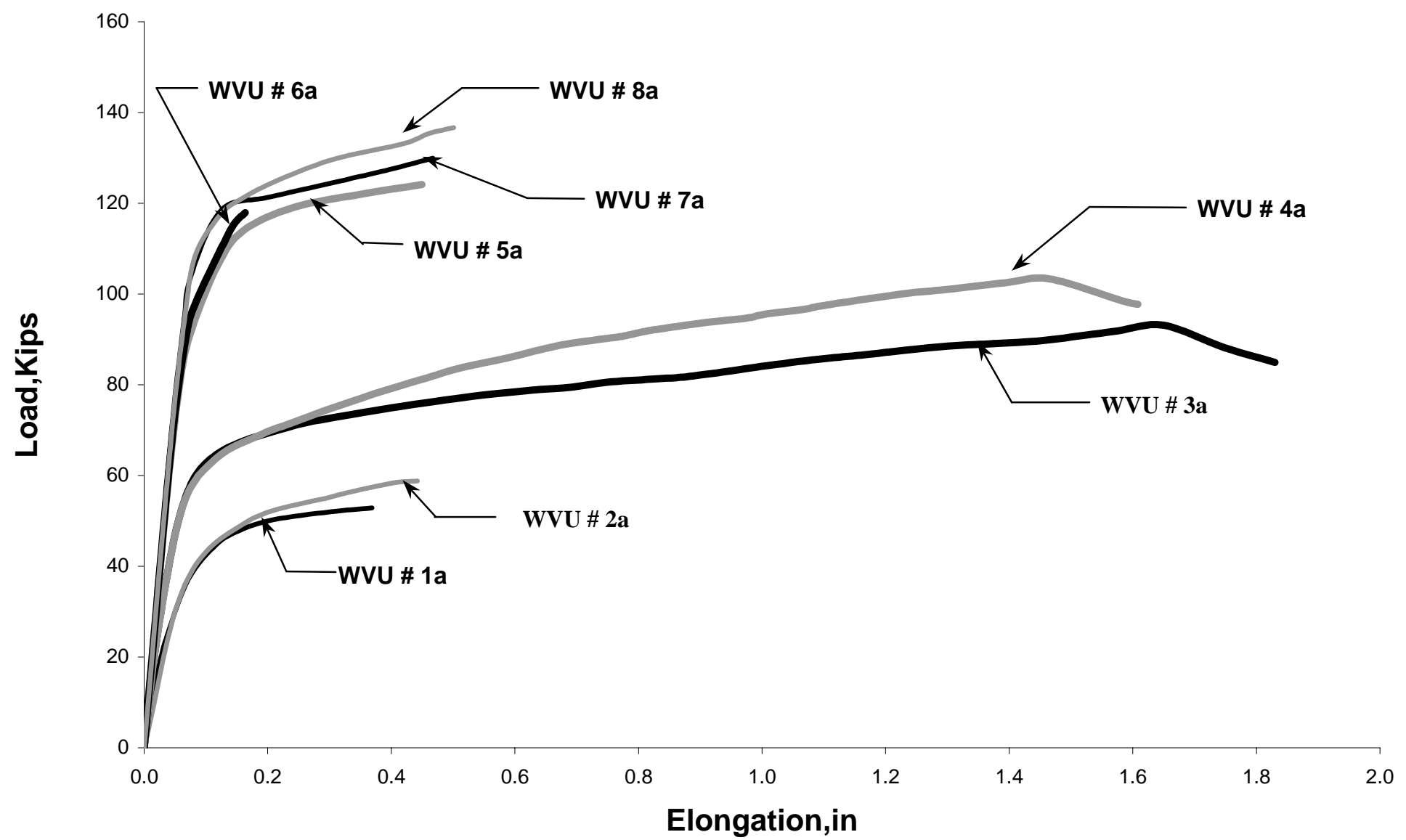

Figure 5.1 Load deflection curve for WVU 4 bolt specimens 


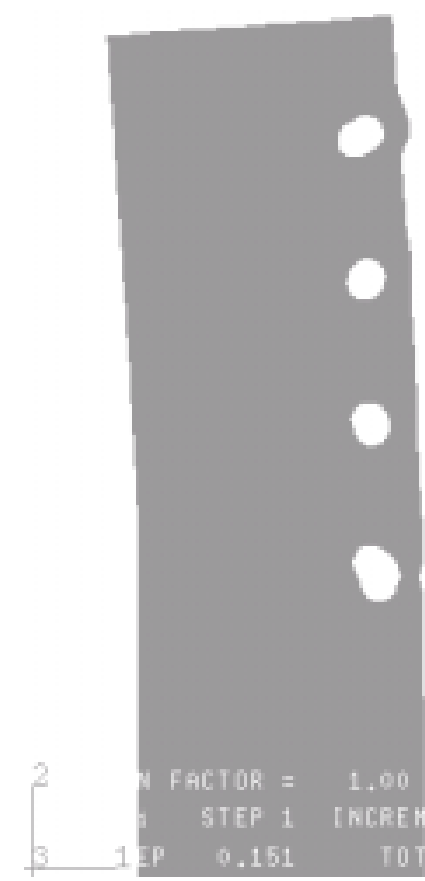

Deformed shape

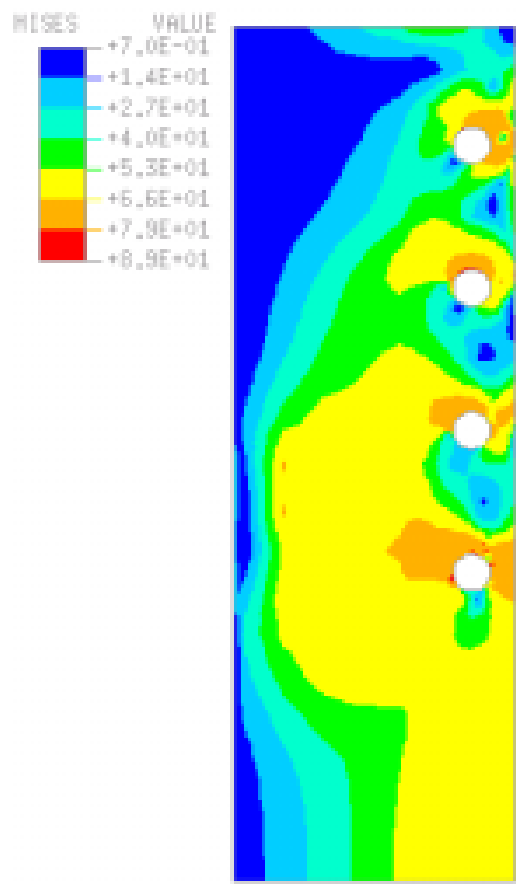

Stress contours

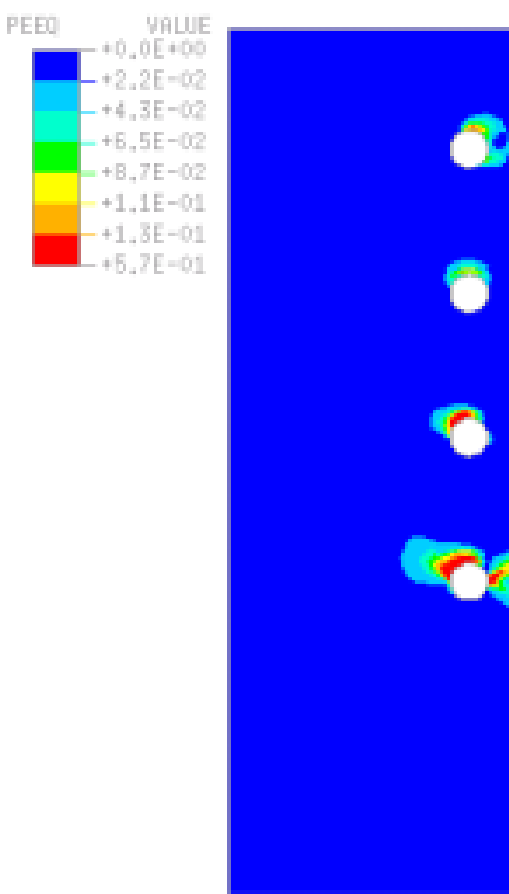

Plastic strain contours

Stress units are in ksi

Figure 5.2 Deformed shape, stress Contours and plastic strain contours of WVU specimen \# 1a 


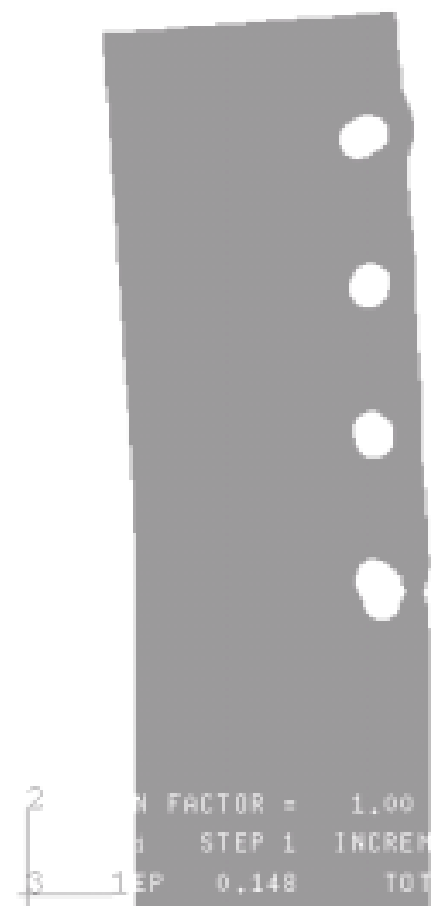

Deformed shape

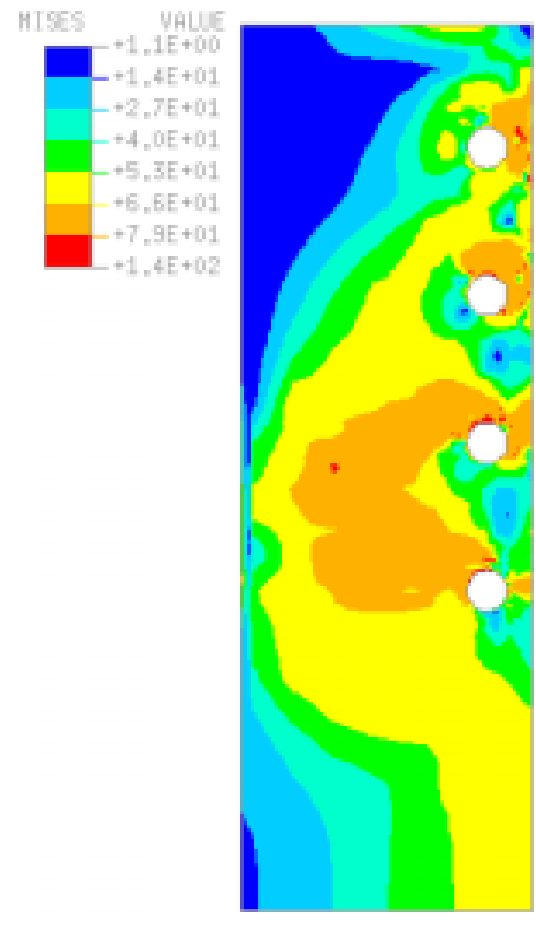

Stress contours

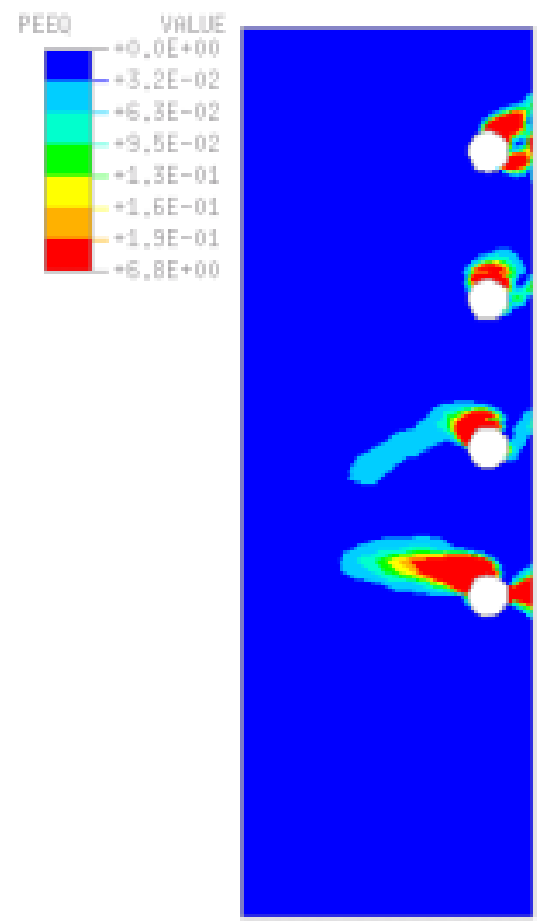

Plastic strain contours

Stress units are in ksi

Figure 5.3 Deformed shape, stress Contours and plastic strain contours of WVU specimen \# 2a 


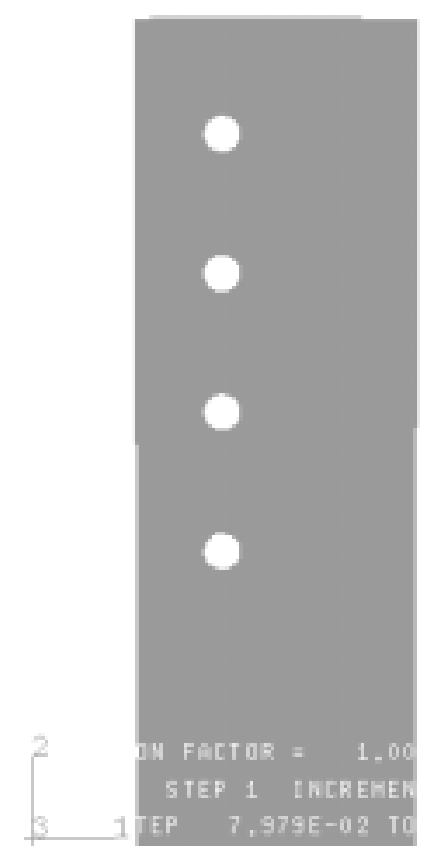

Deformed shape

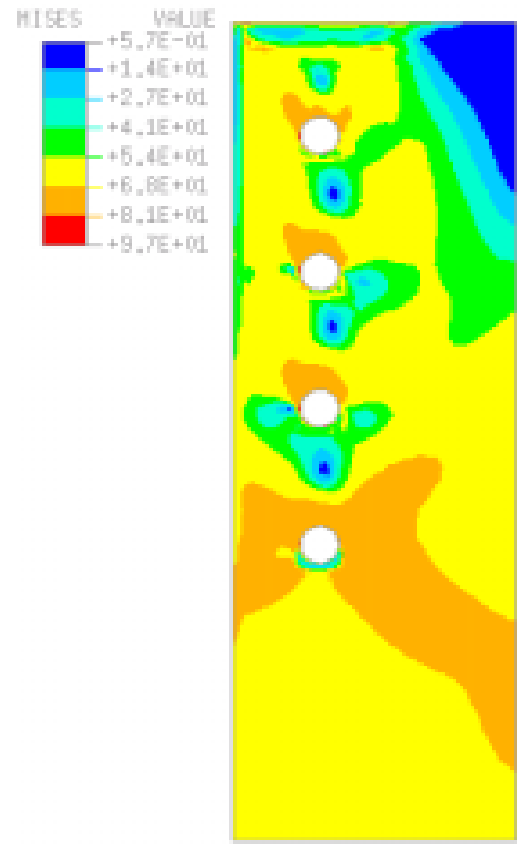

Stress contours

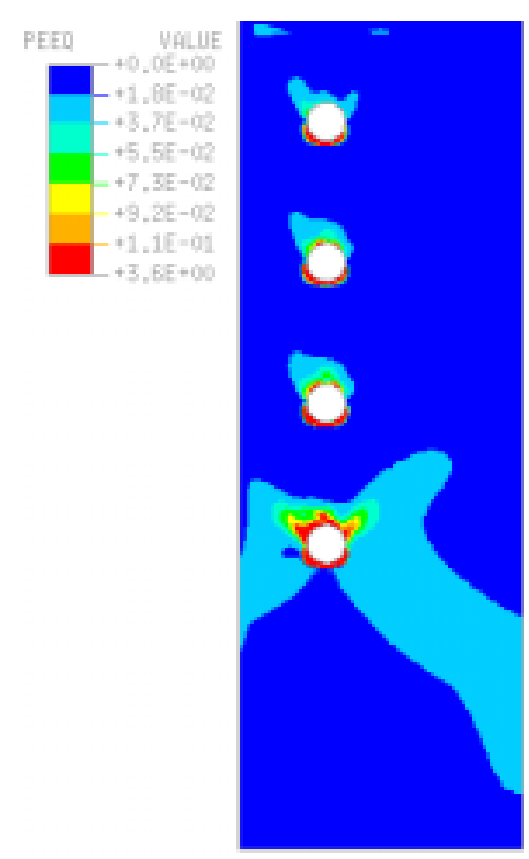

Plastic strain contours

Stress units are in ksi

Figure 5.4 Deformed shape, stress contours, and plastic strain contours of WVU specimen \# 7a 

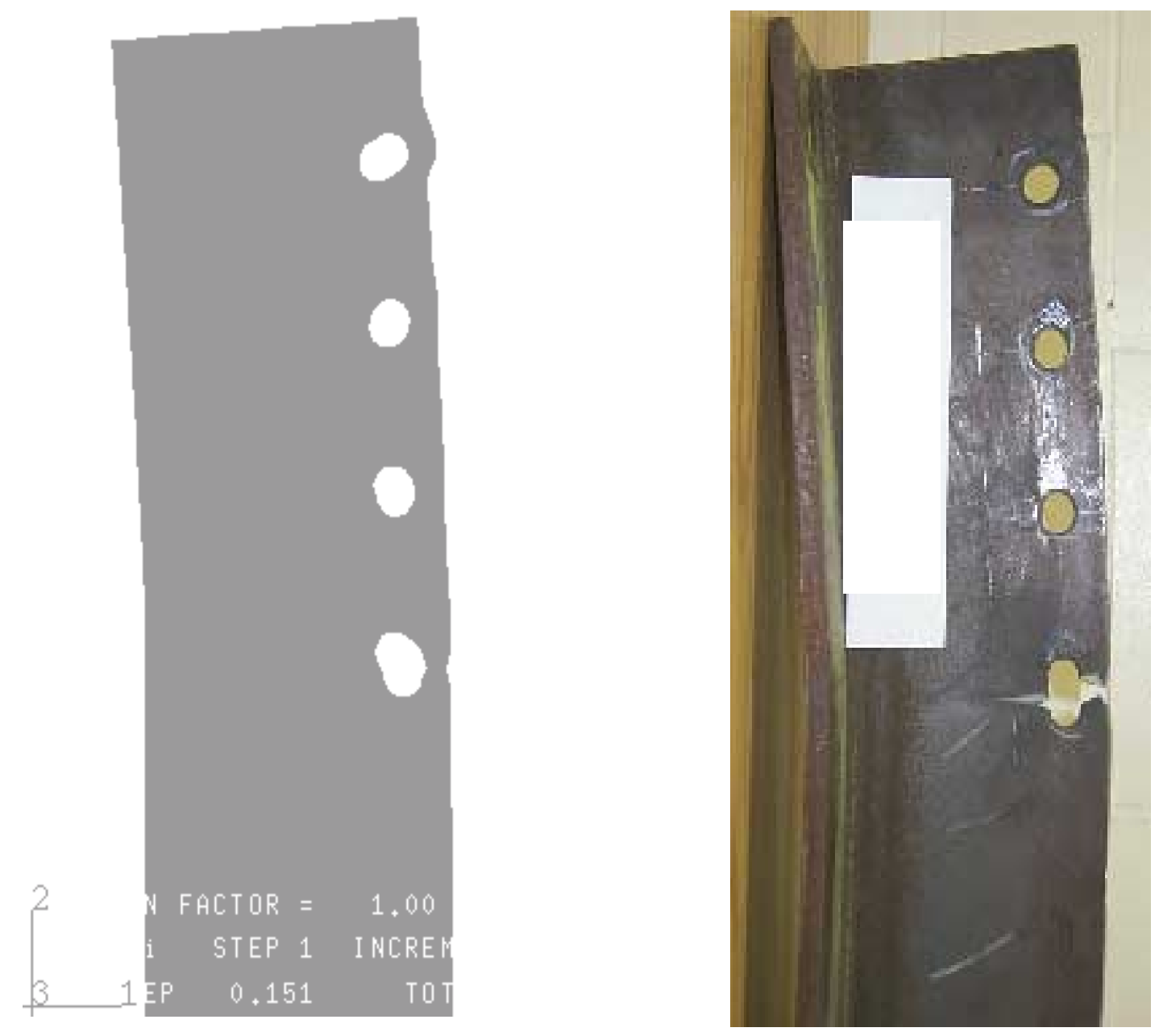

Figure 5.5 FEA and Experimental Deformed Shapes for Specimen 1a 


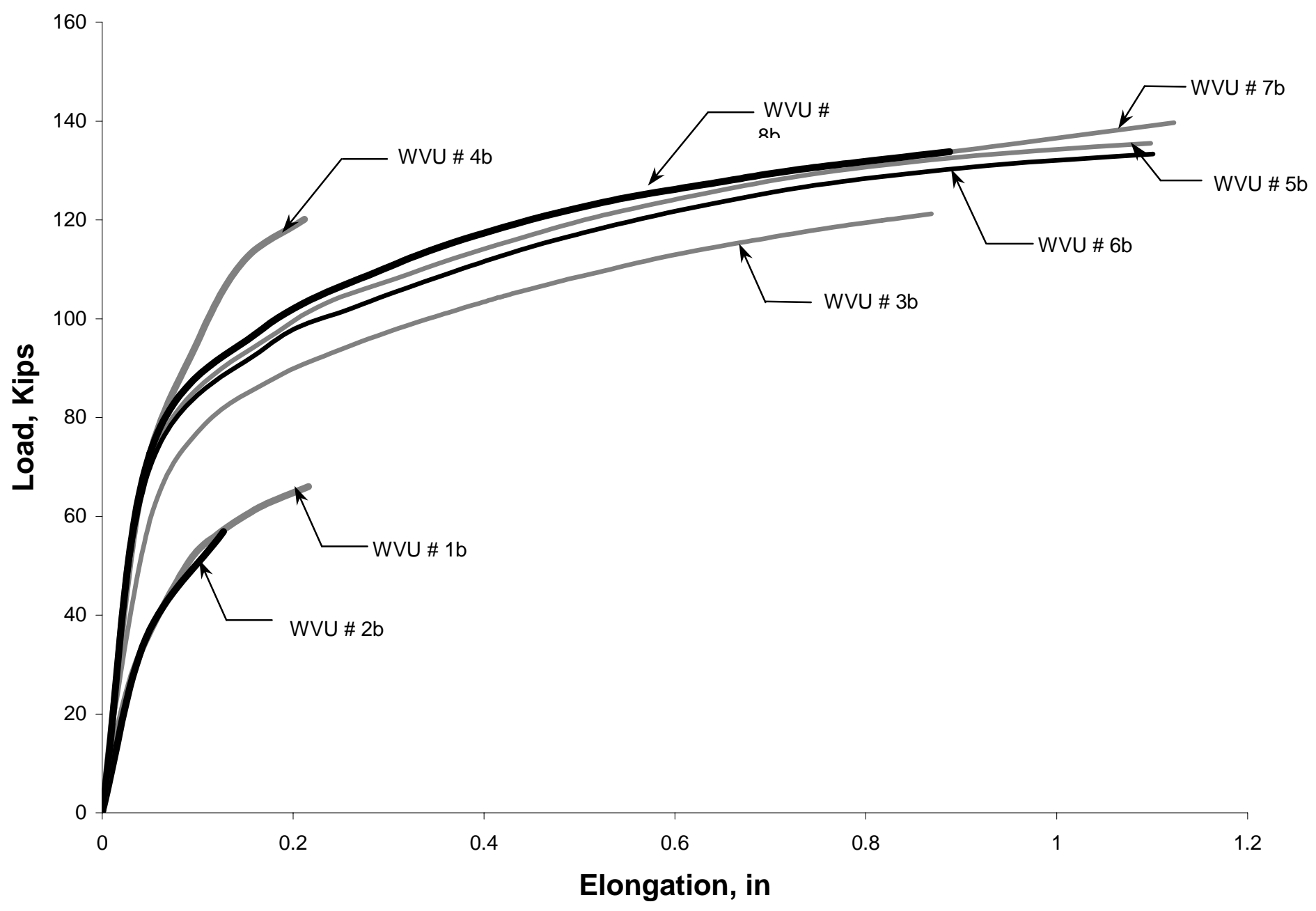

Figure 5.6 Load deflection curve for WVU 5 bolt specimens 


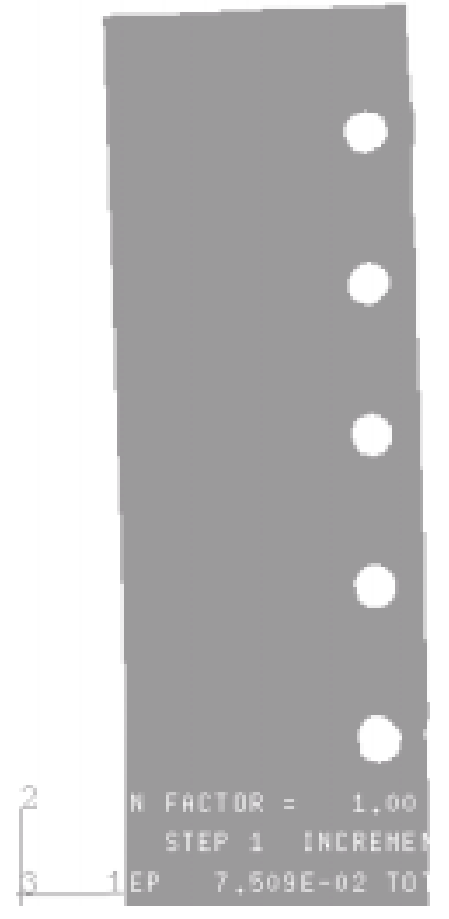

Deformed shape

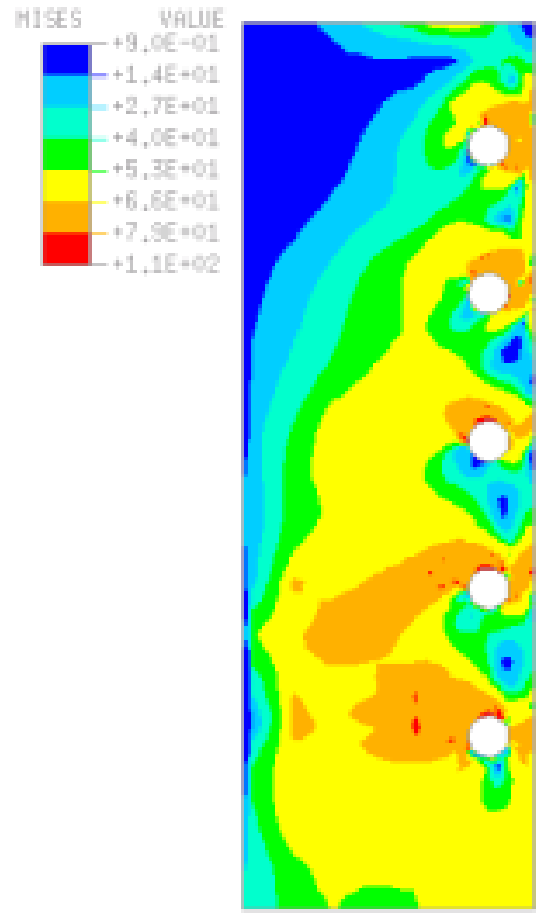

Stress contours

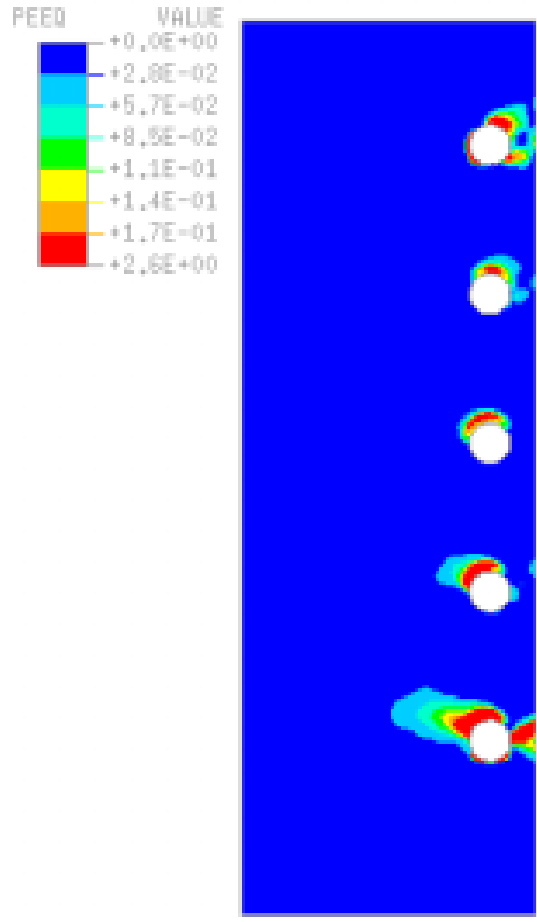

Plastic strain contours

Stress units are in ksi

Figure 5.7 Deformed shape, stress Contours and plastic strain contours of WVU specimen \# 1b 


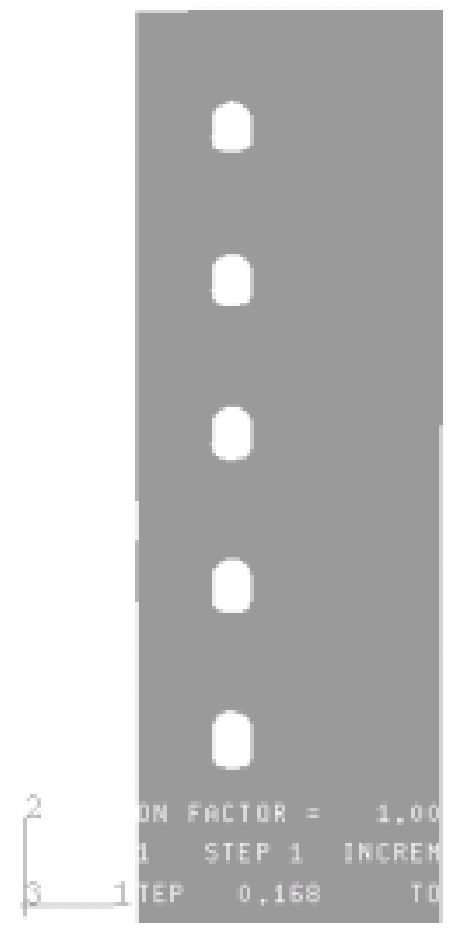

Deformed shape

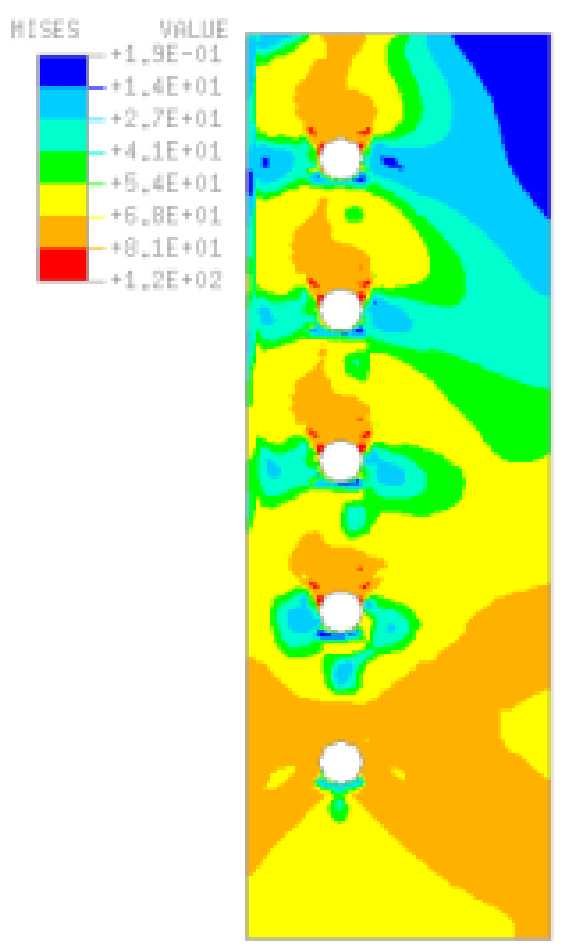

Stress contours

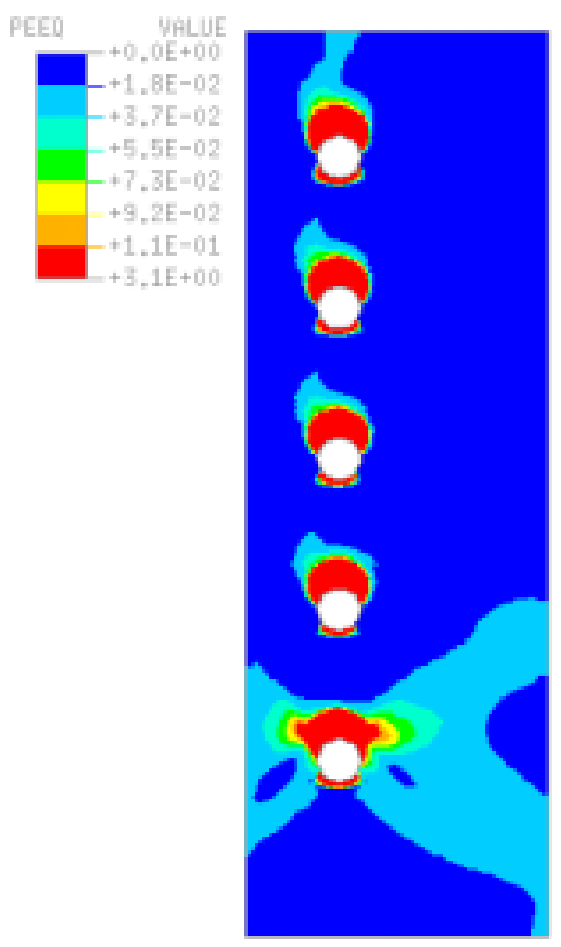

Plastic strain contours

Stress units are in ksi

Figure 5.8 Deformed shape, stress Contours and plastic strain contours of WVU specimen \# 7b 


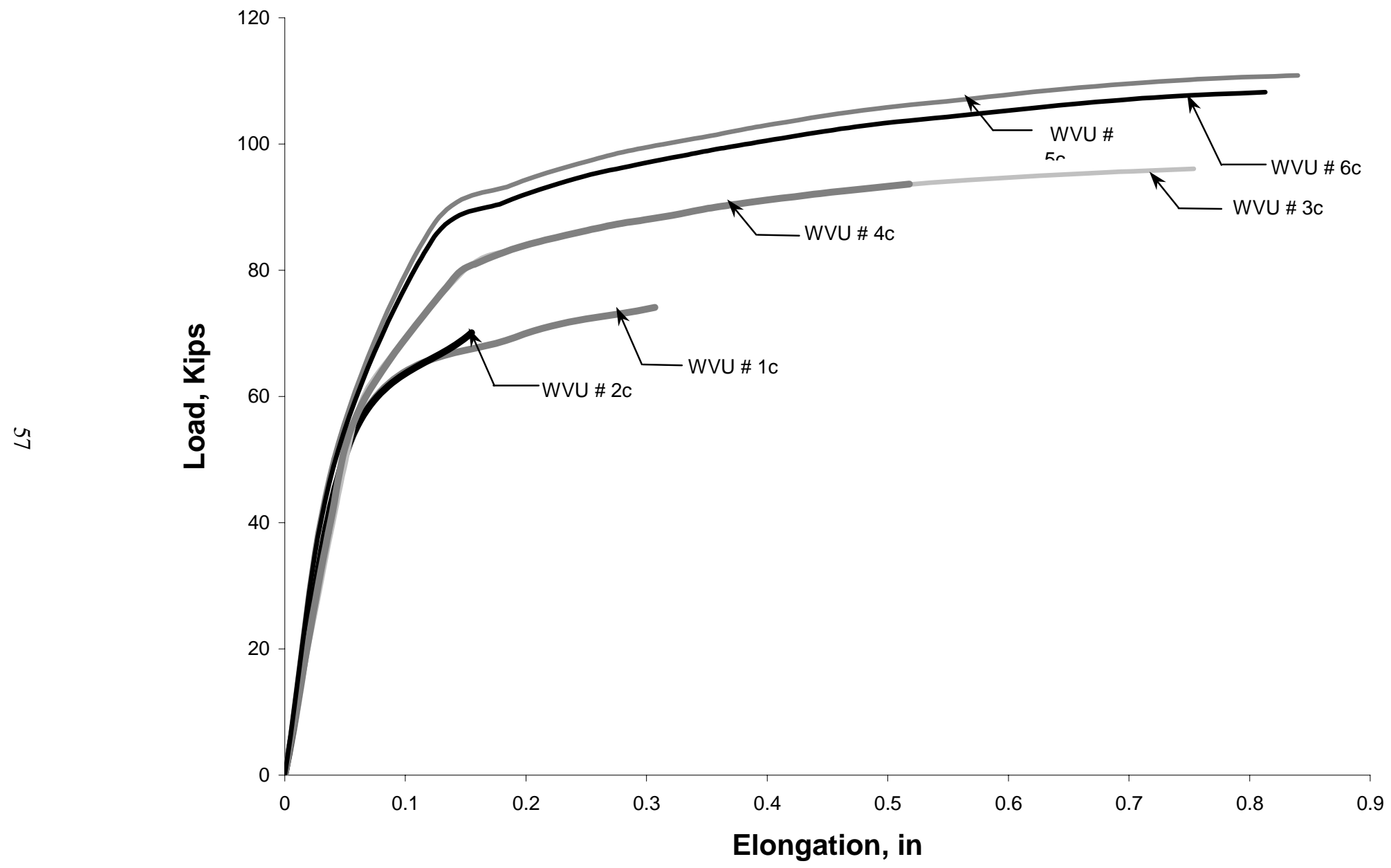

Figure 5.9 Load deflection curve for WVU 3 bolt specimens 


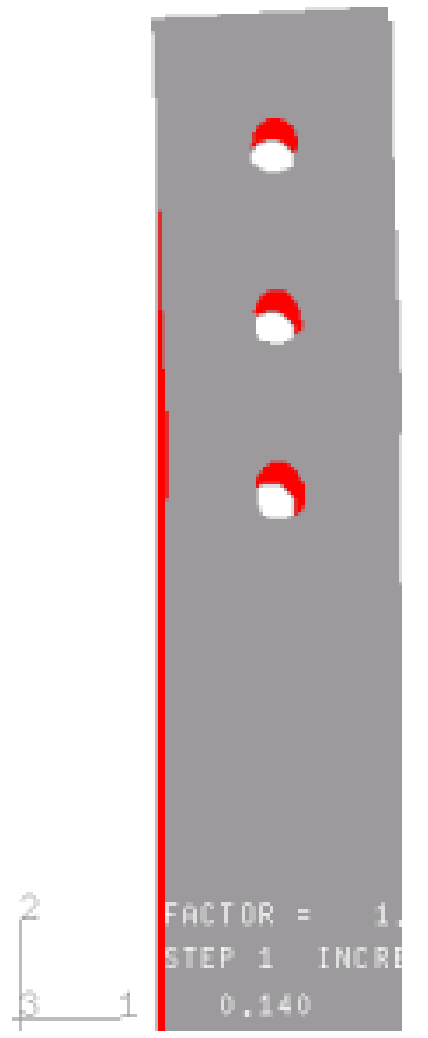

Deformed shape

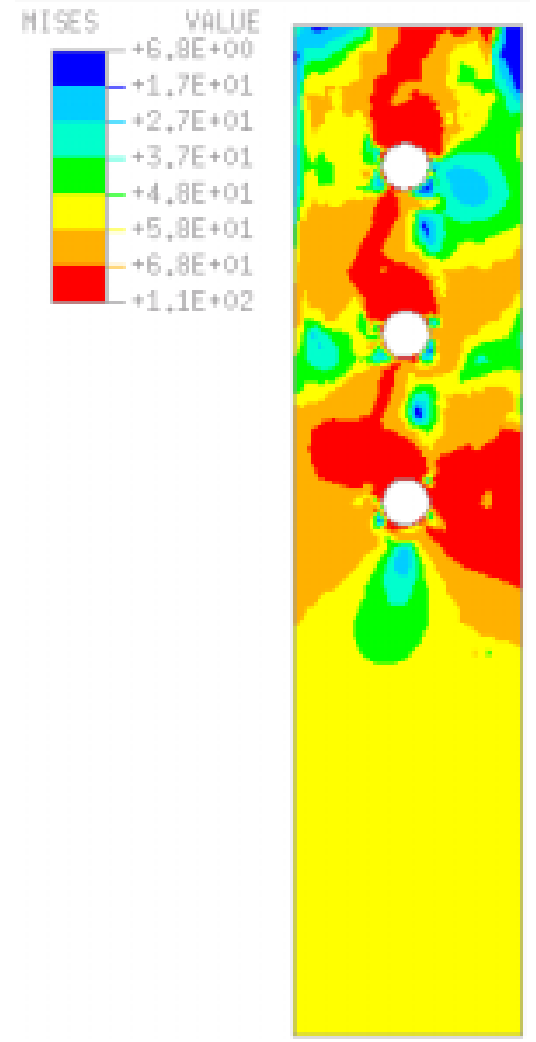

Stress contours

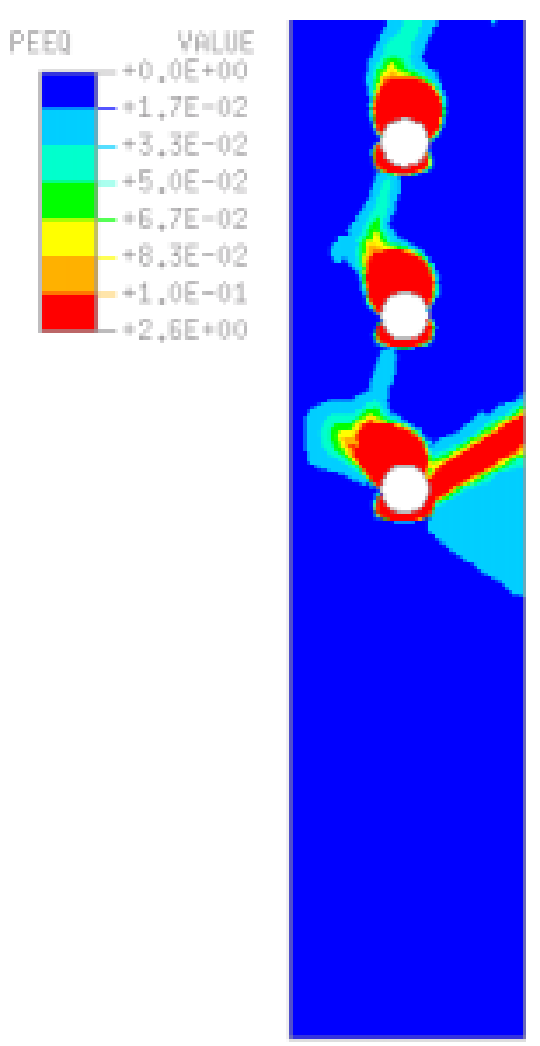

Plastic strain contours

Stress units are in ksi

Figure 5.10 Deformed shape, stress Contours and plastic strain contours of WVU specimen \# 5c 


\section{Chapter 6}

\section{SUMMARY AND CONCLUSIONS}

\subsection{Summary:}

Finite element studies are extremely useful when used in conjunction with an experimental testing program for investigating section behavior. Examining the block shear phenomena using finite element analysis method allows for a more extensive parametric investigation of the underlying behavior than is possible in a laboratory setting.

Present design specifications for tension members do not consider the effects of connection eccentricity as it induces bending in statically loaded members. The connection eccentricity induced bending effects have the potential to significantly reduce the net section rupture capacity of a section.

In the literature, Rickles and Yura (1983) developed a simple modified block shear failure model based on the elastic stress distributions in the vicinity of the bolt holes. Using a small-deformation elasto-plastic analysis, Epstein (1996b) was able to capture the qualitative behavior of bolt stagger spacing and shear lag effects on the failure load of angles in tension. Kulak and Wu (1997) included both geometric as well as material nonlinear effects to capture the pre-peak nonlinear load versus deflection behavior of angles. However, the analysis was unable to trace the entire load versus deflection behavior beyond the load limit point especially in the cases of medium to large 
connection eccentricities. In addition, none of the above analyses include the interaction between the bolt and the web holes and its effect on the failure load. Furthermore, necking of the net area between the leg edge and the lead bolt hole partial net section rupture was not accurately captured by this analysis. Hence, a comprehensive finite element modeling of the WT sections that include large deformation geometric and material nonlinear effects needs to be performed to trace the entire load versus deflection behavior beyond the load limit point. These observations form the basis for the current numerical study of connections subjected to block shear and net section rupture of crosssections.

In this study, the finite element analysis of the WT sections is carried out using an eight node incompatible brick element (ABAQUS C3D8I) that is capable of representing large deformation geometric and material nonlinearities. In the finite element model, the connecting bolts are assumed to be rigid and surface-to-surface contact is used. A trilinear type stress-strain curve is used to represent the material nonlinear effects. Model D1 boundary conditions, as elaborated in section 3.3, are used in the finite element modeling of WT specimens. The finite element model includes both material and geometric nonlinear effects. An incremental iterative strategy based on Newton-Raphson method is used to capture the nonlinear load versus deflection behavior. In the specimens with large connection eccentricities, nonlinear geometric effects are significant along with the material nonlinear effects and the failure is typically caused by partial net section rupture. For these specimens, the load corresponding to the load limit point is taken as the failure load of WT specimen. For specimens with small connection eccentricities, only the material nonlinearity effects are significant and hence a limit point is not observed in 
the analysis. Under these circumstances, the load corresponding to the last converged configuration is taken as the failure load of the WT specimens. In these specimens, failure is typically caused by either in block shear mode or due to net section rupture. Results based on the above analysis indicate an excellent agreement between the experimentally observed and numerically estimated failure capacities of the WT sections subjected to tensile loading. This finite element methodology may then be used to expand the scope of the parameters looked at in the West Virginia University experimental work.

\subsection{Conclusions:}

This work presents the state-of-the-art review of finite element techniques used in modeling the tension members with bolted end connections. In particular, complementing the experimental investigations, the main objective of the work is to predict the failure capacities of tension members with varying connection eccentricities and varying connection lengths using refined finite element modeling. The finite element methodology presented in this work is capable of not only predicting the failure capacities but may also be use to trace in tracing the entire load versus deflection path. The numerical simulation results based on the above analysis, give an excellent agreement with the experimental failure capacities of the WT specimens with large connection eccentricities. Furthermore, the partial net section rupture failure mode, full net section rupture failure mode, and the block shear failure mode of the specimens are accurately captured by using the methodology developed in this study. 


\section{LIST OF REFERENCES}

AISC., Allowable Stress Design and Plastic Design Specifications for Structural Steel

Buildings. $9^{\text {th }}$ edition, Chicago, IL: American Institute of Steel Construction, 1989.

AISC. Load and Resistance Factor Design Specifications for Structural Steel Buildings.

$2^{\text {nd }}$ edition, Chicago, IL: American Institute of Steel Construction, 1995.

Bartels, P. A., "Net Section Rupture in Tension Members with Connection Eccentricity," MS thesis, West Virginia University, June, 2000.

Barth, K. E., Orbison, J. G., and Bartels, P. A. (accepted for publication), "Influence of Bolt-Line Eccentricity on WT Tension Member Capacity,” AISC Engineering Journal.

Epstein, Howard I., "An Experimental Study of Block Shear Failure of Angles in Tension," AISC Engineering Journal, Vol. 29, 1992, pp. 75-84.

Epstein, H. I., and Gulia, F. S., "Finite Element Studies of Bolt Stagger Effects in Tension Members," Computers and Structures, Vol. 48, No.6, 1993, pp. 1153-1156.

Epstein, H. I., and Chamarajanagar, R., "Finite Element Studies for Correlation with Block Shear Tests," Computers and Structures, Vol. 61, No.5, 1996, pp. 967-974. 
Epstein, H. I., and McGinnis, M. J., "Finite Element Modeling of Block Shear in Structural Tees," Computers and Structures, Vol. 77, 2000, pp. 571-582.

Kulak, G. L., and Wu, E. Y., "Shear Lag in Bolted Angle Tension Members", ASCE Journal of Structural Engineering, Vol. 123, No.9, September, 1997, pp. 1144-1152.

Orbison, J. G., Barth, K. E., and Bartels, P.A. (accepted for publication), "Net Section in Tension Members with Connection Eccentricity," ASCE Journal of Structural Engineering.

Ricles, J. M., and Yura, J. A., "Strength of Double-Row Bolted-Web Connections," Journal of Structural Engineering, Vol. 109, No.1, January, 1983, pp. 126-142.

Wu, Y., and Kulak, G. L., "Shear Lag in Bolted Single and Double Angle Tension Members," Structural Engineering Report, No.187, Dept. of Civil Engg., Univ. of Alberta, Edmonton, Canada, 1993. 
APPENDIX A

\section{NOMENCLATURE}




\section{Nomenclature}

$A_{b} \equiv$ nominal bolt cross - sectional area

$A_{e} \equiv$ effective net area

$A_{g} \equiv$ gross cross - sectional area

$A_{g t} \equiv$ gross tension area

$A_{g v} \equiv$ gross shear area

$A_{n} \equiv$ net cross - sectional area

$A_{n t} \equiv$ net tension area

$A_{n v} \equiv$ net shear area

$d \equiv$ specimen depth

$d_{b} \equiv$ bolt diameter

$d_{h} \equiv$ hole diameter

edge $\equiv$ edge distance

end $\equiv$ end distance

$F_{u} \equiv$ material's ultimate tensile strength

$F_{y} \equiv$ material's yield strength

$L \equiv$ connection length

$n \equiv$ number of bolts in a connection

$P \equiv$ bolt pitch

$P_{\text {expt }} \equiv$ ultimate experimental load

$P_{F E A} \equiv$ ultimate finite element load

$t_{w} \equiv$ web thickness 
APPENDIX B

WT 4 BOLT SPECIMEN CONTOUR PLOTS 


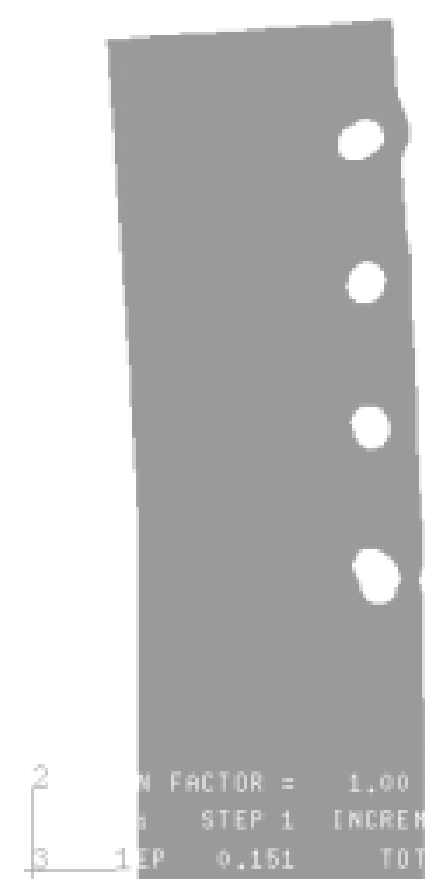

Deformed shape

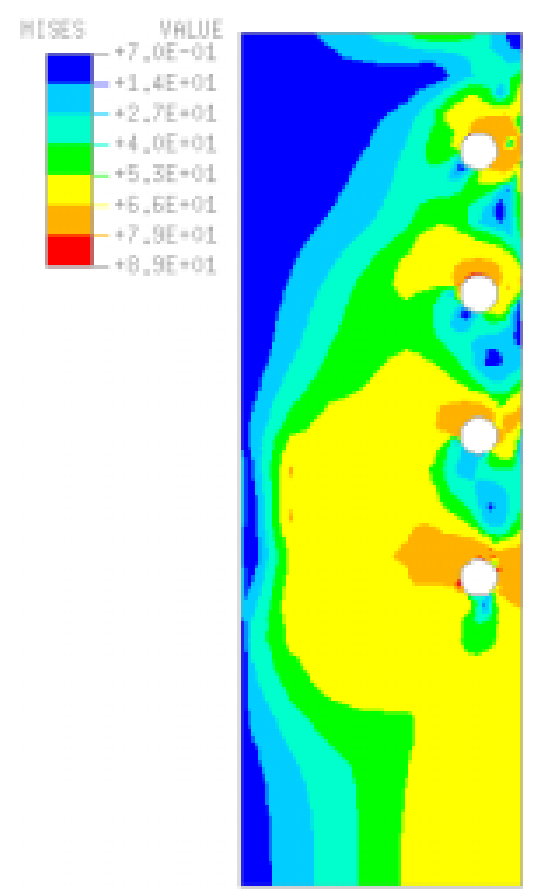

Stress contours

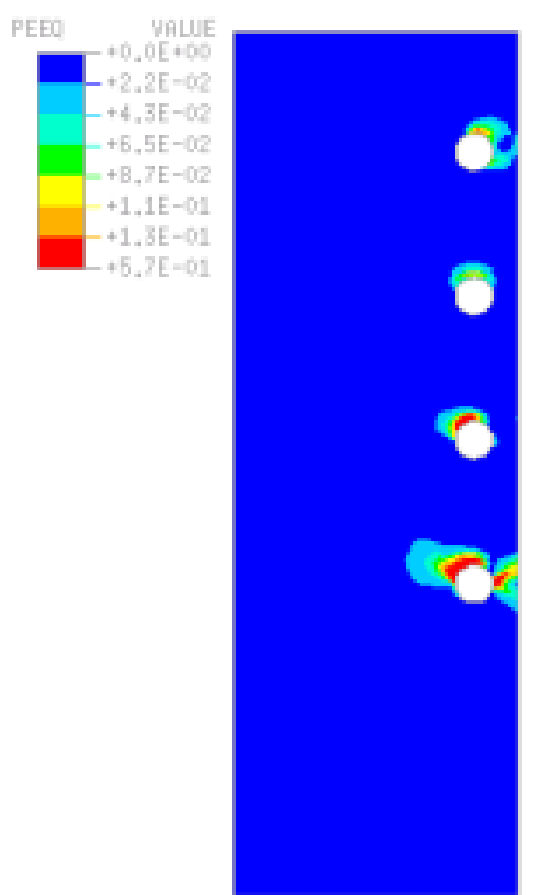

Plastic strain contours

Stress units are in ksi

Figure 1: Deformed shape, stress Contours and plastic strain contours of WVU specimen \# 1a 


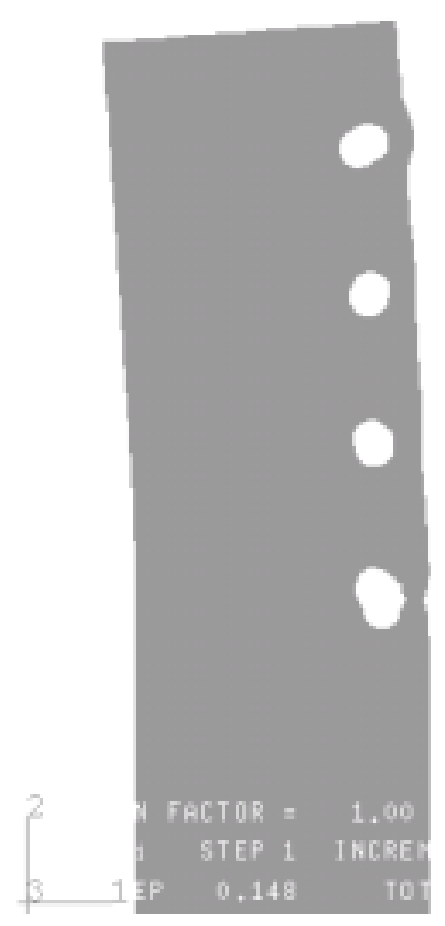

Deformed shape

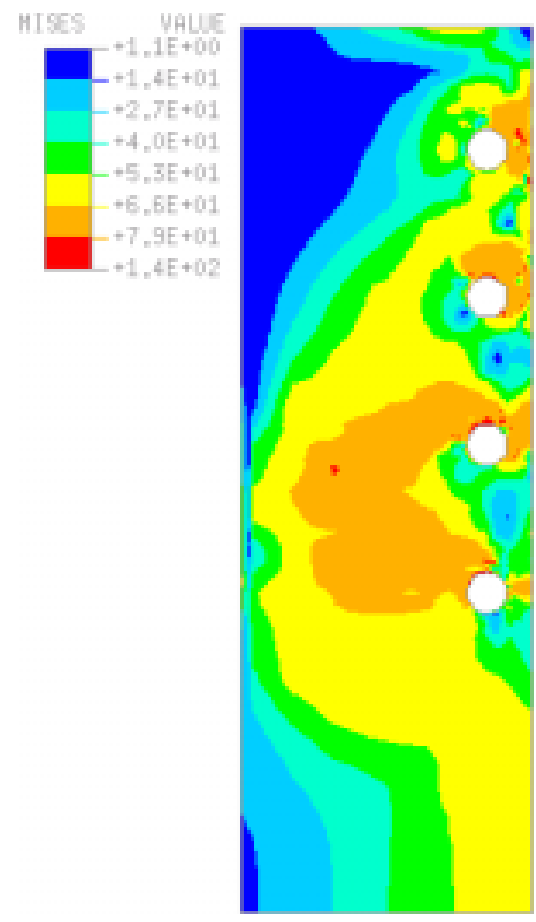

Stress contours

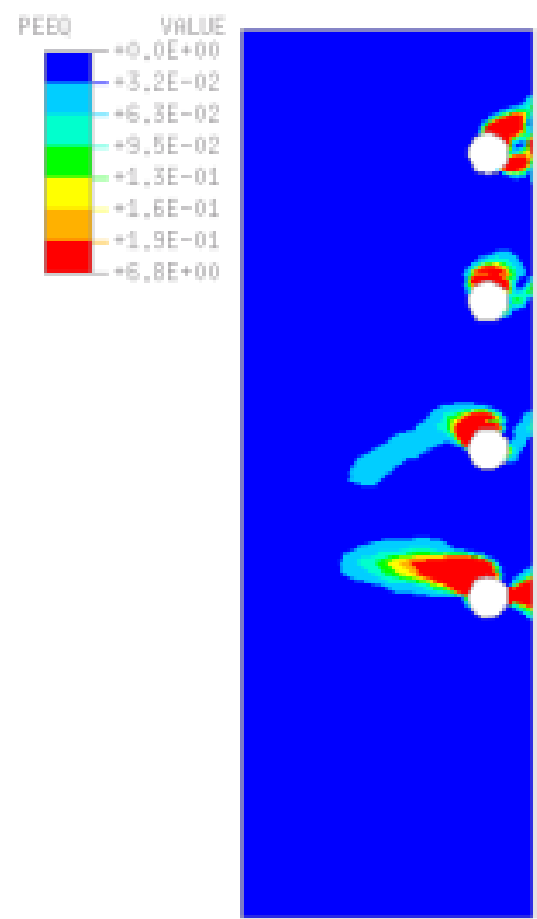

Plastic strain contours

Stress units are in ksi

Figure 2: Deformed shape, stress Contours and plastic strain contours of WVU specimen \# 2a 


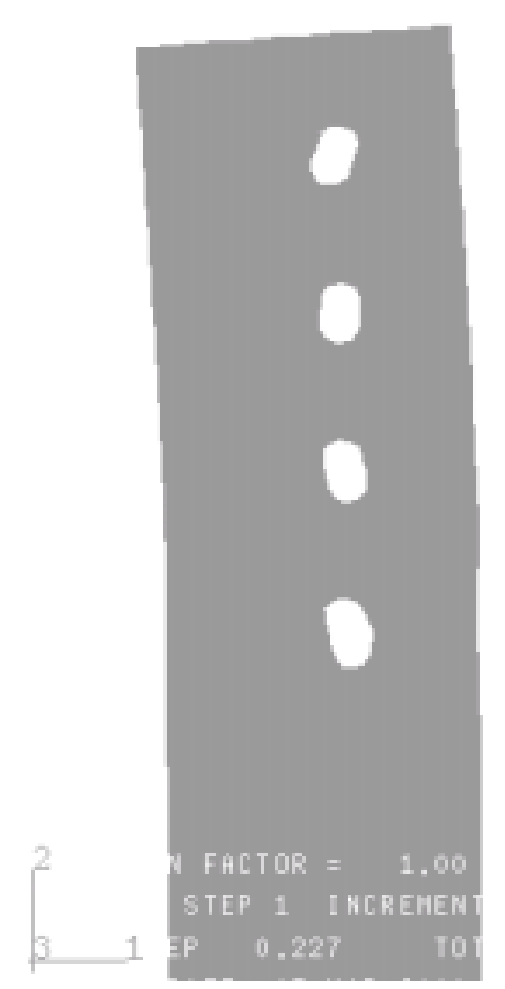

Deformed shape

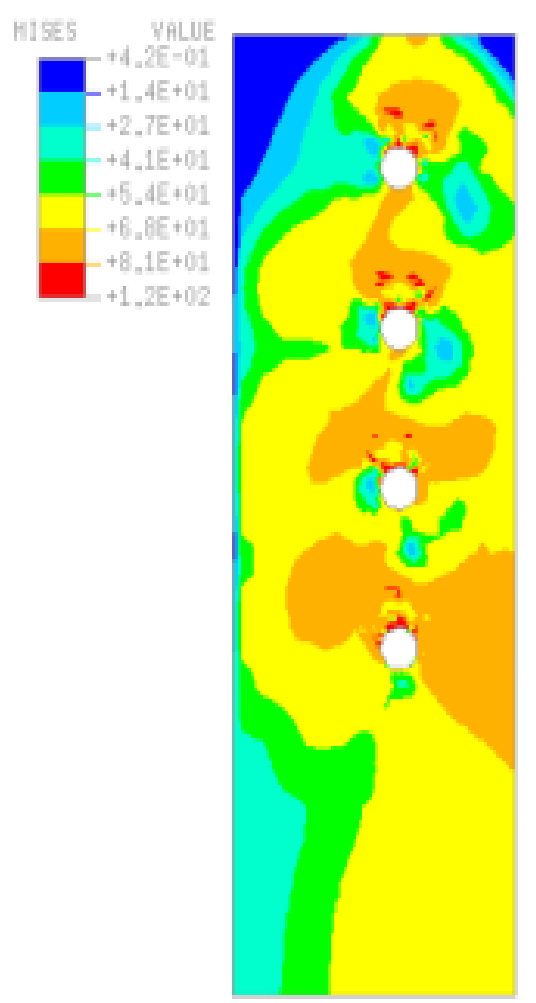

Stress contours

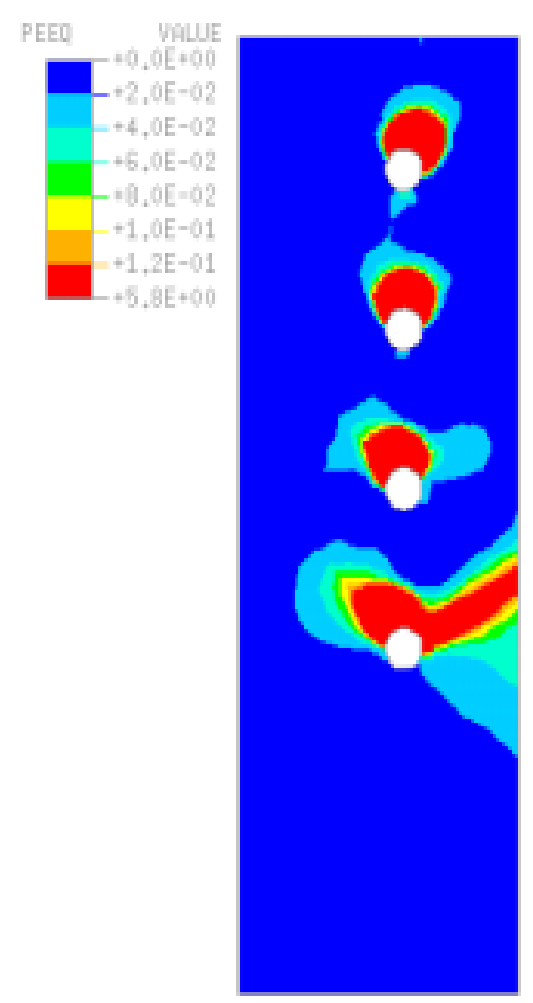

Plastic strain contours

Stress units are in ksi

Figure 3: Deformed shape, stress Contours and plastic strain contours of WVU specimen \# 3a 


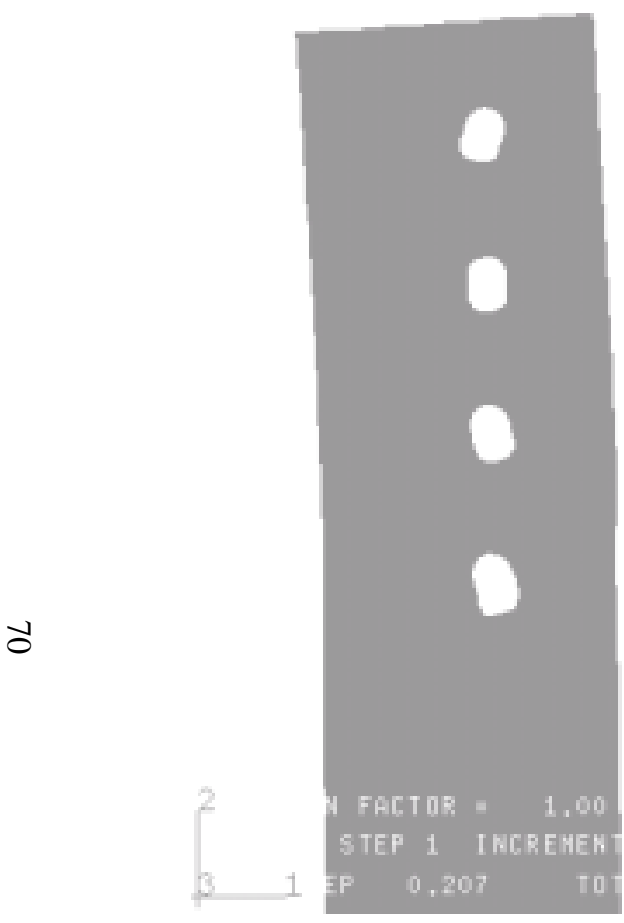

Deformed shape

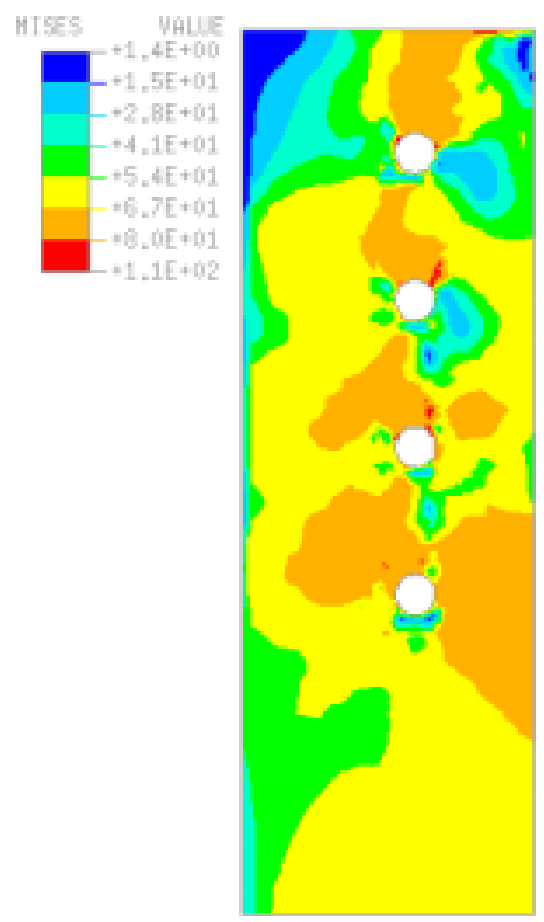

Stress contours

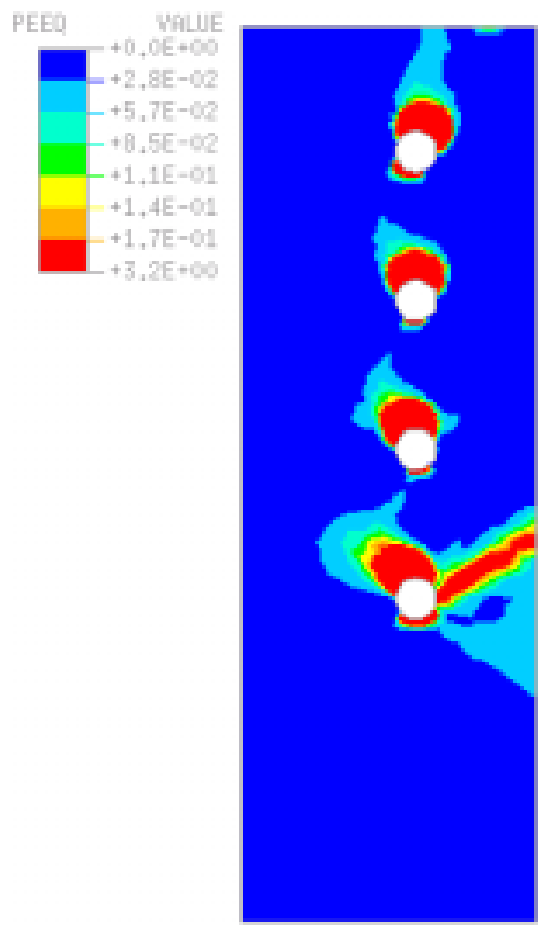

Plastic strain contours

Stress units are in ksi

Figure 4: Deformed shape, stress contours, and plastic strain contours of WVU specimen \# 4a 


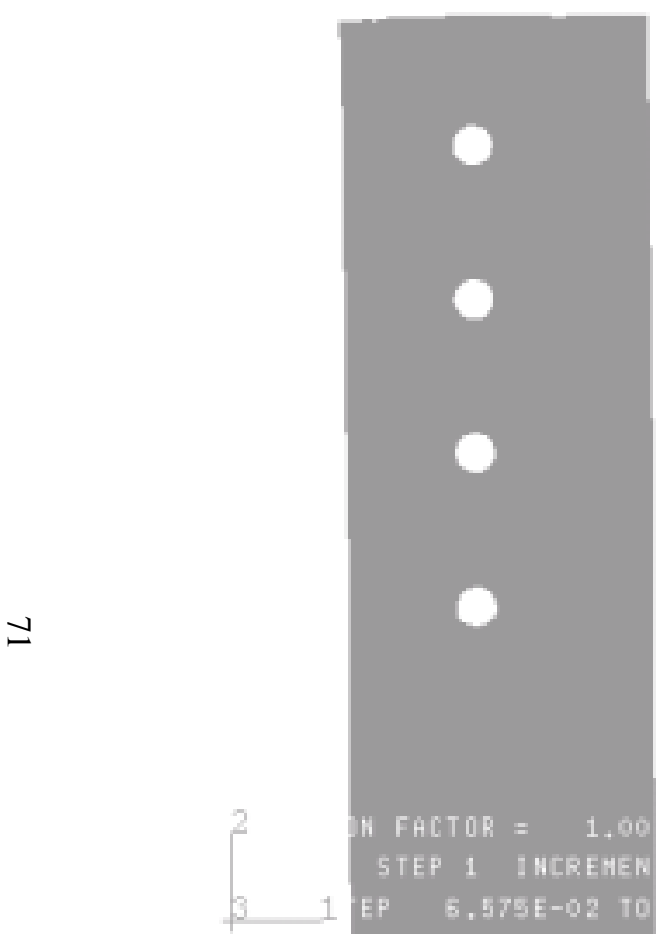

Deformed shape

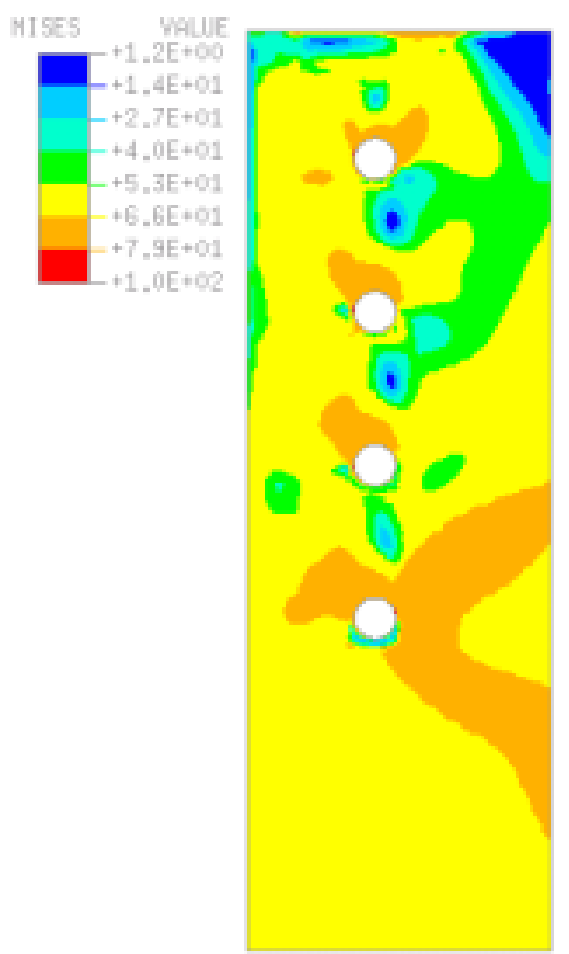

Stress contours

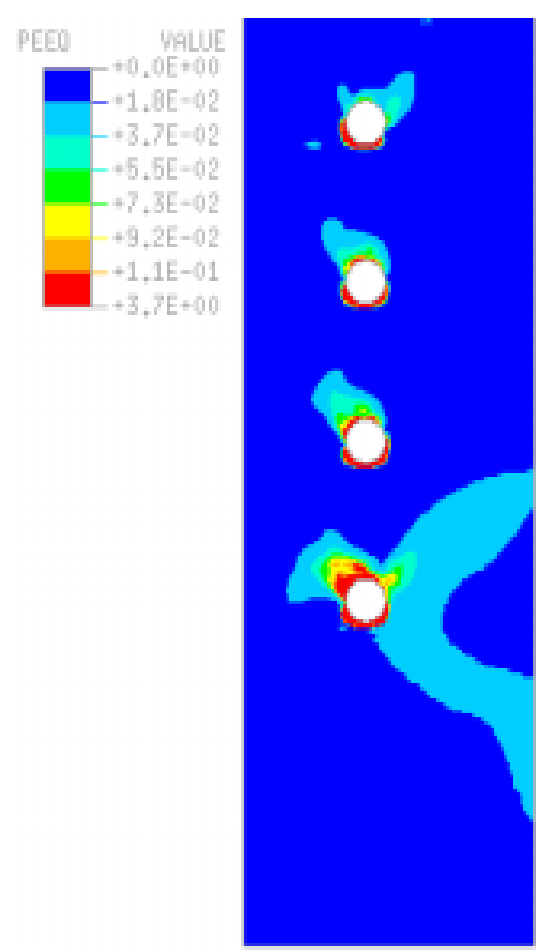

Plastic strain contours

Stress units are in ksi

Figure 5: Deformed shape, stress contours, and plastic strain contours of WVU specimen \# 5a 


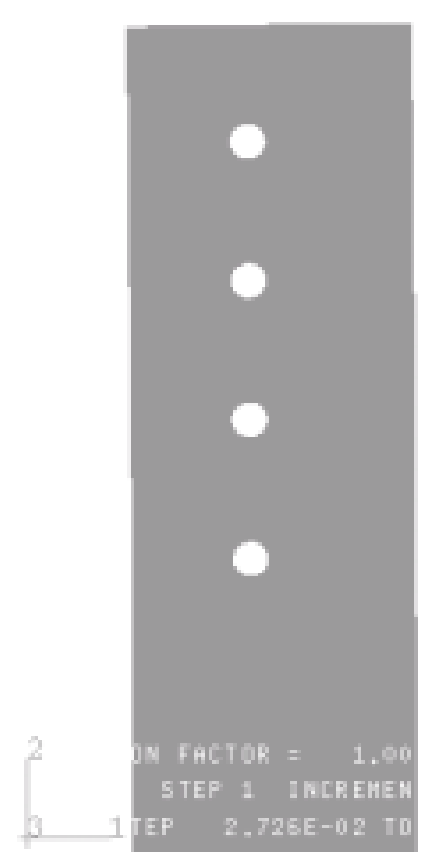

Deformed shape

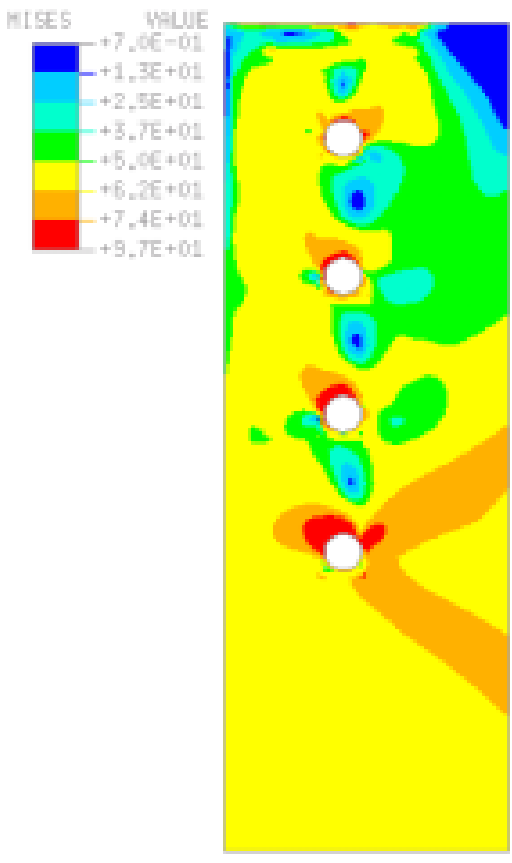

Stress contours

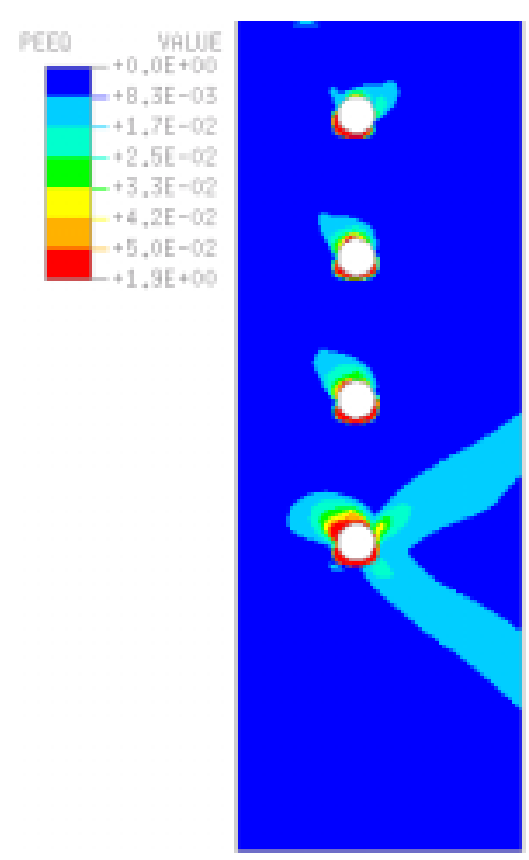

Plastic strain contours

Stress units are in ksi

Figure 6: Deformed shape, stress contours, and plastic strain contours of WVU specimen \# 6a 


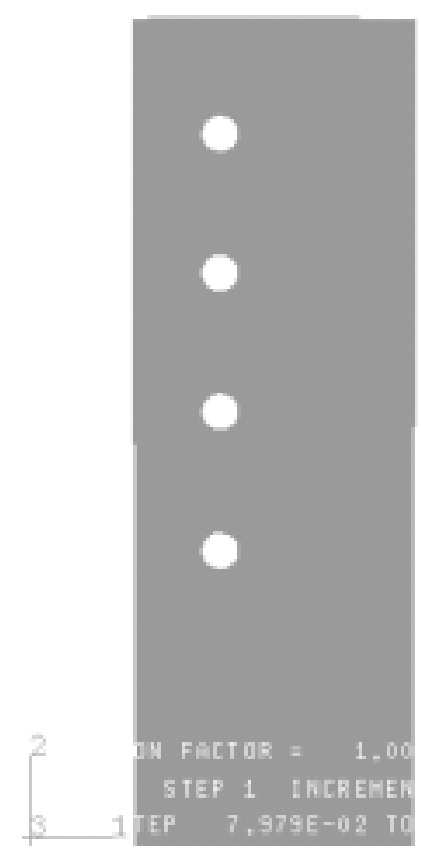

Deformed shape

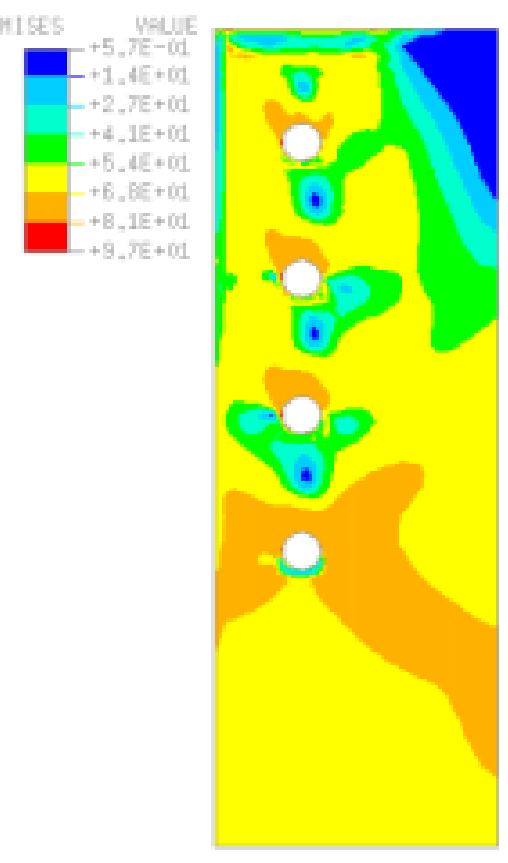

Stress contours

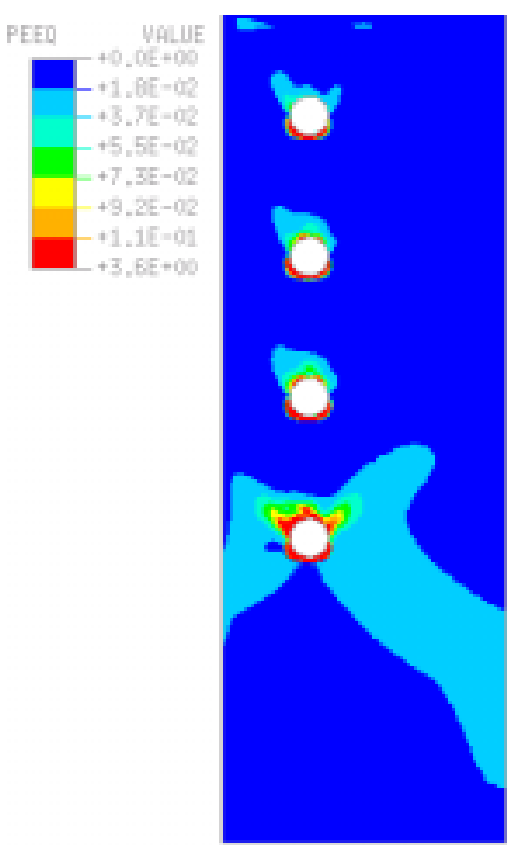

Plastic strain contours

Stress units are in ksi

Figure 7: Deformed shape, stress contours, and plastic strain contours of WVU specimen \# 7a 


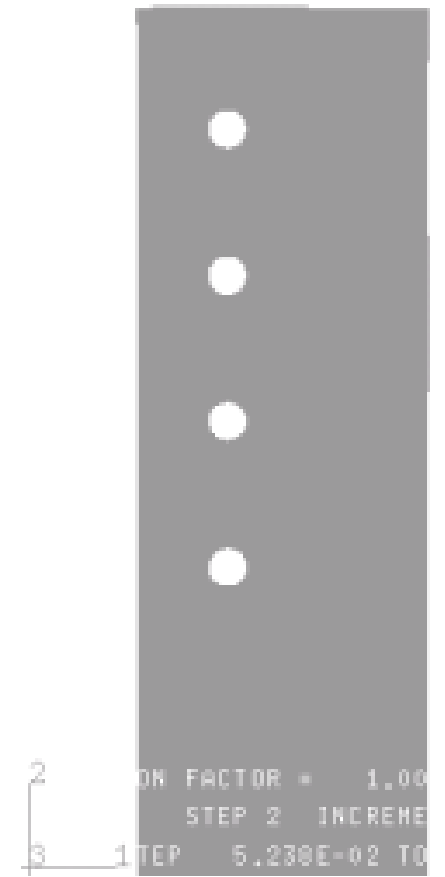

Deformed shape

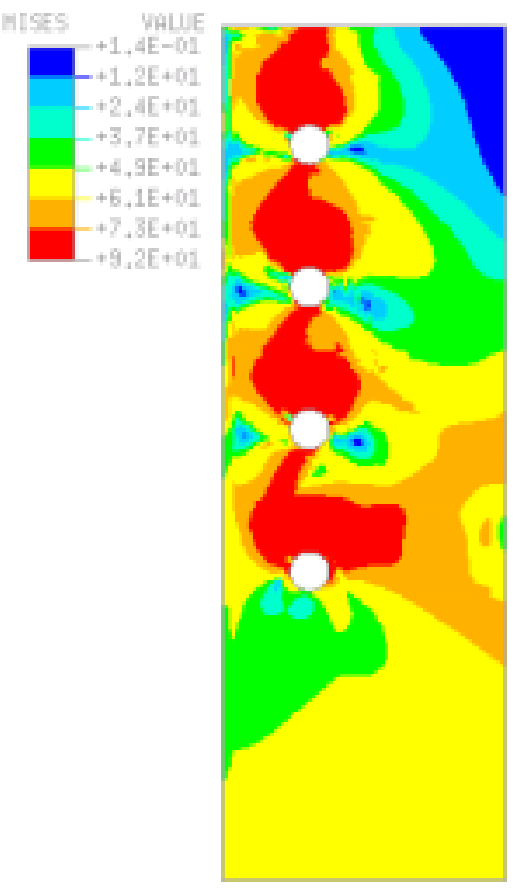

Stress contours

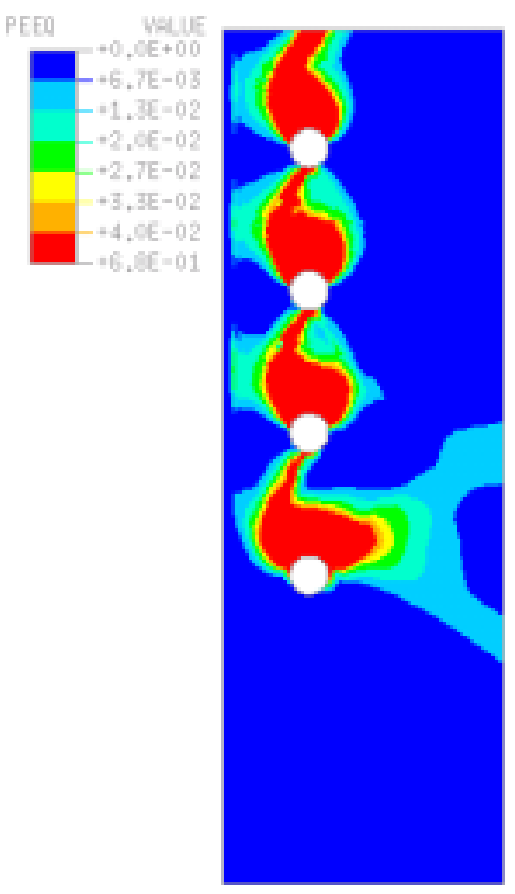

Plastic strain contours

Stress units are in ksi

Figure 8: Deformed shape, stress contours, and plastic strain contours of WVU specimen \# 8a 


\section{APPENDIX C}

WT 5 BOLT SPECIMEN CONTOUR PLOTS 


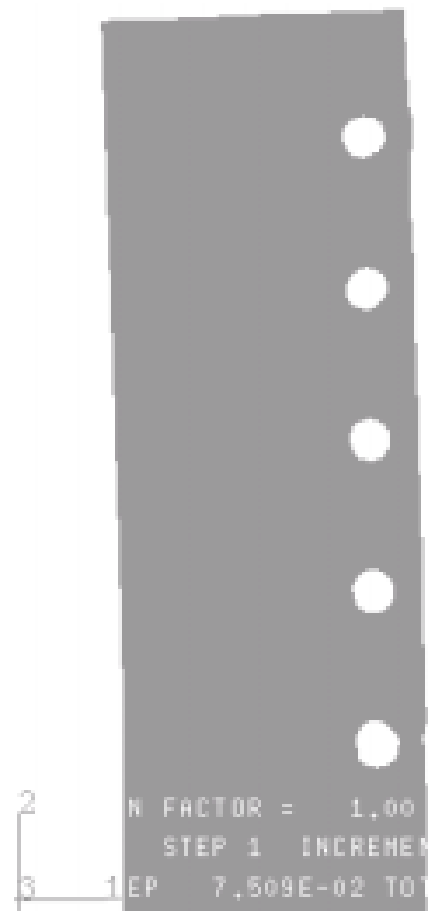

Deformed shape

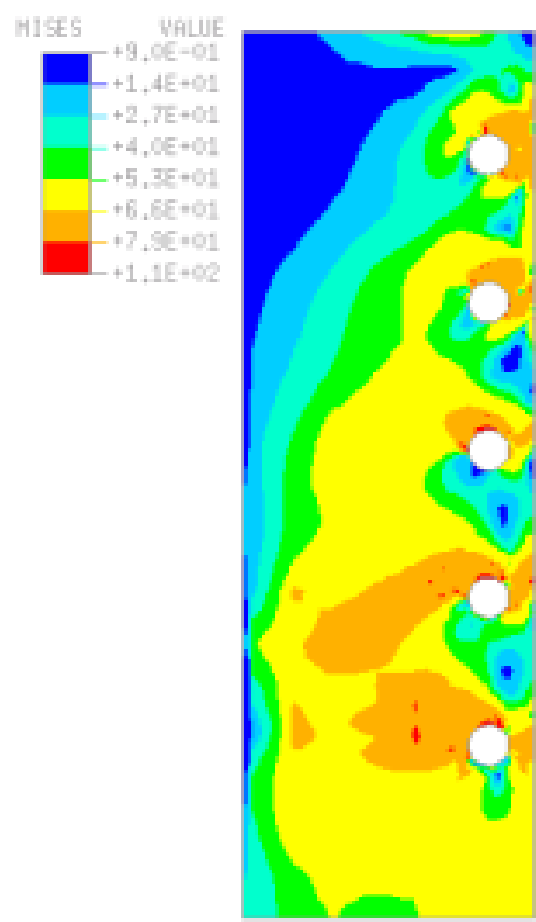

Stress contours

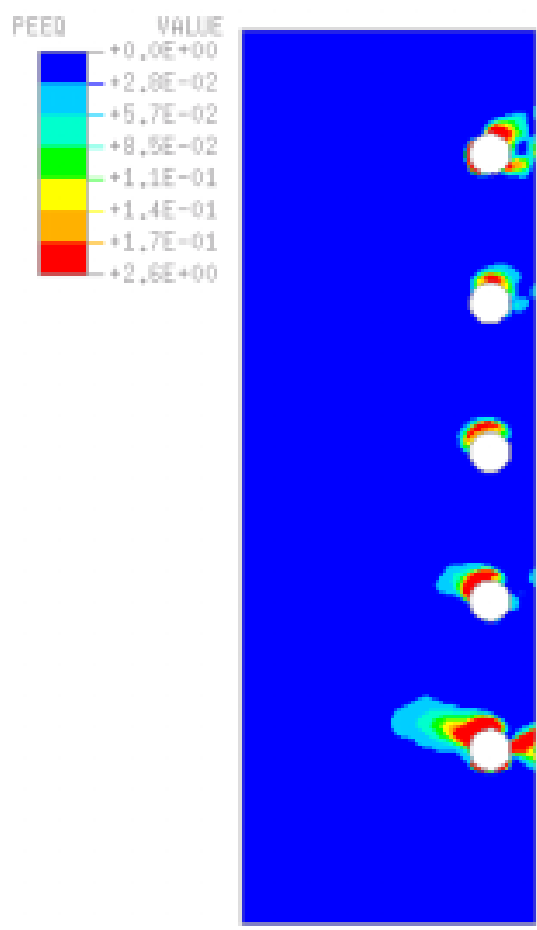

Plastic strain contours

Stress units are in ksi

Figure 1: Deformed shape, stress Contours and plastic strain contours of WVU specimen \# 1b 


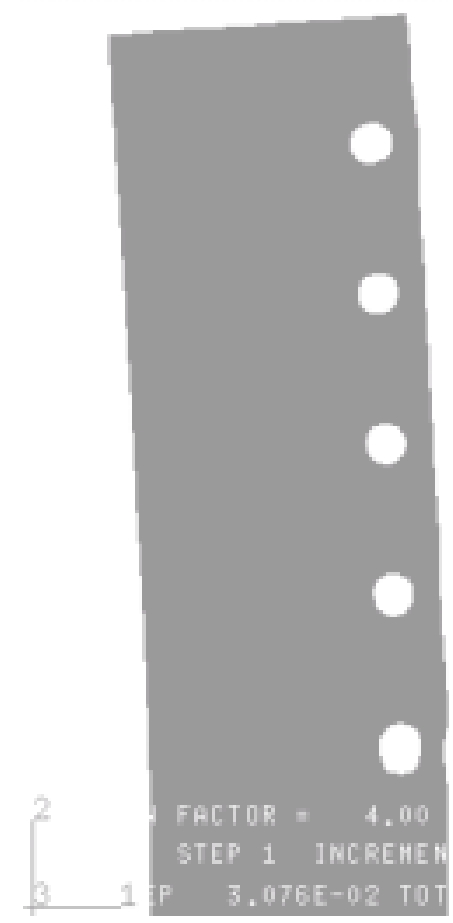

Deformed shape

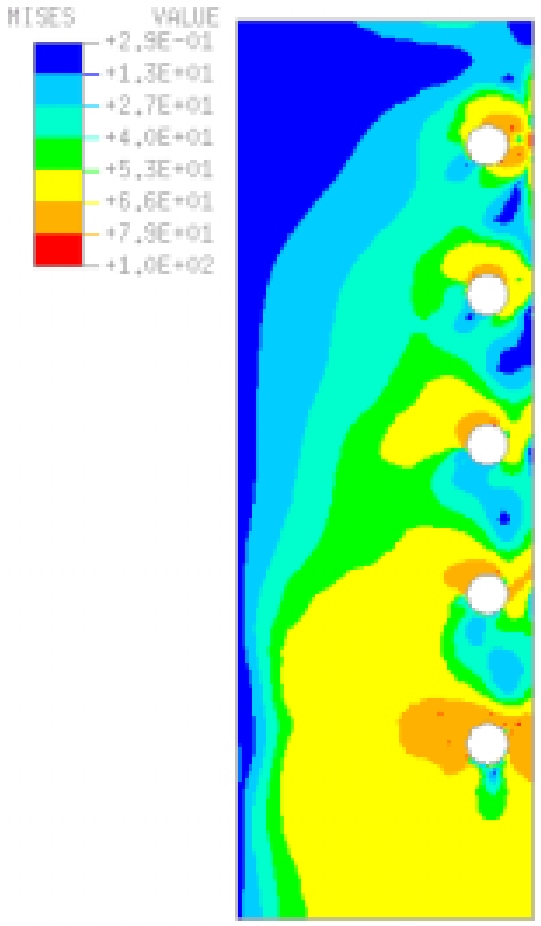

Stress contours

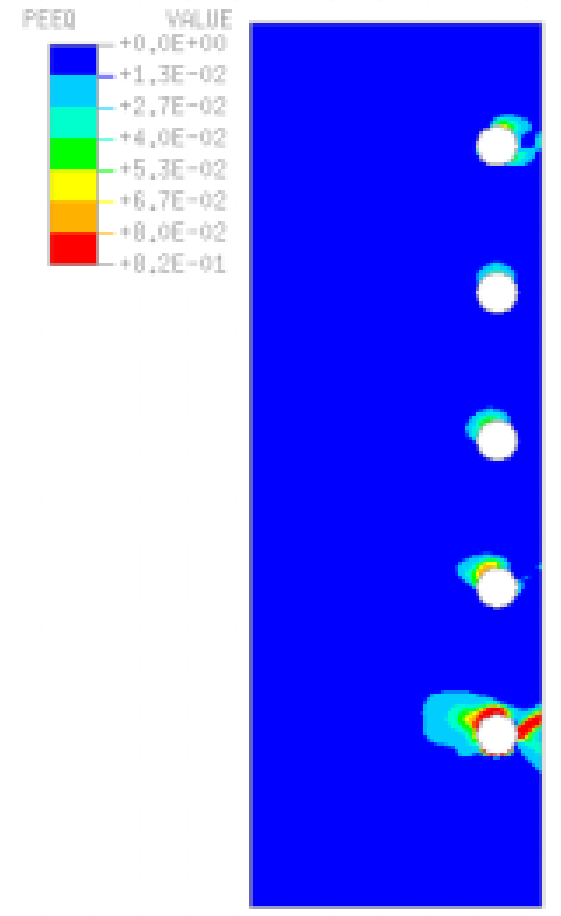

Plastic strain contours

Stress units are in ksi

Figure 2: Deformed shape, stress Contours and plastic strain contours of WVU specimen \# 2b 


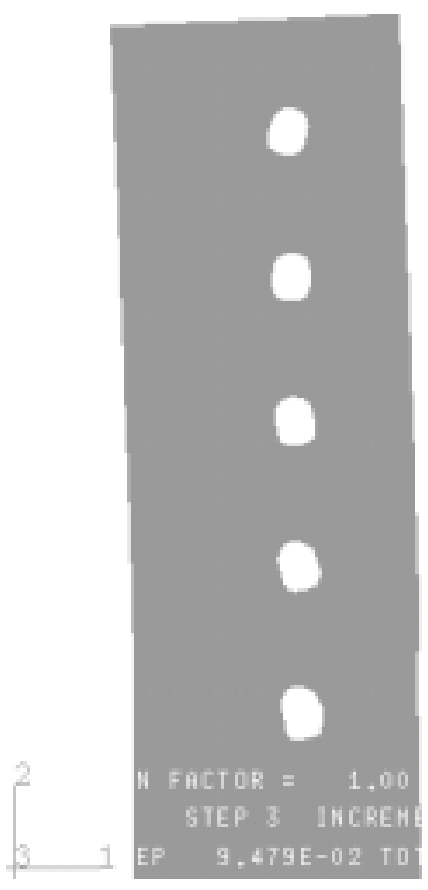

Deformed shape

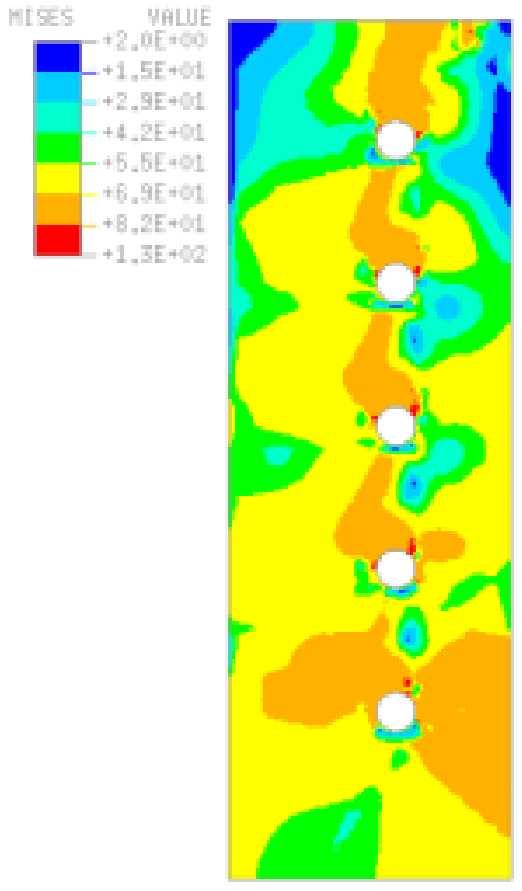

Stress contours

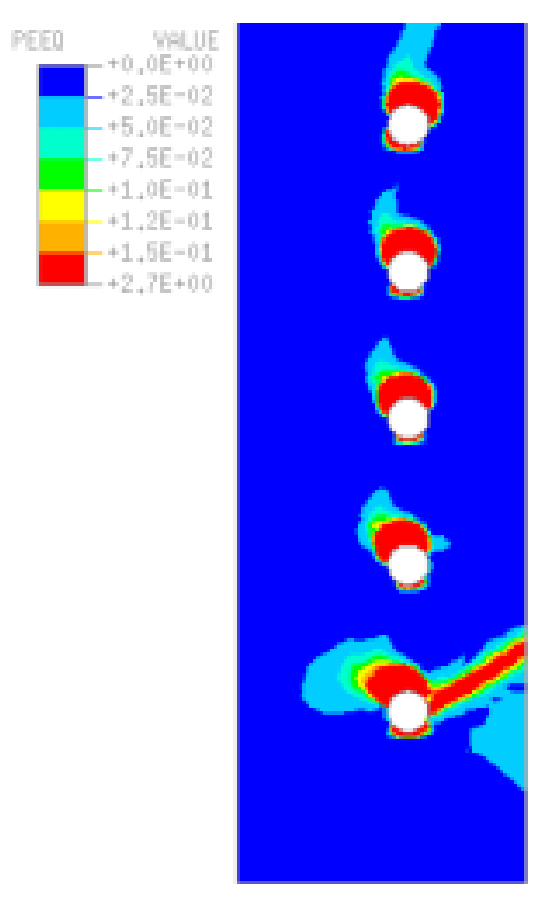

Plastic strain contours

Stress units are in ksi

Figure 3: Deformed shape, stress Contours and plastic strain contours of WVU specimen \# 3b 


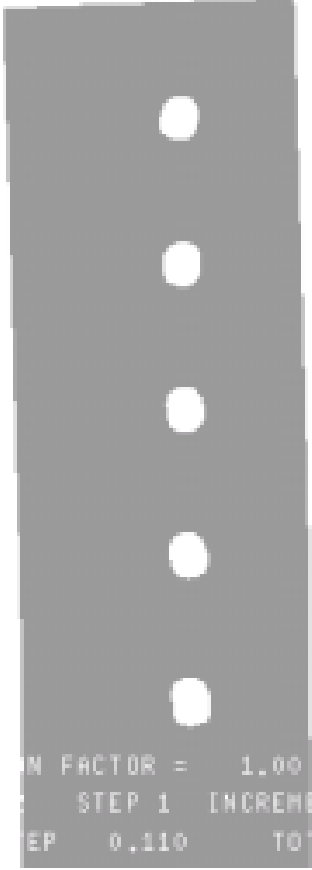

Deformed shape

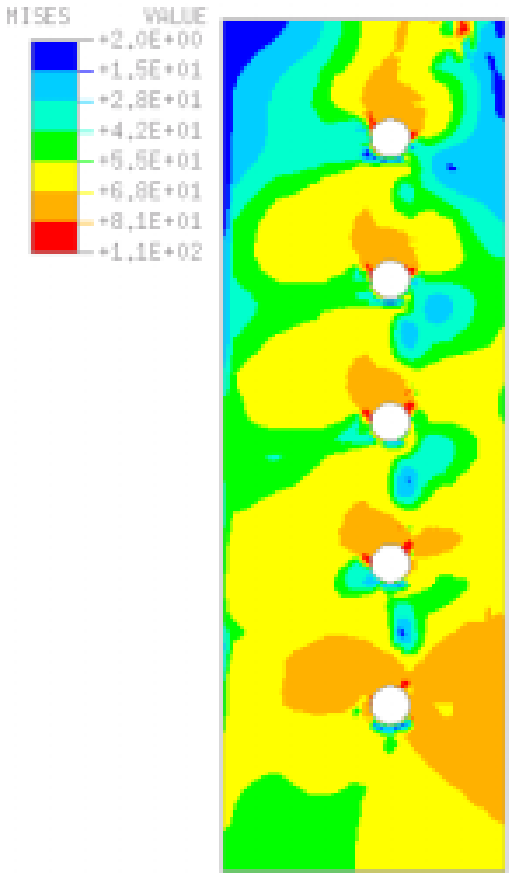

Stress contours

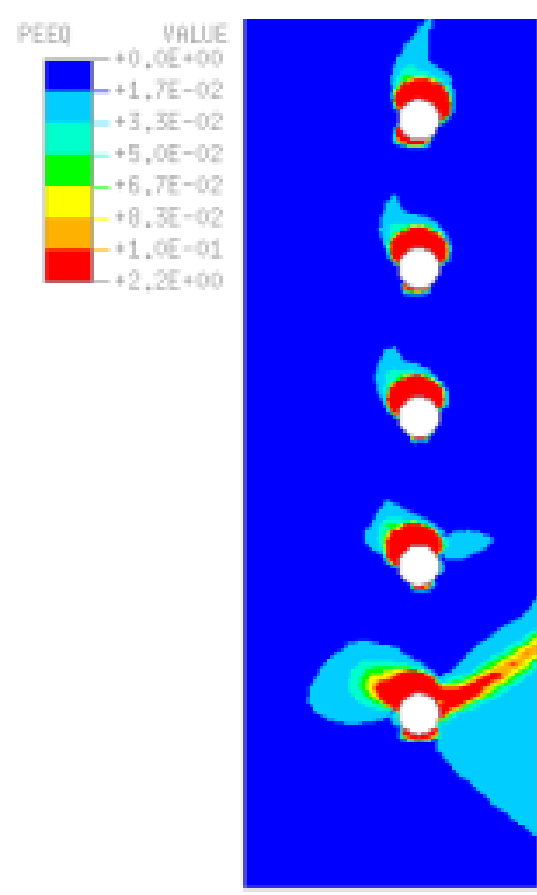

Plastic strain contours

Stress units are in ksi

Figure 4: Deformed shape, stress Contours and plastic strain contours of WVU specimen \# 4b 


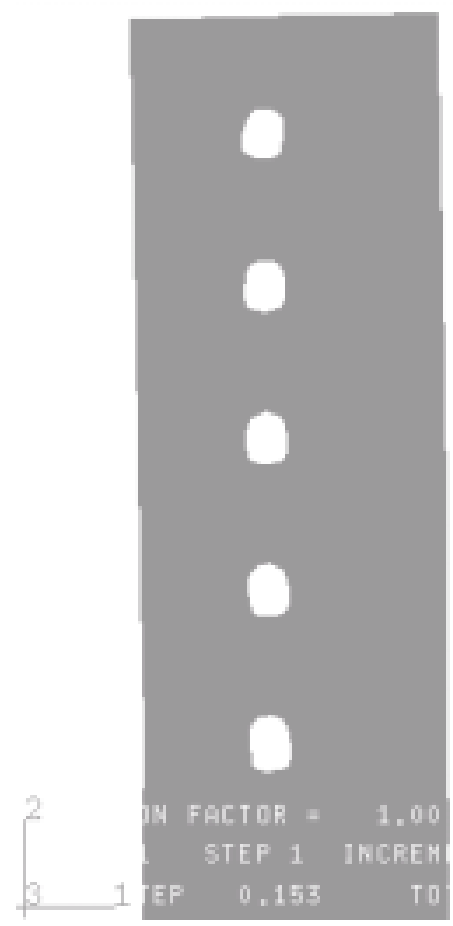

Deformed shape

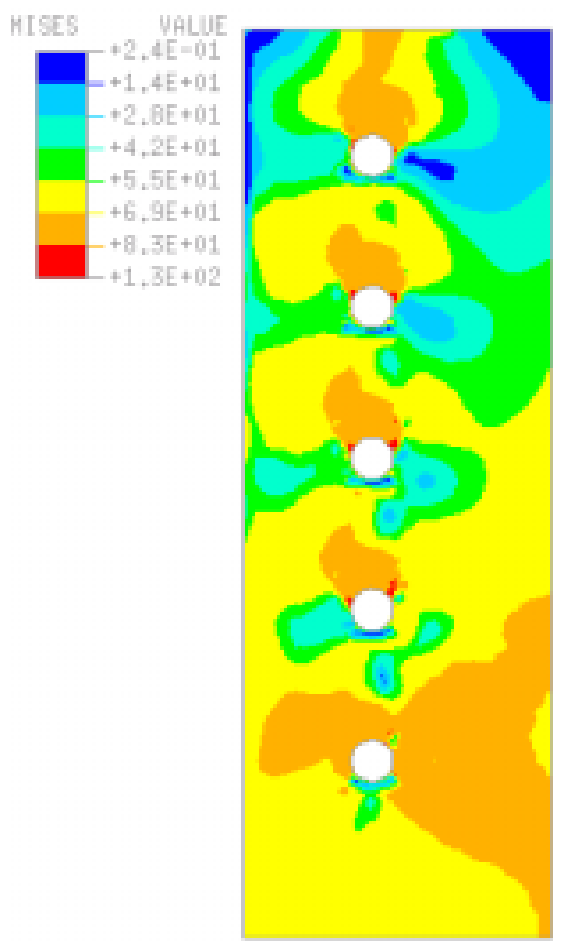

Stress contours

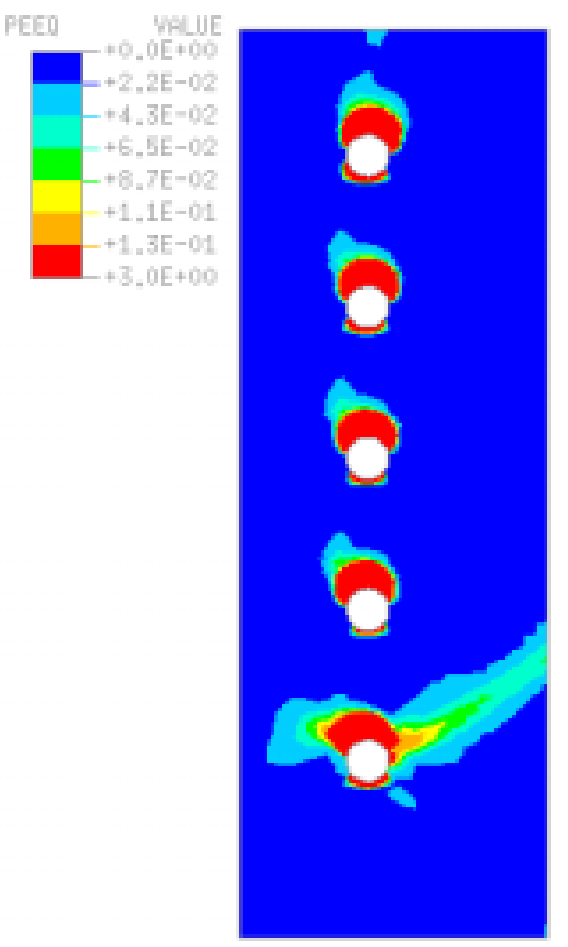

Plastic strain contours

Stress units are in ksi

Figure 5: Deformed shape, stress Contours and plastic strain contours of WVU specimen \# 5b 


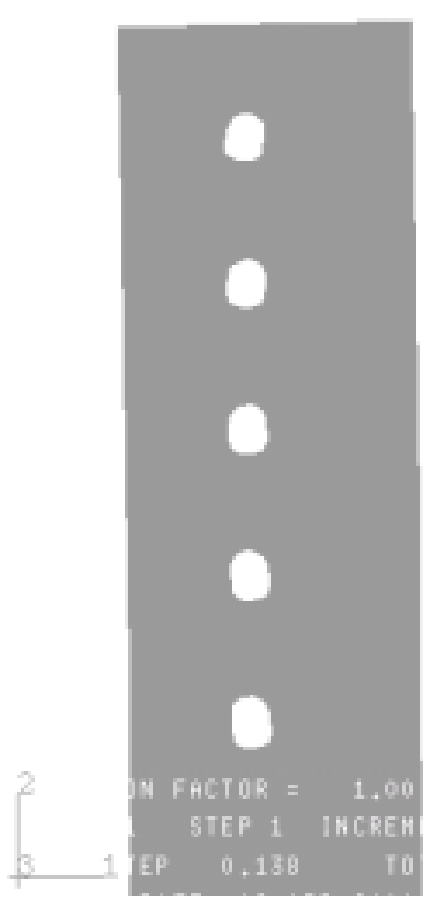

Deformed shape

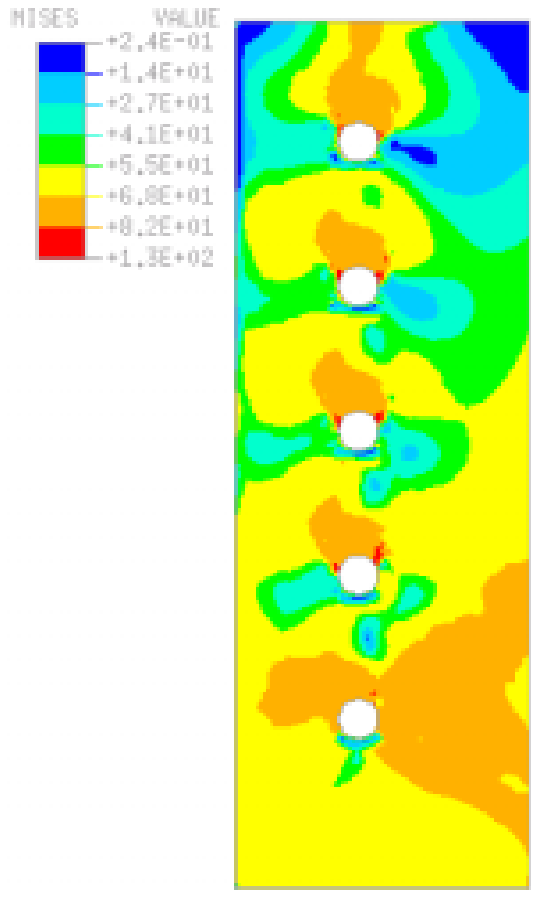

Stress contours
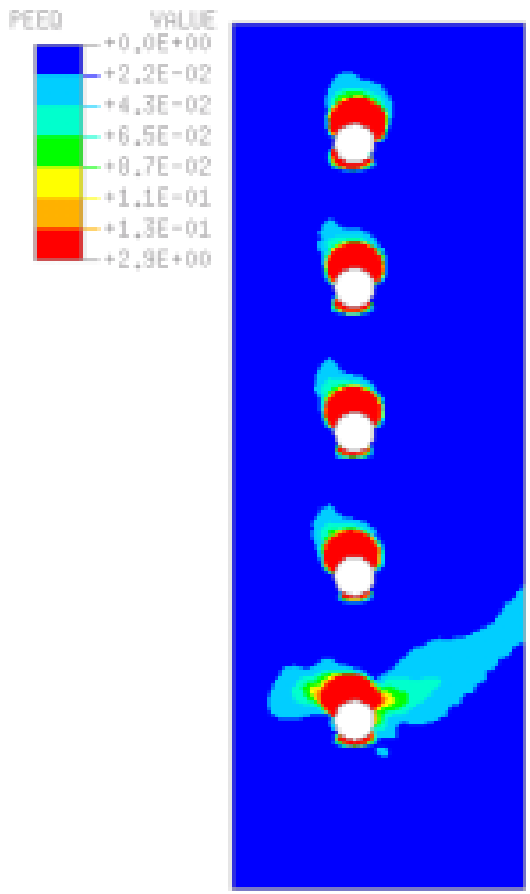

Plastic strain contours

Stress units are in ksi

Figure 6: Deformed shape, stress Contours and plastic strain contours of WVU specimen \# 6b 


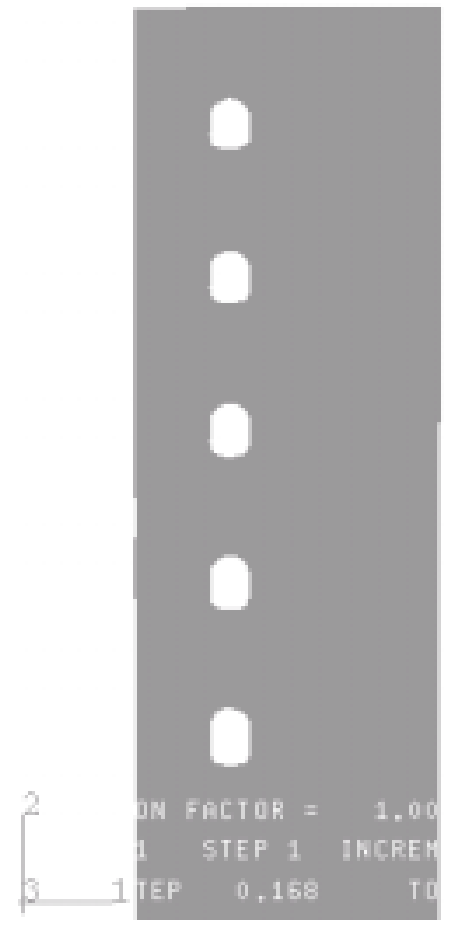

Deformed shape

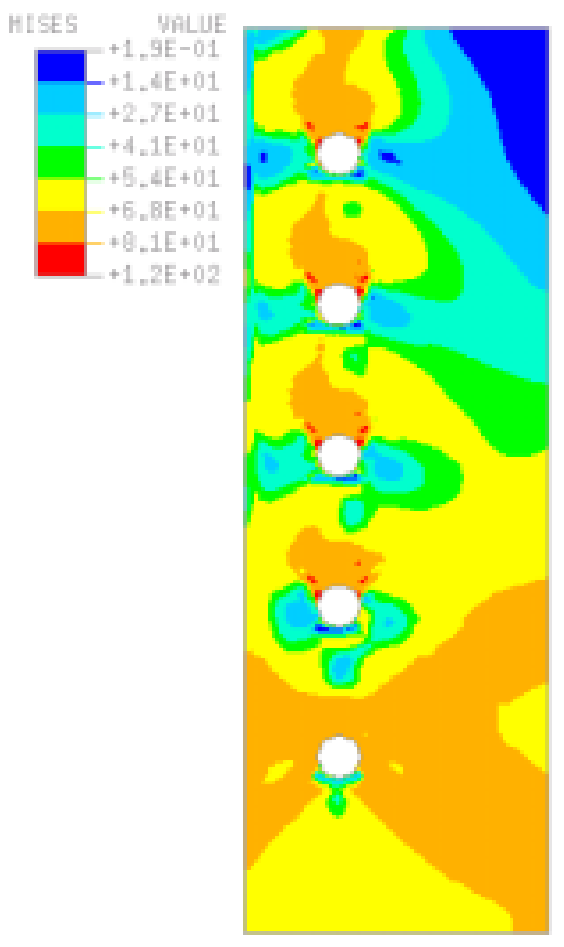

Stress contours

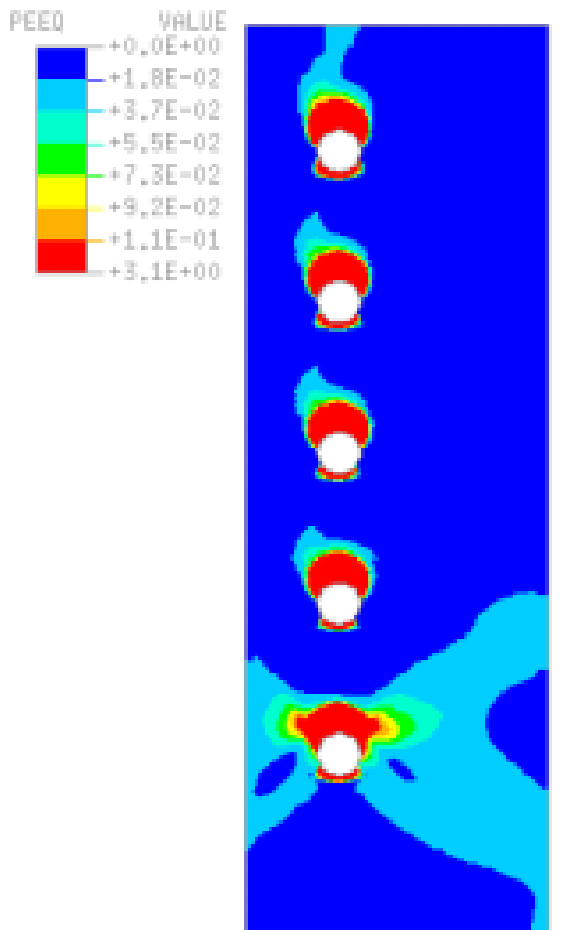

Plastic strain contours

Stress units are in ksi

Figure 7: Deformed shape, stress Contours and plastic strain contours of WVU specimen \# 7b 


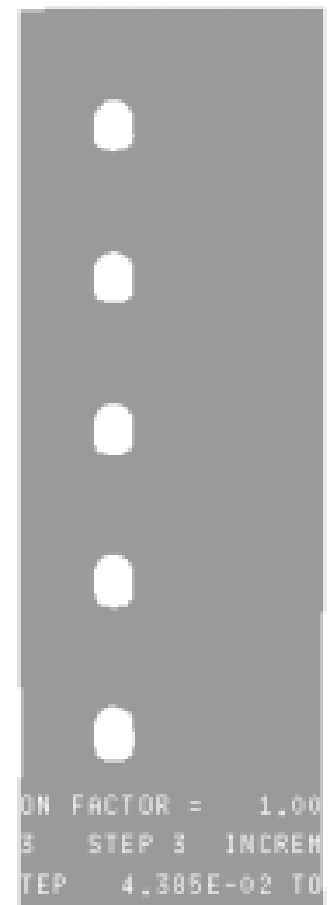

Deformed shape

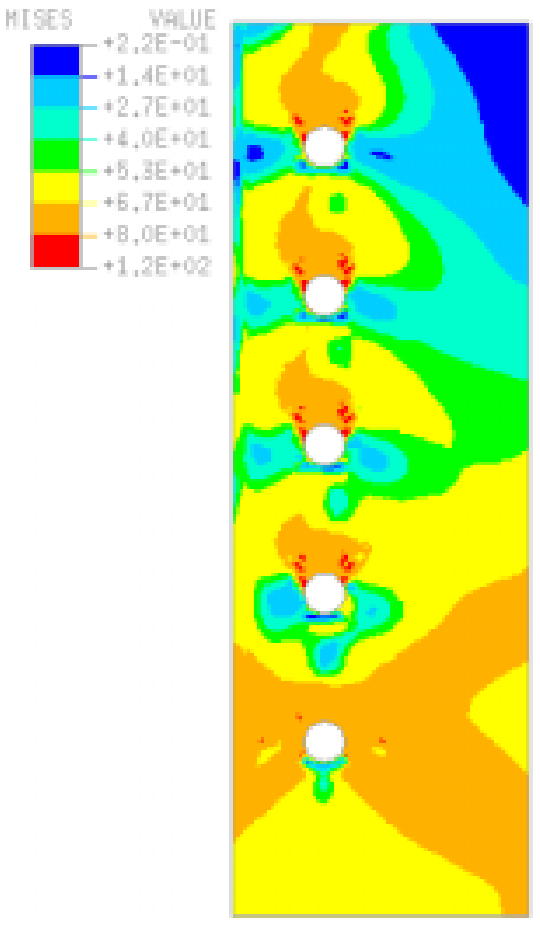

Stress contours

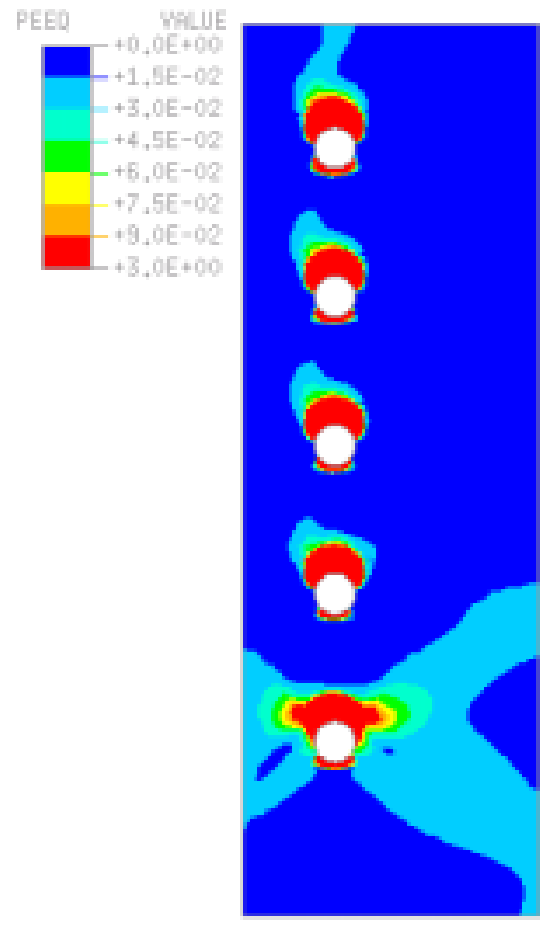

Plastic strain contours

Stress units are in ksi

Figure 8: Deformed shape, stress Contours and plastic strain contours of WVU specimen \# 8b 
APPENDIX D

WT 3 BOLT SPECIMEN CONTOUR PLOTS 


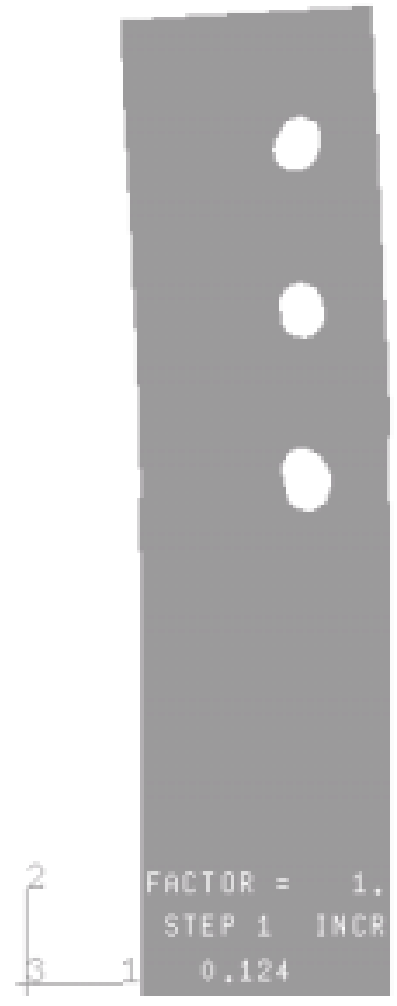

Deformed shape

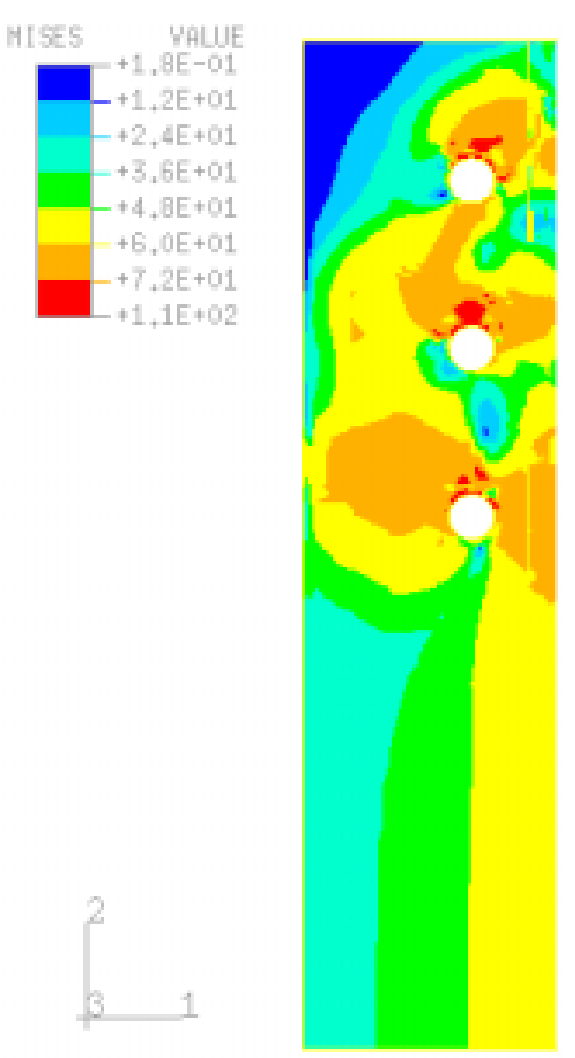

Stress contours
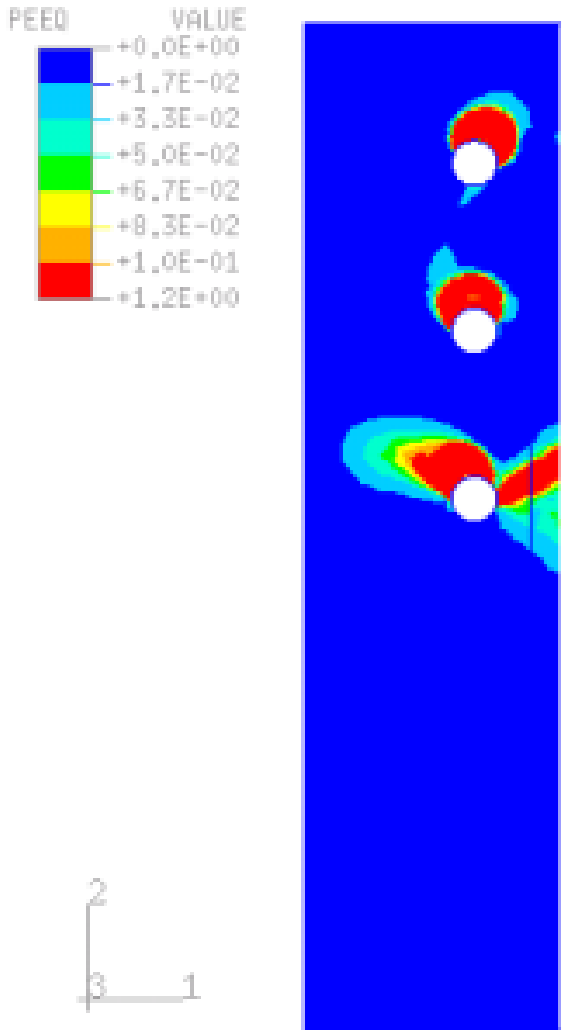

Plastic strain contours

Stress units are in ksi

Figure 1: Deformed shape, stress Contours and plastic strain contours of WVU specimen \# 1c 


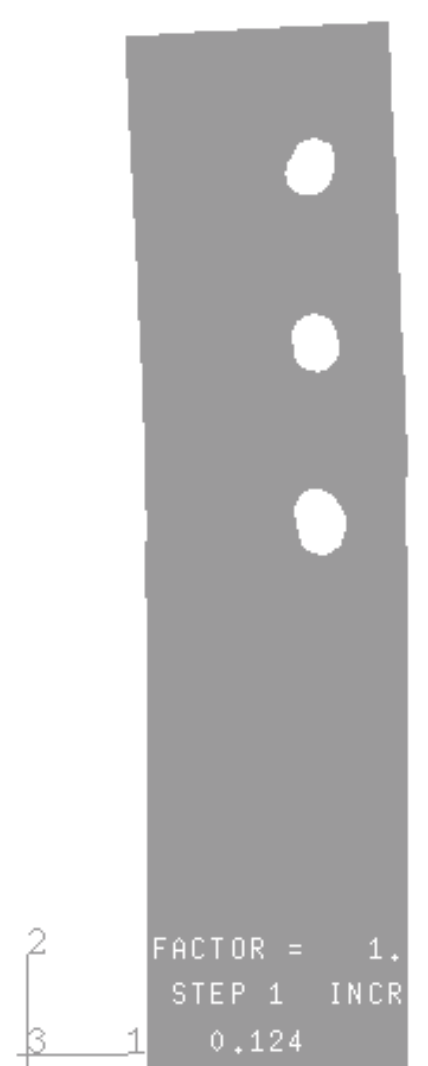

Deformed shape

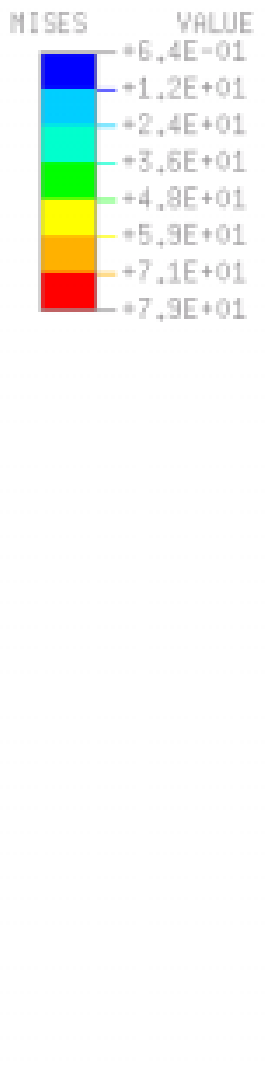

Stress contours
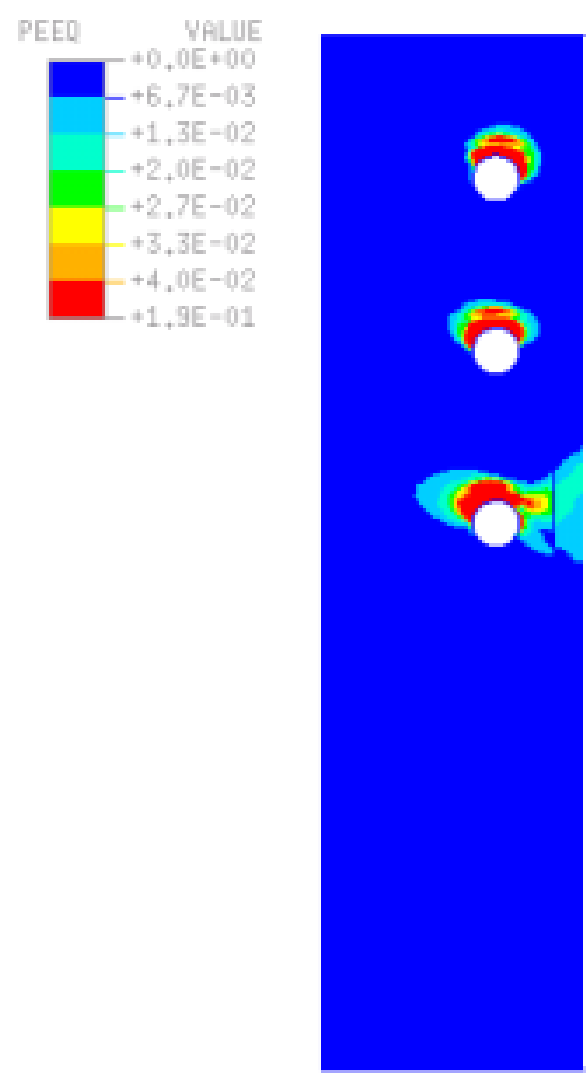

Plastic strain contours

Stress units are in ksi

Figure 2: Deformed shape, stress Contours and plastic strain contours of WVU specimen \# 2c 


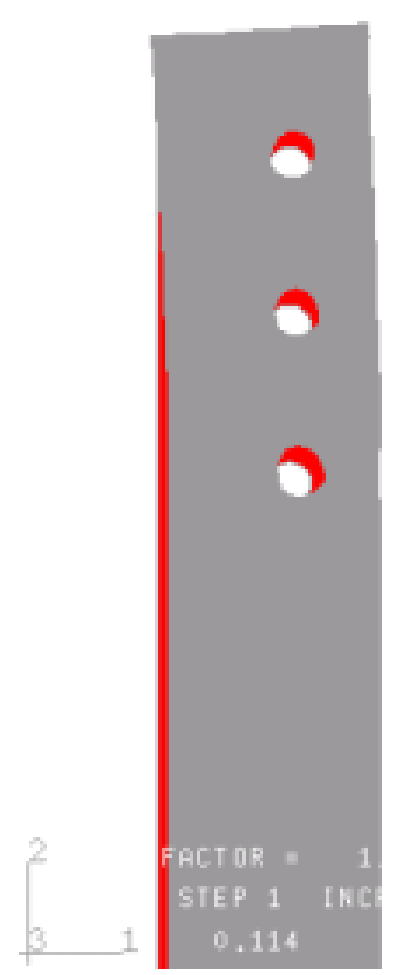

Deformed shape

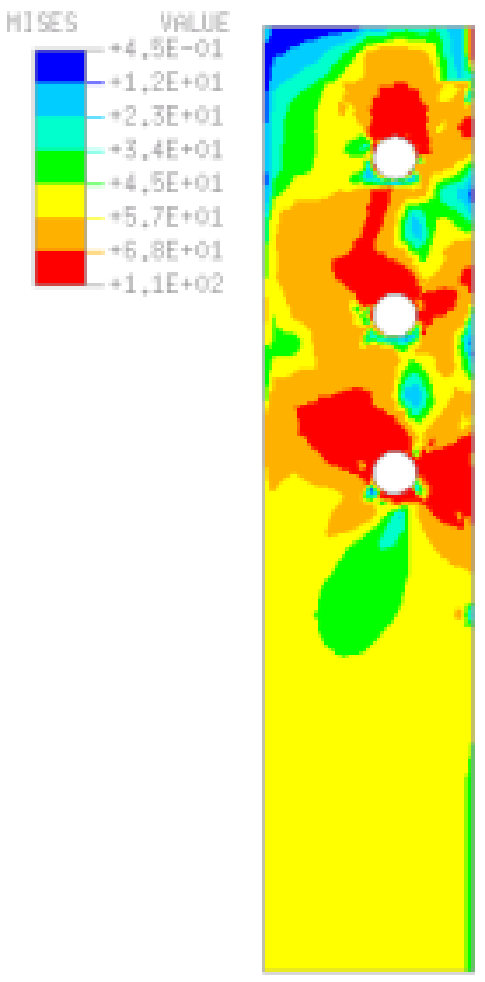

Stress contours
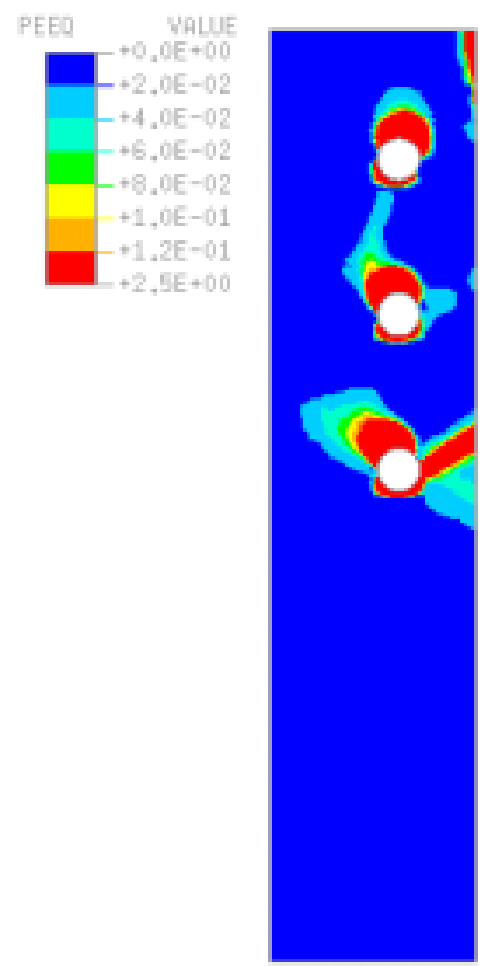

Plastic strain contours

Stress units are in ksi

Figure 3: Deformed shape, stress Contours and plastic strain contours of WVU specimen \# 3c 


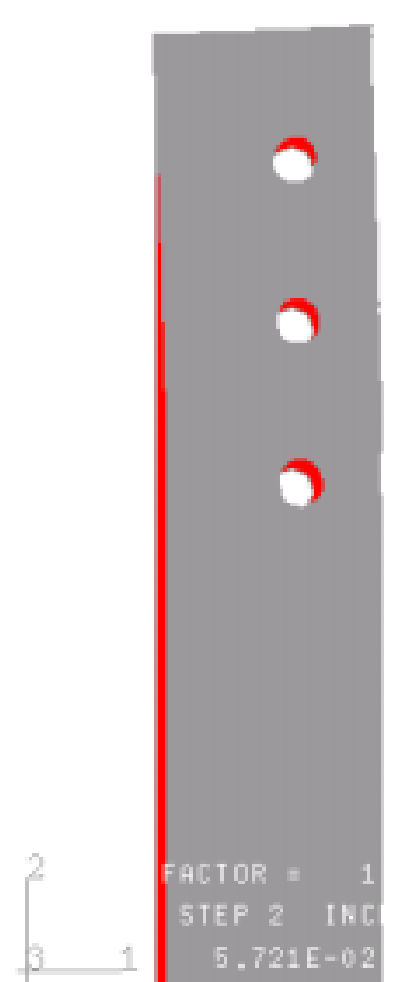

Deformed shape

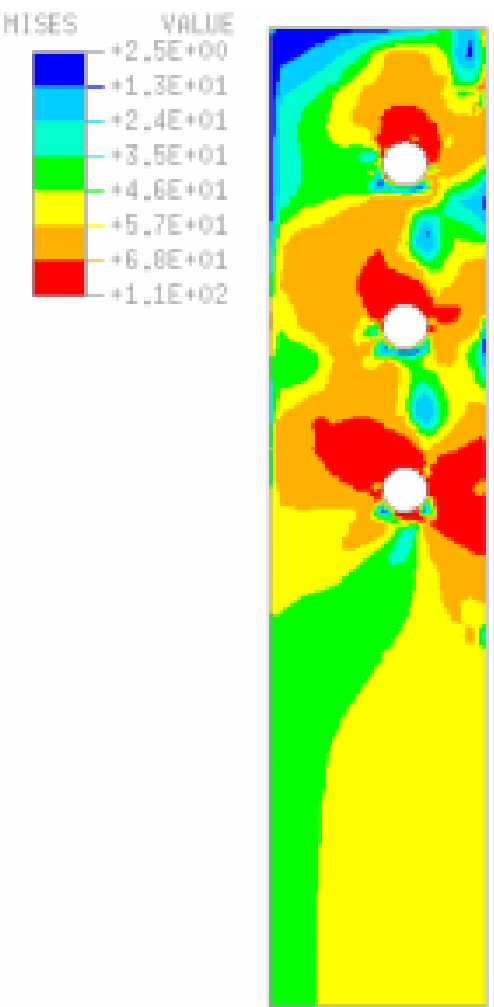

Stress contours
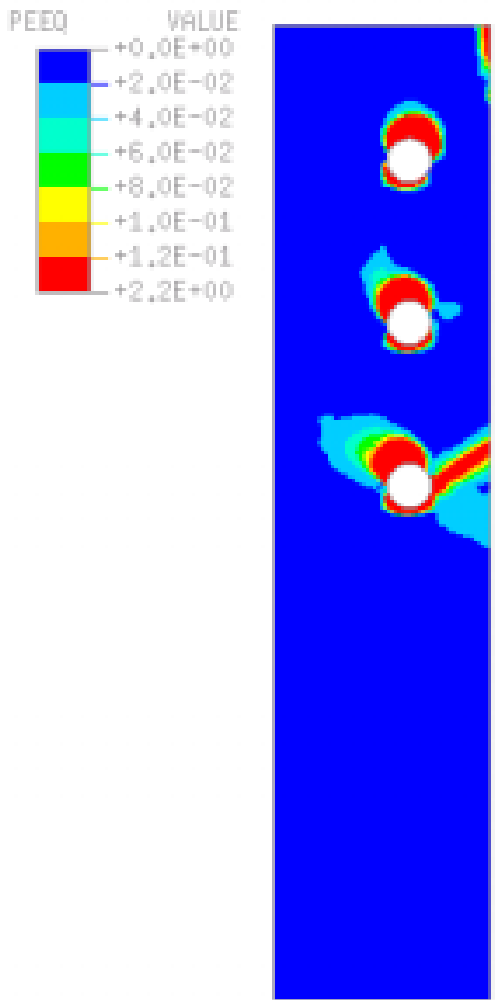

Plastic strain contours

Stress units are in ksi

Figure 4: Deformed shape, stress Contours and plastic strain contours of WVU specimen \# 4c 


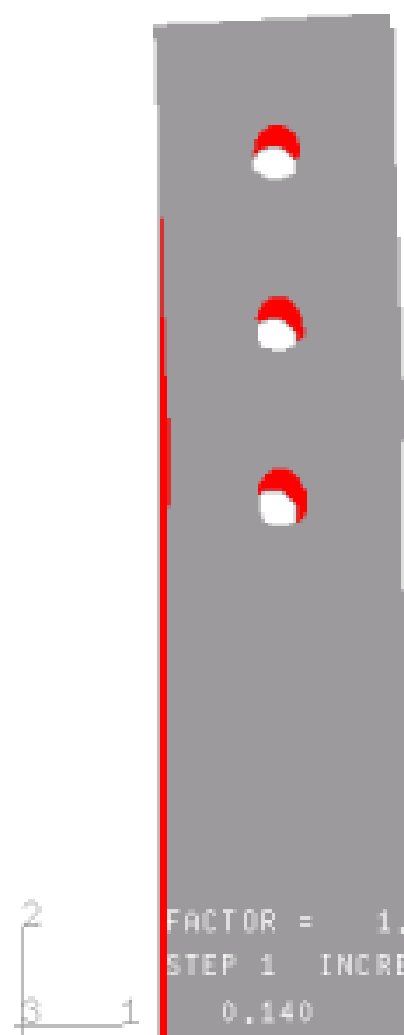

Deformed shape

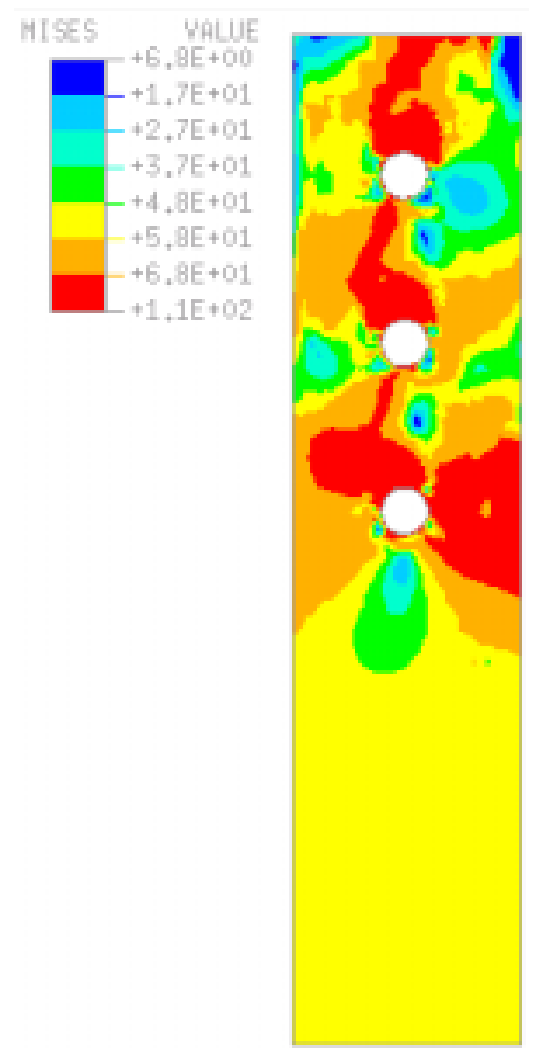

Stress contours
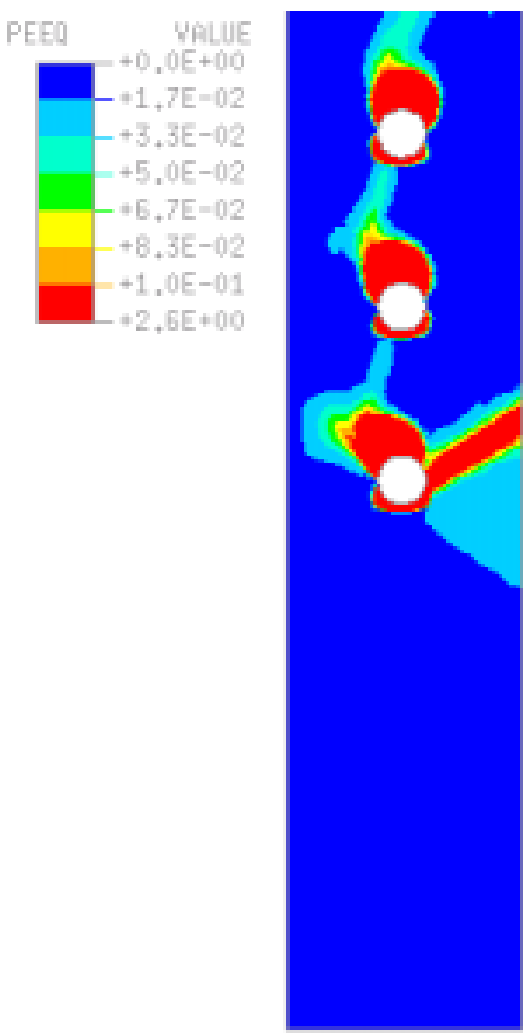

Plastic strain contours

Stress units are in ksi

Figure 5: Deformed shape, stress Contours and plastic strain contours of WVU specimen \# 5c 


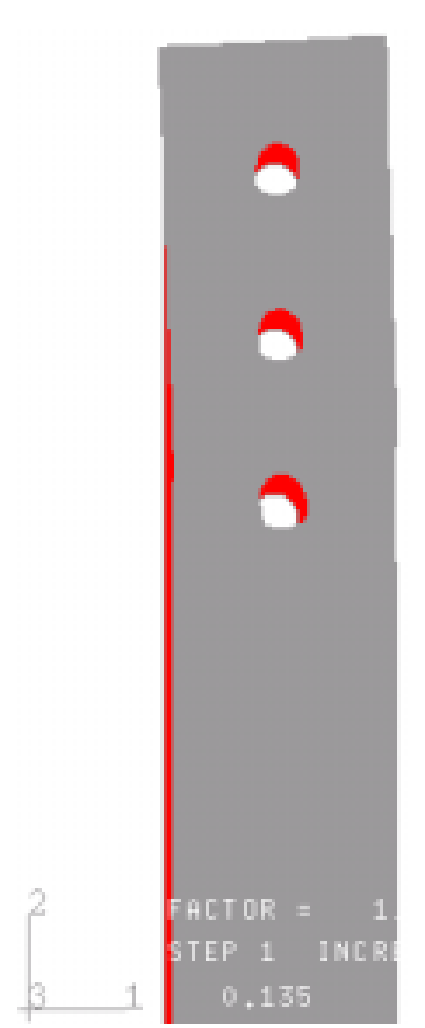

Deformed shape

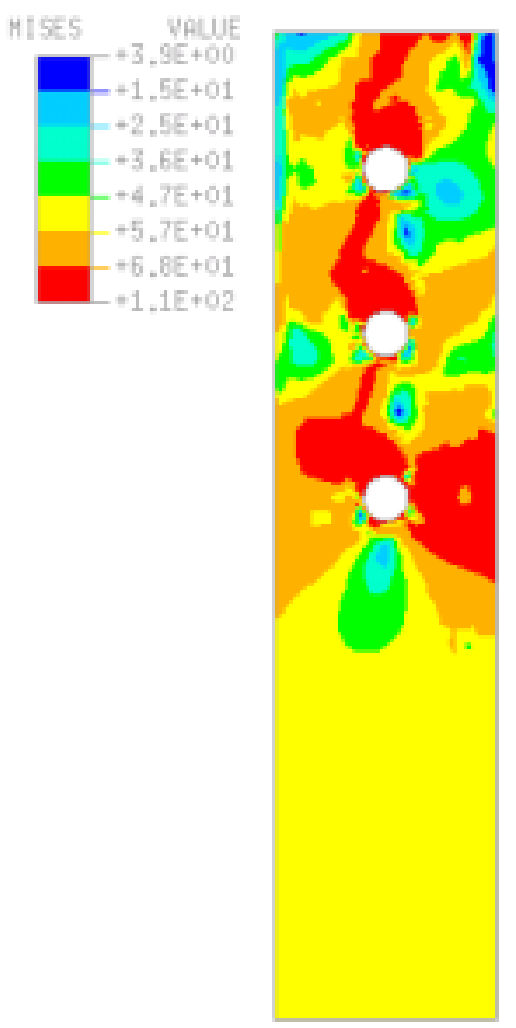

Stress contours
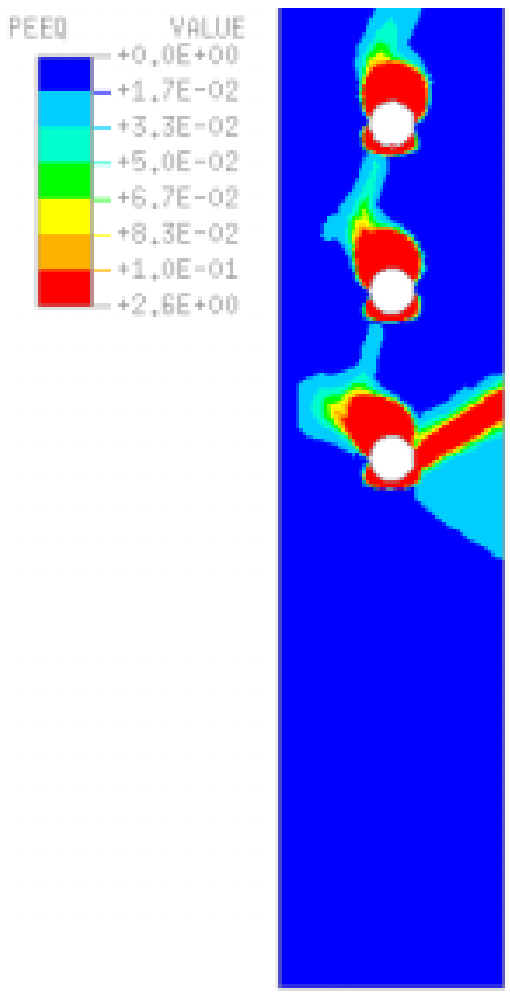

Plastic strain contours

Stress units are in ksi

Figure 6: Deformed shape, stress Contours and plastic strain contours of WVU specimen \# 6c 